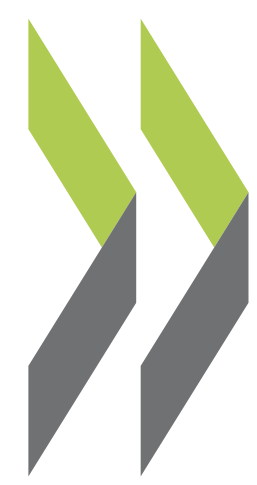

OECD Local Economic and Employment Development (LEED) Papers 2013/11

\title{
Tackling Long-Term Unemployment Amongst Vulnerable Groups
} Andrew Dean 


\section{Tackling Long-Term Unemployment Amongst Vulnerable Groups}

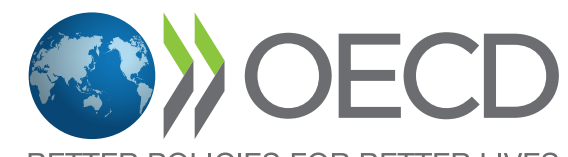





\section{Tackling Long-Term Unemployment Amongst Vulnerable Groups}


This work is published on the responsibility of the Secretary-General of the OECD. The opinions expressed and arguments employed herein do not necessarily reflect the official views of the Organisation or of the governments of its member countries.

This document and any map included herein are without prejudice to the status of or sovereignty over any territory, to the delimitation of international frontiers and boundaries and to the name of any territory, city or area.

\author{
Cover: ( $)$ OECD LEED
}

() OECD 2013

You can copy, download or print OECD content for your own use, and you can include excerpts from OECD publications, databases and multimedia products in your own documents, presentations, blogs, websites and teaching materials, provided that suitable acknowledgment of OECD as source and copyright owner is given. All requests for public or commercial use and translation rights should be submitted to rights@oecd.org. Requests for permission to photocopy portions of this material for public or commercial use shall be addressed directly to the Copyright Clearance Center (CCC) at info@ copyright.com or the Centre français d'exploitation du droit de copie (CFC) contact@cfcopies.com. 


\title{
ABOUT THE OECD
}

The OECD is a multi-disciplinary inter-governmental organisation of 34 member countries which engages in its work an increasing number of non-members from all regions of the world. The Organisation's core mission today is to help governments work together towards a stronger, cleaner, fairer global economy. Through its network of 250 specialised committees and working groups, the OECD provides a setting where governments compare policy experiences, seek answers to common problems, identify good practice, and co-ordinate domestic and international policies.

The OECD member countries are: Australia, Austria, Belgium, Canada, Chile, the Czech Republic, Denmark, Estonia, Finland, France, Germany, Greece, Hungary, Iceland, Ireland, Israel, Italy, Japan, Korea, Luxembourg, Mexico, the Netherlands, New Zealand, Norway, Poland, Portugal, the Slovak Republic, Slovenia, Spain, Sweden, Switzerland, Turkey, the United Kingdom and the United States. The European Commission takes part in the work of the OECD. For more information on the OECD, please visit www.oecd.org/about.

\begin{abstract}
ABOUT LEED
The OECD Programme on Local Economic and Employment Development (LEED) has advised governments and communities since 1982 on how to respond to economic change and tackle complex problems in a fast-changing world. Its mission is to contribute to the creation of more and better quality jobs through more effective policy implementation, innovative practices, stronger capacities and integrated strategies at the local level. LEED draws on a comparative analysis of experience from the five continents in fostering economic growth, employment and inclusion. For more information on the LEED Programme, please visit www.oecd.org/cfe/leed.
\end{abstract}




\section{ACKNOWLEDGEMENTS}

The report was prepared by Dr Andrew Dean, Marchmont Observatory, University of Exeter (UK), under the supervision of, and with inputs provided by, Emma Clarence (Policy Analyst) and Antonella Noya (Senior Policy Analyst) of the OECD LEED Programme.

The author would like to thank Adam Crews (Crews Associates and the Marchmont Observatory, University of Exeter) for his help with analysing the PES Survey; the many people who have written case studies and learning models for this report; all of those who presented and attended the OECD LEED Seminar on 'Tackling Long-term Unemployment Amongst Vulnerable Groups' held at the OECD LEED Trento Centre in June 2012; and, in particular, Peter Ramsden (Freiss Ltd), Emma Clarence, Antonella Noya and Michela Meghnagi (all OECD LEED), and Chris Evans (Marchmont Observatory, University of Exeter) for their support and valuable contributions to this document. Finally, the author would also like to thank Hilary Todd (Marchmont Observatory, University of Exeter) for her meticulous proofreading. 


\section{TABLE OF CONTENTS}

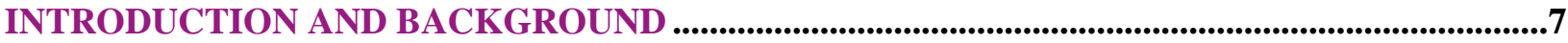

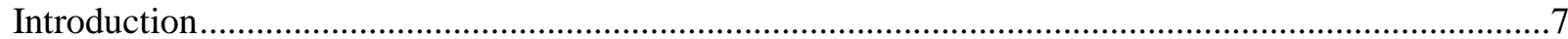

Long-term unemployment and the already disadvantaged ............................................................. 8

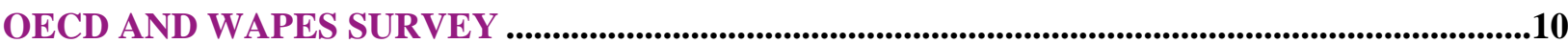

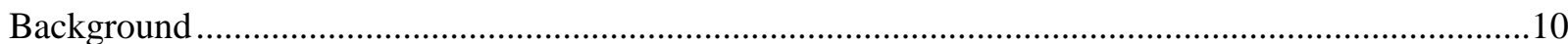

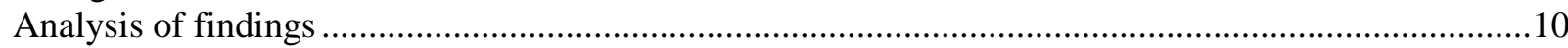

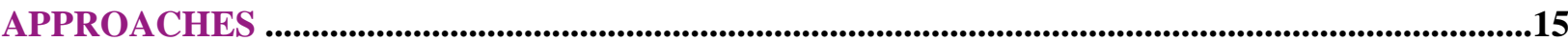

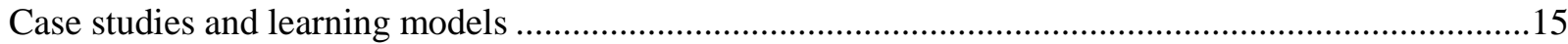

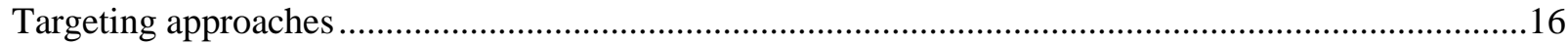

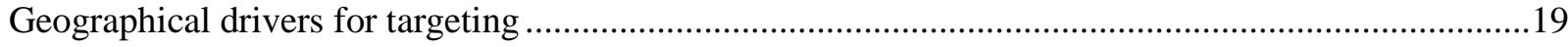

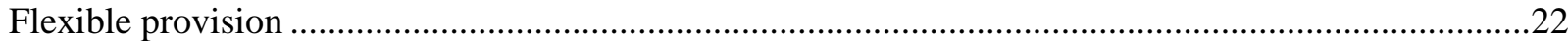

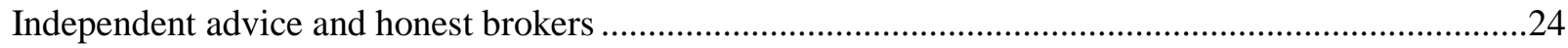

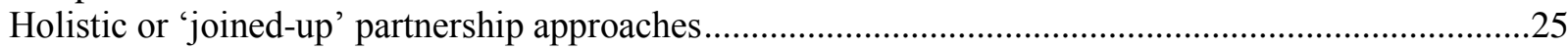

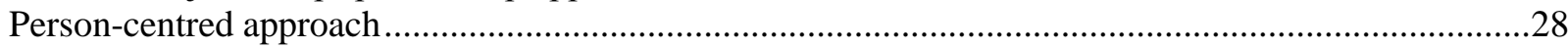

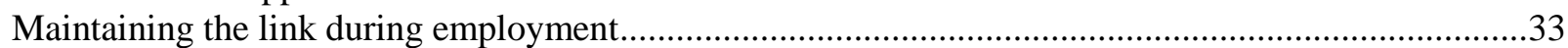

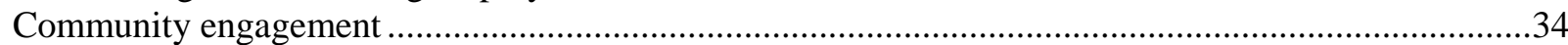

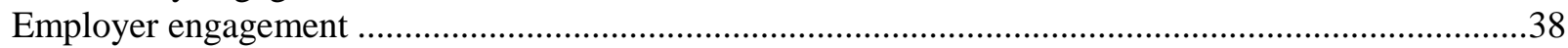

The potential role of trade unions in supporting vulnerable people back to work ...................................39

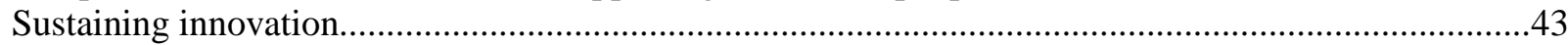

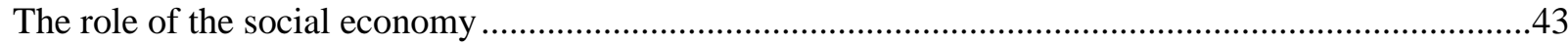

Concluding thoughts on SEOs and labour market integration.............................................................51

SUPPORT FOR INTERVENTIONS _............................................................................................................53

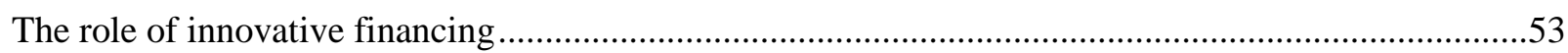

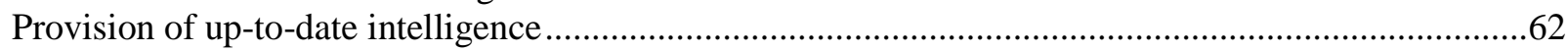

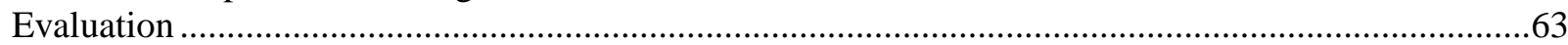

RECOMMENDATIONS FOR LOCAL APPROACHES TO TACKLING LONG-TERM

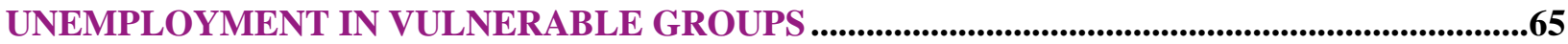

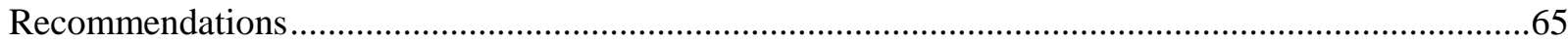

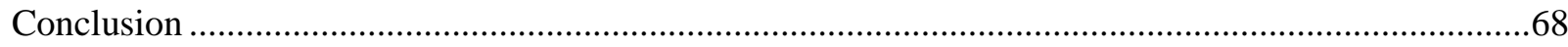

REFERENCES ............................................................................................................................................69

ANNEX 1: TABLES FROM THE INTERNATIONAL SURVEY OF PES..............................................75 


\section{Tables}

Table 1. Case Studies and Learning Models commissioned by the OECD and used in this

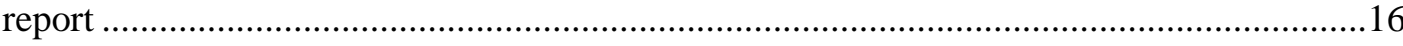

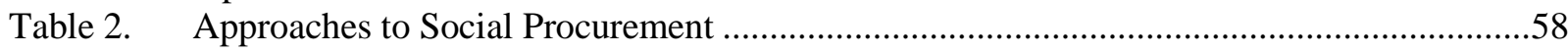

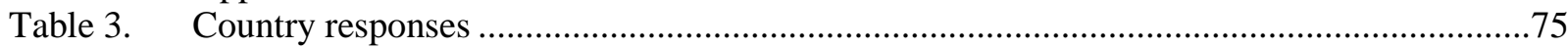

Table 4. Approach to tackling long-term unemployment - TARGETING ………..........................76

Table 5. Approach to tackling long-term unemployment - GROUPS TARGETED ………..............76

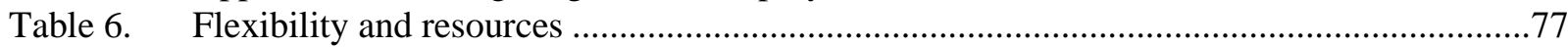

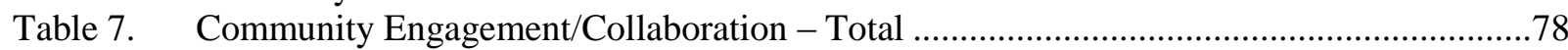

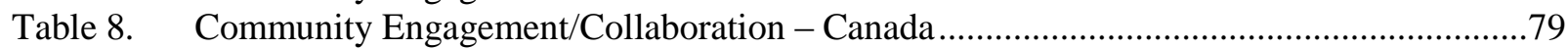

Table 9. Community Engagement/Collaboration - Other Countries ..................................................80

\section{Figures}

Figure 1. Gloucester Works Integrated Employment and Skills System...........................................21

Figure 2. Client journey and offer as delivered by Gloucester Works ...............................................

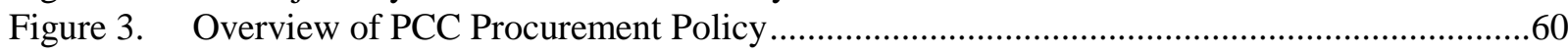

Figure 4. Parramatta's Sustainable Social Procurement Framework ................................................61

\section{Boxes}

Box 1. Tackling Generational Poverty - The Alost Project, Antwerp............................................18

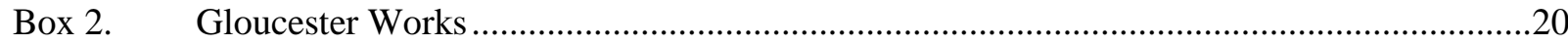

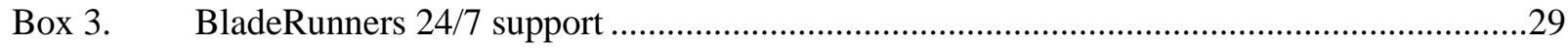

Box 4. The crucial role of the Work Welfare Counsellor in the Targeted Trajectories activities in Antwerp and Alost, Belgium ........................................................................

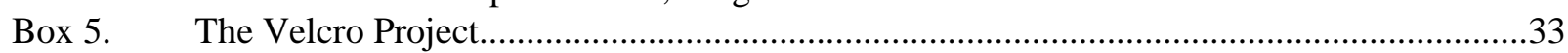

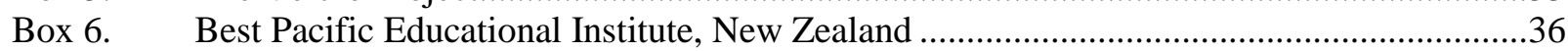

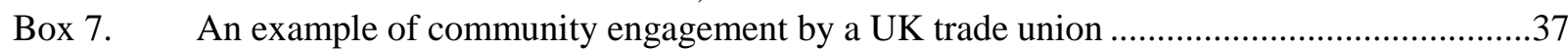

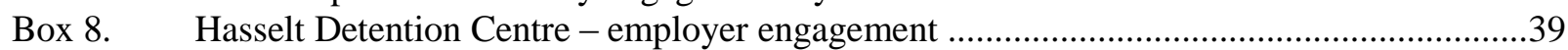

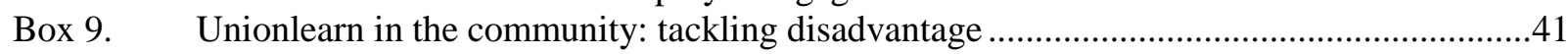

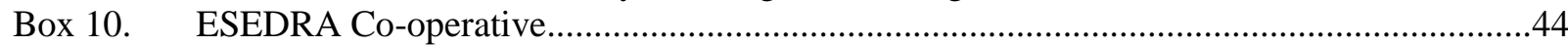

Box 11. Job creation through social entrepreneurship and the social economy at VZW IN-Z.........47

Box 12. Ardelaine, a co-operative dedicated to local sustainable development ................................50

Box 13. Claros: The Dream of a Worker Co-operative Fusion ....................................................51

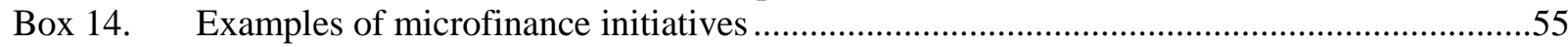

Box 15. Example of a Social Impact Bond, Peterborough, UK ......................................................56

Box 16. A social procurement strategy implemented by Parramatta City Council, Australia............59 


\section{INTRODUCTION AND BACKGROUND}

\section{Introduction}

As with all Local Economic and Employment Development (LEED) Programme studies, this report is firmly rooted in the art of the possible. It seeks to explore what works, where and why, and highlights what the author believes to be good and innovative practices. Specifically, this report has explored the role that a large number of innovative and successful area-based approaches have played in tackling the long-term unemployment of vulnerable groups. In doing so, it has sought to develop a nuanced understanding of the critical success factors, exploring elements such as context, approach, funding, the nature of client support, sustainability and the evidencing of success. The report seeks to identify the most significant factors informing the success of these approaches and sets out a number of recommendations for those looking to reproduce similar area-based interventions.

This report also reviews the multiple factors leading to long-term unemployment amongst vulnerable groups at the local level, and the range of local measures being put in place to support labour market integration. Local partnership working is a key feature of many of these approaches and the report will look also at the role of such partnership arrangements. It examines the relative advantages and disadvantages of targeted approaches. Finally, it looks at the increasing use of innovative financing mechanisms and what role they may have in future back-to-work interventions.

The report is presented in five sections:

1. Introduction and Background.

2. OECD and World Association of Public Employment Services (WAPES) Survey.

3. Approaches.

4. Support for Interventions.

5. Recommendations for Local Approaches.

To produce this report, the author has drawn on information from two key activities carried out in support of it. The first was a large online survey, held in collaboration with the WAPES, exploring how different Public Employment Services (PES) are responding to the challenge posed by long-term and structural unemployment. The second was the commissioning by the LEED Programme, in 2011/2012, of a series of innovative case studies and learning models, each exploring a different approach to tackling unemployment in vulnerable groups. The full list of those case studies is presented in the Approaches section along with further details of the forthcoming Innovative Financing and Delivery Mechanisms for Getting the Unemployed into Work report, whose findings are also incorporated here.

This report forms part of a consistent body of work presented by the Organisation for Economic Cooperation and Development (OECD) related to labour market decentralisation and co-ordination, which includes the important Venice Action Statement (OECD, 2008). The OECD argues that proper co- 
ordination of regional and local labour markets is needed to find solutions to some of their most important deficiencies.

\section{Long-term unemployment and the already disadvantaged}

Unemployment is an area of critical concern across OECD countries. The global economic crisis that began in 2008 has had a particularly detrimental effect upon those furthest from the labour market who often include vulnerable and disadvantaged groups such as: young people; people with a disability; minorities; migrants; aboriginals; and early school leavers.

The $30^{\text {th }}$ edition of the OECD Employment Outlook (July 2012) examined recent labour market trends and short-term prospects in OECD countries. It found that the recovery from the recent economic and financial crisis had been slow and uneven. Unemployment remained unacceptably high in many countries and long-term unemployment had risen, increasing the risk of higher unemployment becoming entrenched. An analysis of how labour markets weather economic shocks shows that policies to lower structural unemployment also help to dampen the adverse effects of economic downturns on unemployment, earnings losses and earnings inequality. The number of people out of work for two years or more in the OECD area had grown by 2.6 million since 2007 to reach 7.8 million in 2011.

The work done by the OECD Directorate for Employment, Labour and Social Affairs shows that in the decade prior to the global economic recession, labour market conditions had improved significantly but this masked significant differences across countries, and even in the good times, long-term unemployment amongst disadvantaged communities persisted. The OECD recognised that, even if unemployed jobseekers were not disadvantaged generally, especially vulnerable groups such as new entrants (e.g. young persons) may find it particularly difficult to gain a foothold in a labour market where labour hoarding has reduced the flow of new job openings (OECD, 2010a).

Long periods of unemployment have been shown to have potentially 'scarring' effects which have a harmful impact in later life, particularly for young people 'not in education, employment or training' (NEET). It can lower future income levels, skills validity, future employability, job satisfaction, happiness, and health levels. Bell and Blanchflower (2010) estimate that a six-month spell of unemployment at the age of 22 would result in an $8 \%$ lower wage at 23, and even at ages 30 and 31, wages would be 2-3\% lower than they would have been otherwise. The lower the level of initial qualification, the longer these scarring effects are likely to last (OECD, 2010b).

In a modern economy, unemployment has a variety of causes. Some of them relate to the general level of economic activity, others are the result of a failure of the labour market in an economy to work optimally. The main types of unemployment remain:

- Real wage unemployment - when real wages for jobs are forced above the market clearing level.

- Demand deficient unemployment - associated with the transition of the economy through the business cycle. When there is an economic recession, we expect to see a rising level of unemployment because of plant closures and worker lay-offs. This is due to a fall in demand leading to a contraction in output across many industries.

- Frictional unemployment - transitional unemployment due to people moving between jobs.

- Structural unemployment - where there is a mismatch between their skills and the requirements of the new job opportunities. 
- Hidden unemployment - people who are interested in taking paid work but who, for one reason or another, are not classified as unemployed.

The OECD and WAPES survey emphasises the very significant funding pressures facing the programmes that provide support for the long-term unemployed. The causes of long-term unemployment have long been documented in western countries; indeed, as Machin and Manning (1998) pointed out, one of the most striking features of European labour markets is the high incidence of long-term unemployment. Machin and Manning concluded that there was no evidence that, for a given level of unemployment, the incidence of long-term unemployment had been ratcheting up over time. Their findings suggested that long-term unemployment is not a problem independent of unemployment itself, though they recognised that the experience of long-term unemployment was "a horrid one for those unfortunate enough to experience it". 


\section{OECD AND WAPES SURVEY}

\section{Background}

In 2012, the LEED Programme of the OECD conducted a joint survey with the World Association of Public Employment Services (WAPES). The survey was undertaken as part of LEED work on 'Tackling long-term unemployment amongst vulnerable groups'. The survey, sent to WAPES members around the world, examined local responses to long-term unemployment. Drawing on long-standing LEED work, key themes were identified for examination. These themes included: which, if any groups, were targeted; the flexibility available at the local level; financing; the role of evaluation; and with whom local respondents collaborated, as well as the frequency of that collaboration. 171 valid responses were received from 23 countries. The results are only indicative and should not be interpreted as being representative at a country level. The survey was primarily aimed at local employment services offices. Of the total, 154 responses were from sub-national offices and 17 from national offices.

The response from the Canadian public employment service was particularly enthusiastic and generated a remarkable $65 \%$ of the total responses. With Canada providing so high a proportion of the overall survey responses, the Canadian perspective could have a disproportionate weight in the overall results. Therefore, this report, though presenting results for the entire survey, will discuss in the text where there is a large difference between the data from Canada and that of the rest of the world. Selected tables can be found in Annex 1 .

\section{Analysis of findings}

\section{Targeting}

Whilst the labour market challenges across WAPES members vary, it nevertheless remains the case that long-term unemployment is an important challenge for employment services the world over. Targeting the long-term unemployed can be undertaken spatially (such as at a neighbourhood or community level) or to ensure that the specific needs of certain groups of individuals can be effectively addressed. Overwhelmingly, the targeting being undertaken by respondents was group-based rather than spatial, with over $70 \%$ of respondents reporting that they targeted specific groups. The three most commonly targeted groups were: older workers; young persons (up to 24); and the low-skilled, although over $50 \%$ of respondents also reported that all of the long-term unemployed were helped in the same way, while very local targeting was less common (29\%).

The most commonly assisted beneficiaries of targeting are: older workers (aged 50+); the low-skilled; and young people (up to age 24), all of whom are targeted by over $50 \%$ of respondents. Targeting based on disability (46\%) and ethnic minority groups (39\%) was slightly less common, as was the targeting of women (30\%), single parents (28\%) and ex-offenders (27\%). 15\% of respondents identified 'other groups' at which assistance is also targeted. The Canadian results were comparable to the rest of the world sample with a slightly reduced focus on the low-skilled and ex-prisoners.

The most commonly cited 'other' groups are: veterans; the long-term unemployed; the deaf and hearing impaired; employers; people in poverty; academics; and those made redundant. In Canada, the most commonly cited other groups are: Aboriginals; migrants and immigrants; and Francophones. 


\section{Flexibility}

Flexibility in terms of local service delivery has been identified by OECD LEED as an important element in developing effective local responses. Local actors with local knowledge can identify and respond to local needs. Research by OECD LEED has found that local flexibility in the development and implementation of government policies is the most important factor affecting policy integration. Even in centralised systems, sufficient latitude can be provided to local actors to allow for the delivery of responsive, effective, localised employment services. From the responses to the survey, it is clear that the importance of local flexibility in addressing long-term unemployment is being recognised in many parts of the world, with around $80 \%$ of respondents reporting that flexibility in the three areas of programme design, budget management and programme eligibility was sufficient or barely sufficient. However, for those reporting that budgetary flexibility was insufficient, qualitative responses suggested that financial constraints were an important factor in the limitations placed on budget management flexibility.

\section{Flexibility and resources}

A significant proportion of respondents suggested that more flexibility could be afforded to local areas in assisting the long-term unemployed. This was particularly the case in relation to contracting/outsourcing arrangements, where $22 \%$ felt that current levels of flexibility were insufficient (the figures being higher in Canada than the rest of the world sample). 19\% of respondents felt that flexibility in budget management was insufficient. The following statements give some flavour as to the reasons why current arrangements were deemed insufficient:

- Depends on contract/funder. Some offer great flexibility whilst some offer no flexibility.

- The contract funding has been further tightened making it more difficult to sub-contract services to allow both parties to cover costs.

- The current model precludes this and created a very competitive exclusive contracting model in a lot of cases. In others we can develop this but it is always subject to approval and usually required at the proposal stage rather than as the programme is running.

- We are not to outsource at all other than agency referrals to send a client elsewhere.

- We cannot choose to outsource.

Flexibility was perceived as a means of improving levels and quality of service delivery and allowing a focus on meeting client needs instead of funder needs. Flexibility also offered the opportunity to move money between budget headings to meet real and speciality needs. Further criticism of funding regimes cited a worry that if cost savings were realised during lower programme use, when programme usage increased, funders would expect the same programme for the same cost. There was a recognition that, in some cases, levels of flexibility were absent due to federal and state governments setting frameworks centrally. The short-term nature of investments also came under fire for prohibiting proper planning and investment.

\section{Flexibility for deciding eligibility for assistance}

$15 \%$ of respondents felt that flexibility in deciding eligibility for assistance was insufficient (13\% in Canada, $19 \%$ in other countries), with restrictions commonly being imposed by funding organisations or from regional/national governments. There were a number of criticisms relating to the fact that policy was centrally dictated and frameworks and eligibility governed centrally. Some (particularly in Canada) felt 
that even though they had theoretical flexibility, the reality was that behaviour was constrained by unrealistic outcomes. It was felt, across a number of countries, that there was a too-rigid interpretation of eligibility requirements for programmes and some policies have recently been redeveloped to further restrict programme eligibility.

\section{Flexibility in the design of programmes}

Only $12 \%$ felt that flexibility in relation to the design of programmes was currently insufficient. There was recognition that contracts can be restricting and centralised and some countries had suffered relatively recent severe budget cuts resulting in a loss of some programmes.

In Canada, there was recognition that flexibility to meet individual needs was critical to client success and whilst some programs are sufficiently flexible, some are not. It was also felt by some that provincial authorities attempted to reduce flexibility and control the work flow to the detriment of the programmes. Ultimately, flexibility depended upon the funder and Provincial funders offered no flexibility.

\section{Financing}

In terms of financing, $25 \%$ of respondents noted that the general financial resources available for working with the long-term unemployed were insufficient and anecdotal reporting suggested that some individuals who confronted complex barriers to the labour market were receiving less support due to cuts in the assistance available. This chimes with the OECD Employment Outlook (2012a) which found that, whilst the response of governments to the crisis "was to scale up ALMPs [Active Labour Market Programmes] ... the increases were modest and resources per unemployed person decreased between 2007 and 2010 by an average of $21 \% \%$.

The OECD (2012a) has suggested that, rather than reducing spending, consideration should be given to expanding active labour market policies during recessions because of the important role they play:

New analysis in this report shows that OECD governments scaled up ALMP spending more strongly following the onset of the financial crisis than in earlier recessions, probably due to their fuller appreciation of the need to retain an activation stance even during a deep recession. However, these spending increases were modest in scale and the resources available per unemployed job seeker have declined by $21 \%$ on average (in real terms) across the OECD between 2007 and 2010. This suggests that ALMP spending should generally be spared when implementing broad spending cuts as part of current, short-term fiscal consolidation packages. More generally, serious consideration should be given to redesigning both active and passive labour market programmes so that they automatically expand and contract in response to cyclical variations in the number of job seekers.

It is interesting to note that, despite the financial constraints, the overwhelming majority of respondents (around 90\%) were able to deliver personalised approaches to meet the needs of the long-term unemployed in their localities.

Other concerns from participating countries were largely related to cuts in budgets, cuts to programmes, short-term programmes and the removal of target groups, all in response to the economic crisis. In Canada, there was a more mixed response with some citing: general financial and programme delivery restrictions on flexibility; insufficient room for growing programmes; limited budgets, based on outcomes; a need for more funding for general access supports; resultant problems in maintaining staffing; and problems that too many contracts did not provide sufficient funds and were subsidised through in-kind contributions. 


\section{Evaluation}

Timely, appropriate evaluation is critical to ensuring that activities being undertaken to support the long-term unemployed are having an impact. Evaluation should be seen as an integral part of policy and programme delivery and needs to be appropriately financed, although this should not involve overlooking that, in some 'soft' areas, such as building aspirations and motivation, success can be difficult to prove in the short-term. In the survey, some $91 \%$ of respondents highlighted that evaluation was available, utilised and contributed to policies and programmes.

However, despite the apparent availability of data, respondents were evenly split about how it was used - with half suggesting evaluation was used regularly and the other half indicating that it was used only on an ad hoc basis. The results further suggested a link between respondents' use of evaluation and the resources available for it. Those who deemed their financial resources for evaluation to be insufficient were much less likely to make regular use of evaluation data to inform policy (29\%) than those whose resources were deemed sufficient (63\%). Respondents also noted that evaluation had contributed to identifying gaps in service provision - such as older people and the young, as well as the need to develop programmes to address 'soft skills'.

\section{Collaboration}

Nearly $90 \%$ of respondents reported regular (at least every month) contact with employers. Indeed, employers were the most common local actors with whom employment services collaborated. Other actors, including colleges/universities/training institutions, public sector social welfare organisations, representatives of 'at-risk' groups, and social economy/voluntary sector organisations, were also regularly contacted, with respondents reporting monthly contact with these actors ranging from $68-77 \%$.

OECD LEED publications have highlighted the need for a better alignment of employment and economic development policies and between the organisations and institutions responsible for developing and implementing them. Aligning economic and workforce development is important both for tackling long-term unemployment and for future local economic growth. Although nearly three-quarters of respondents to the survey reported collaboration between themselves and economic development organisations and regional development specialists, that collaboration was less than frequent with only $45 \%$ reporting such contact was at least once month and $13 \%$ collaborating less than every six months.

Trade unions are another actor that can play a key role in supporting people in the workplace and also work with people in skills development, although they would appear to be a somewhat undervalued resource amongst many survey respondents. Only around half of respondents reported any collaboration with trade unions and contact was often infrequent with nearly one third only in contact less than every six months. Work done as part of the wider OECD LEED project has highlighted that trade unions can play a valuable role in supporting the long-term unemployed as they re-enter work and also in working with people who are at risk of unemployment due to low skills levels.

The value of creating partnerships involving a wide range of different actors should not be underestimated not only for the development of effective policies and programmes to tackle unemployment and the ability which partnerships bring to leverage the knowledge and resources of those actors, but also for the creation of future inclusive, sustainable local economic growth.

Looking at differences between Canada and other countries, the most significant were in collaboration with health care organisations and trade unions, where collaboration in Canada appears to be well below that for other countries. 
Personalised approaches

The vast majority of respondents $(92 \%)$ stated that they were able to develop personalised approaches (where a case worker follows an individual and provides solutions based on their particular barriers to employment and/or strengths and aptitudes) to meet the needs of the long-term unemployed in a locality. This was particularly high in Canada (95\%), compared with $86 \%$ in other countries.

Of those who were able to develop personalised approaches, $84 \%$ stated that their involvement with individuals continued after finding employment. Again, this was much higher in Canada (93\%) than other countries $(65 \%)$.

\section{Summary}

The majority of respondents suggested that they were granted sufficient flexibility to provide locallyadapted labour market programmes to help the long-term unemployed, even if around one quarter felt that their financial resources to do so were insufficient. Whilst the respondents reported strong collaboration between local employment services and employers, the data suggested that there was scope to create stronger, more frequent collaboration with other important actors. There was also scope to make better use of evaluation results to influence delivery. The difficult economic circumstances were impacting on delivery. 


\section{APPROACHES}

\section{Case studies and learning models}

A series of detailed case studies and learning models have informed this research. All were commissioned by the LEED programme and most were presented at the LEED event in Trento, Italy, in June 2012. It is from these that the bulk of this report has been derived and excerpts from each are presented throughout this document. All case studies and learning models explore distinct projects or programmes and are available as stand-alone documents on the LEED website. The table below presents a summary of each project or programme, along with details of its intended beneficiaries and geographic focus.

This report also incorporates elements from the forthcoming report by Peter Ramsden, Innovative Financing and Delivery Mechanisms for Getting the Unemployed into Work, commissioned separately by the OECD LEED Programme. 
Table 1. Case Studies and Learning Models commissioned by the OECD and used in this report

\begin{tabular}{|c|c|c|}
\hline Geographic focus & Study title and type & Study focus area \\
\hline City of Gloucester, England & $\begin{array}{l}\text { Gloucester Works: An Area Based } \\
\text { Approach Targeting } \\
\text { Disadvantaged and Minority } \\
\text { Populations }\end{array}$ & $\begin{array}{l}\text { An area-based intervention to support } \\
\text { disadvantaged and vulnerable groups within the } \\
\text { City of Gloucester, with the aim of enhancing the } \\
\text { skills levels of individuals and supporting them } \\
\text { into employment. }\end{array}$ \\
\hline Parramatta City, Australia & $\begin{array}{l}\text { Generating social value through } \\
\text { public procurement: the case of } \\
\text { Parramatta City Council }\end{array}$ & $\begin{array}{l}\text { How Parramatta City Council in Australia are } \\
\text { using social procurement to generate enhanced } \\
\text { social outcomes for its disadvantaged } \\
\text { communities. }\end{array}$ \\
\hline City of Vancouver, Canada & $\begin{array}{l}\text { The BladeRunners Program - } \\
\text { Supporting the transition to } \\
\text { employment of disadvantaged } \\
\text { youth in Vancouver, Canada }\end{array}$ & $\begin{array}{l}\text { A programme that helps youth (ages } 15-30 \text { ) with } \\
\text { multiple barriers to employment, to build careers } \\
\text { in construction and other industries throughout } \\
\text { the province of British Columbia (BC), Canada. }\end{array}$ \\
\hline $\begin{array}{l}\text { Antwerp and Alost, } \\
\text { Belgium }\end{array}$ & $\begin{array}{l}\text { Targeted Trajectories towards } \\
\text { durable work for persons from } \\
\text { impoverished backgrounds }\end{array}$ & $\begin{array}{l}\text { Information on two projects in Antwerp and Alost } \\
\text { in Belgium which focused on experimental } \\
\text { trajectories towards work for persons living in } \\
\text { poverty. }\end{array}$ \\
\hline United Kingdom & $\begin{array}{l}\text { Unionlearn in the Community: } \\
\text { tackling disadvantage }\end{array}$ & $\begin{array}{l}\text { The role played by Unionlearn in England in } \\
\text { tackling disadvantage through its community } \\
\text { learning activities, carried out in partnership with } \\
\text { the TUC's member unions. }\end{array}$ \\
\hline Belgium & $\begin{array}{l}\text { 'Back at Work' Trajectories for } \\
\text { (former) detainees }\end{array}$ & $\begin{array}{l}\text { Information on four projects run in Belgium to } \\
\text { help former detainees into employment. }\end{array}$ \\
\hline Auckland, New Zealand & $\begin{array}{l}\text { BEST Pacific Institute of } \\
\text { Education - Pacific Model }\end{array}$ & $\begin{array}{l}\text { Institutional approach by an educational } \\
\text { establishment to embrace the cultural values of } \\
\text { its often disadvantaged minority community. }\end{array}$ \\
\hline Cantú, Italy & ESEDRA Co-operative & $\begin{array}{l}\text { Work integration is the main mission of ESEDRA } \\
\text { which works in the energy and environmental } \\
\text { sectors. Its development has been driven by a } \\
\text { desire to give work opportunities to } \\
\text { disadvantaged people. }\end{array}$ \\
\hline $\begin{array}{l}\text { Valencia and Andalusia, } \\
\text { Spain }\end{array}$ & $\begin{array}{l}\text { Claros - the dream of a worker } \\
\text { co-operative fusion }\end{array}$ & $\begin{array}{l}\text { 'Claros' champions the work reintegration of } \\
\text { women. It began with four home care contracts to } \\
\text { its respective city councils, and in } 2011 \text { - its tenth } \\
\text { anniversary - it had } 41 \text { contracts with public } \\
\text { authorities in various cities of Andalusia and } \\
\text { Valencia, which implied own resources of } 4.5 \\
\text { million Euros. }\end{array}$ \\
\hline $\begin{array}{l}\text { Ardèche, } \\
\text { France }\end{array}$ & $\begin{array}{l}\text { Ardelaine - a co-operative } \\
\text { dedicated to local sustainable } \\
\text { development }\end{array}$ & $\begin{array}{l}\text { Ardelaine is a co-operative whose primary } \\
\text { mission is sustainable local development by } \\
\text { promoting respect for the environment throughout } \\
\text { the supply chain. }\end{array}$ \\
\hline Belgium & $\begin{array}{l}\text { Job creation through social } \\
\text { entrepreneurship and the social } \\
\text { economy }\end{array}$ & $\begin{array}{l}\text { Social flexibility and attention to local needs as } \\
\text { the levers for large-scale sustainable job creation } \\
\text { by the Flemish organisation 'vzw IN-Z'. }\end{array}$ \\
\hline
\end{tabular}

\section{Targeting approaches}

In this section we look at example of interventions to support vulnerable groups. These interventions have been driven by the recognition of the particular needs of specific vulnerable groups which have been used to inform the design of the activities. 
Local employment and skills initiatives target in different ways. They may target spatially by focusing on a particular neighbourhood or community, often disadvantaged, or they may target by need. They may direct services at a particular gender, at a specific age category (such as youth), or at particular migrant and ethnic groupings - often overlapping with spatial targeting.

Targeted approaches are normally centred upon particular groups, often found to be over-represented among the long-term unemployed, such as: the homeless, minorities, aboriginals, migrants, people with a disability, and those living in particular poverty. An example of a targeted approach working with the latter group took place in the Belgian cities of Antwerp and Alost.

As with most European countries, Belgium has been badly affected by the recent economic crisis. Working with its social partners, the Regional (Flemish) Government's response was to introduce a 'Work and Investment Plan' (WIP) which paid specific attention to vulnerable groups within the labour market, including persons living in poverty. This enabled the start of two projects, one in Antwerp and the other in Alost, which focused on "experimental trajectories towards work". These trajectories contained particular elements, which can reasonably be described as innovative (Van de Voorde et al., 2012):

- A non-fragmented, cyclical guidance model, that could last for more than 18 months;

- A mediator/'buddy' for every jobseeker who would remain with the client throughout their time with the project;

- Every trajectory was tailor made (bespoke), and;

- The bespoke interventions were devised by the public employment sector working in partnership with local organisations containing people from the target group, intermediary organisations often delivering welfare services and the local authorities of the two cities.

The projects were similar, though the Alost project also sought to target intergenerational poverty and all the participants were people who not only lived in poverty, but whose parents had also lived in poverty. Both projects kept in regular contact.

The Antwerp activities commenced in November 2010, and the project has supported more than 300 jobseekers living in poverty to find work. The project was initiated by a local partnership led by the local PES, in this case the local branch of the Flemish Service for Employment and Vocational Training (VDAB), which specialises in matching labour market supply to demand and has established expertise in training and back-to-work support. VDAB worked in close co-operation with community based organisations and welfare agencies already engaged in activities with this target group. Crucially, the projects saw its Jobseekers not just as 'clients' but as 'partners' in the project, helping to design the resultant tools and methodologies.

The project chose to integrate both its 'work' and its 'welfare' activities into a holistic offer, entitled ' $\mathrm{W}^{2}$-trajectories'. The characteristics of the $\mathrm{w}^{2}$-trajectories can be summarised as follows:

- An integrated and structured methodology combining work and welfare support;

- The maintenance of permanent engagement with the jobseeker and with the different organisations that form the existing network for welfare provision; 
- An approach focused on an individual's strengths and participation, responding to the jobseeker's potential, interests and existing competences, with the clear ultimate aim of gaining employment and/or skills enhancement;

- One work-welfare counsellor (buddy) who acts as an 'anchor', and who follows and supports the jobseeker in mapping hopes, expectations and competences with a view to employment and/or training.

\section{Box 1. Tackling Generational Poverty - The Alost Project, Antwerp}

The Alost project was very similar to that carried out in Antwerp, but with two major differences. In Alost, all of the jobseekers were 'generational poor', meaning that the Jobseeker's parents were already living in poverty. As a consequence, the coaching methodology was modified to include more of a focus on group work sessions, where Counsellors would discuss the consequences of, and damage caused by, poverty, culminating in recommendations on how they may be overcome.

The second key difference was in the role of the 'anchoring' Counsellor. In Alost, this function was carried out by two people. A W2 Counsellor, as in the Antwerp project, working together with a type of mentor - a well-trained/skilled individual, who themselves had lived for several years in similar, severe, inter-generational poverty.

Source : Van de Voorde et al. (2012)

Although both the Antwerp and Alost projects faced many difficulties, the overall results were promising (Van de Voorde et al., 2012). Both projects were evaluated in 2011 and the lessons learned are now being integrated in a single methodology which is now (as of mid-2012) being rolled out to 500 new jobseekers a year.

The social partners may also have a role in targeting disadvantaged communities. In the UK, Unionlearn has, for many years, successfully targeted people with low skills levels already in the workplace. However, in recent years, it has extended its focus, typically in partnership with other agencies and community organisations, to foster greater links with vulnerable groups seeking employment.

The logic for extending the role of trade unions and social partners into the community is clear as union representatives are more likely than others to become active in their communities and these developments build links between communities and employers.

Amongst those outside of the labour market, former detainees are often the hardest to place in sustainable work. There is a growing consensus on the need to improve the skills of those in prison and former detainees, to give them a reasonable chance of not re-offending.

One of our case studies (from Belgium), looked at later in more detail, examines innovative approaches to getting detainees into sustainable employment. Back-to-work initiatives for former detainees are not unusual and typically combine lifelong learning and vocational training. Schuller (2009) recognised that making lifelong learning an effective instrument against crime requires action on several fronts. Increasing human capital through skills and qualifications must go with improved social capital, building useful networks and peer/family support; and with building appropriate self-esteem and the belief in a better life ahead. He emphasised that learning would only have significant effect if linked with other policies, particularly on employment and accommodation, and that this is particularly crucial at key transition points, particularly at the point of release. Schuller argued that there is a strong case for all prisoners to be given access to education or training as a matter of course immediately when they leave prison, combined with pre-release preparation for it. 
Vocational training, individual vocational training on the job, work-based training or employment in the social economy sector are, for most detainees, an ideal stepping stone to a job, and certain technical and non-technical competences usually need refreshing. The Belgian case study recognised the importance of close effective collaboration between the different parties involved: the federal level (Ministry of Justice) and the different Flemish service providers (Departments of Welfare, Education, Work, etc.). To make things even more complicated, a jobseeking (former) detainee often faces a multitude of problems and barriers, notably housing, finances, family, welfare, health, etc.

Many employers are rather reluctant to hire former detainees for a lot of reasons, and sensitising and persuading employers to give former detainees a genuine chance will always be problematic. However, activities such as the matching of the competences of detainees with the demands of specific employers, guidance and counselling for detainees and for the employer after hiring; valuing all the acquired competences of the detainee; and facilitating the transition between detention and work are all beneficial.

\section{Geographical drivers for targeting}

Many good examples of labour market interventions have been driven primarily by the need to support a particularly hard-hit or economically struggling locality. Though these often include activities focused on particular groups, the policy drivers for the intervention were initiated due to a concentration of deprivation and of vulnerable people within one locality. The origins of place-based interventions are often routed through the structures of government, with labour ministries focusing interventions on groups and individuals, whilst local or regional government initiatives are more likely to tackle unemployment concentrations within communities.

A comparison of education and income disadvantage evaluation reports by Griggs et al. (2008) recognised the problems in comparing the effectiveness of place-based versus individually-targeted interventions (in the UK). They concluded that: "Most policy interventions, whether person or placetargeted, had small, favourable impacts. In the rare cases where information on expenditure was available, costs were generally offset by savings to the Exchequer. Both forms of intervention had significant positive impacts on particular aspects of education results and employment. However, it was not possible to determine whether person or place-based policies were better, as they tended to have different objectives that prevented direct comparison." Nonetheless, in some comparisons, place-based interventions fared well.

A good example of just such a geographical approach to targeting occurred in our case study example, Gloucester Works, a project located within the City of Gloucester, in south-west England. 


\section{Box 2. Gloucester Works}

The Gloucester Works' activities sought to improve the engagement of workless and low-skilled individuals from particular neighbourhoods. Its key features were:

- a co-ordinated approach at the local level;

- $\quad$ support to improve the employability and skills of those not in work and in low-skilled occupations through more intensive, flexible and bespoke approach; and

- $\quad$ engage with employers to encourage and support them to recruit from priority groups, retain people in employment and commit to re-skill, up-skill and succession plan their workforces.

For individuals, Gloucester Works offered skills advice on everything from interview techniques, CV-writing, basic literacy and numeracy skills through to leadership and management training. They could arrange a personal one-toone interview at a time that suited the client and offered a personal action programme to help identify current skills, what the client was seeking to do and how they could get there; free training and qualifications and support to identify childcare and transport options. The timing of the Gloucester Works activities was key. A number of major developments within the City were starting and the project was able, through developing partnerships with job centres and employers, to include links to real jobs, for example, the Quays (a major retail development), expanding Business Parks and other developments recruited through the programme's Jobs Bank. Individuals could be offered work trials and a promise of guaranteed interviews. Following recruitment, if things went well, they received ongoing support during employment and further training to enable progression. If things went less well, they could access redundancy advice and support to help clients obtain relevant qualifications to confirm their skills, and provide training that could enhance their future job prospects. To achieve this, Gloucester Works needed to develop new forms of partnerships working at both the strategic and operational levels, with clear lines of responsibility. Joint investment plans and joint commissioning was utilised along with a new client-centred approach to referral between contracted agencies and providers. Programmes needed to be more flexible and responsive to create an end-to-end service to ensure that no matter where the potential beneficiary entered the system, they were supported along a route towards work.

Crucial to the success of the project was the work of Gloucester City Council which included requirements for training and employment as part of planning consents. Employers were then linked with Gloucester Work's employer engagement team, their needs scoped and suitable candidates from among the Gloucester Works' clients trained and signposted to them. All beneficiaries, whether unemployed or employed, first underwent an intensive skills diagnostic to identify what skills, and in particular what employability and 'basic' skills, they needed support with. This crucial role was performed by a private company, Prospect Training Services, under the title of the 'Gloucester Gateway Programme'. This Gateway Programme was an integral element of the Gloucester Works network and provided seamless support to workless or employed clients seeking sustainable employment or more productive careers. The venue for Gateway (and training) support was crucial. A former shop in the city centre was used a great deal, but other locations were also often utilised, particularly if a certain geographic or minority group needed particular support, such as women-only meetings for some of the City's Asian women.

\section{Link to regeneration and new job-rich activities via Gloucester Works}

Regeneration investment in Gloucester included the redevelopment of Gloucester Docks and the Gloucester City Employment Programme, funded by the South West Regional Development Agency (SWRDA) plus a plethora of other supporting organisations, funds and authorities. The Gloucester Works Programme aimed to ensure that local people could take advantage of new opportunities brought about by regeneration. Between 2001 and 2011, the SWRDA invested around GBP 17.7 million in the Docks project, with a further GBP 11.2 million to complete the area's renaissance. The Gloucester Docks and Quays had been designed as a focus for regeneration activities to include retail facilities as well as a college site. The investment was envisaged to lead to 3000 new homes, 2000 new jobs and an improved infrastructure linking to the city centre, with a significant boost to heritage visitors (SLIM, 2010). Gloucester Works offered European Social Fund (ESF) support via the Learning and Skills Council (the then national funding agency for skills) working alongside mainstream regeneration initiatives, using providers at neighbourhood level to fill programmes. It aimed to provide new forms of partnership at the strategic and operational levels, spatial targeting, joint investment and commissioning, a client-centred approach and flexible, more responsive programmes (SLIM, 2009). Key components of Gloucester Works illustrated strong principles of alignment between ESF and mainstream activities. There was a common approach to employer engagement and a central Jobs Bank: 'bringing job opportunities to a wider audience'. There was an integrated service for employment, skills and aftercare and personal support and bespoke training for individuals. Investment was linked to sustained employment outcomes and strategy aligned to Integrated Locality Action Plans. Further strategic linkages were sought with employment, skills and other services. Below, is a diagrammatic representation of the Gloucester Works Integrated Employment and Skills System. 
Box 2. Gloucester Works (cont'd)

Figure 1. Gloucester Works Integrated Employment and Skills System

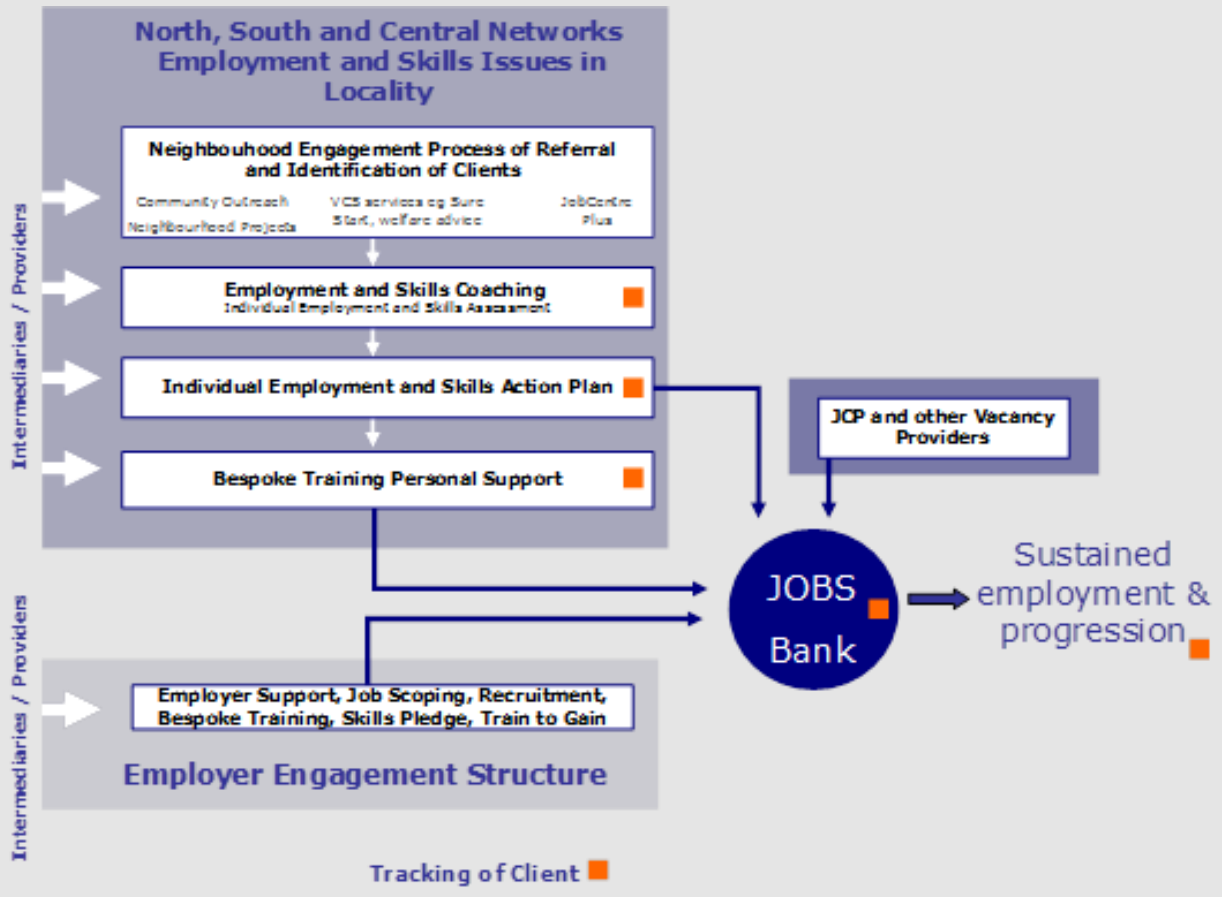

Source : Gloucester Works

The linkages formed between employment and skills and the areas of Planning and Regeneration were helpful in ensuring that the employment benefits that accrued from new developments were targeted at the most disadvantaged. Gloucester Works was developed as a strategic response to a then tight labour market. Partners proactively developed clear and shared objectives and priorities based on the drivers at that time and agreed to align resources to deliver the Plan. This had never been achieved in Gloucester before and, indeed, had not been achieved anywhere else in England (EMB Consulting and Buckman Associates Ltd, 2011).

\section{Evaluation of Gloucester Works}

In the Gloucester Works activities, monitoring and evaluation was built in from the outset. This was carried out by a team of local consultants and the evaluation looked at five areas:

- Impact achieved on the ground, particularly in helping individuals furthest from the labour market develop skills and access employment opportunities created in Gloucester.

- Progress made in supporting and retaining people into sustainable employment, particularly those from the central wards in Gloucester identified as having particularly concentrated worklessness problems.

- The success with which employers and investors were supported, able to grow their workforces, grow their businesses and recruit staff to vacancies being created.

- The strength, quality and robustness of the partnerships that underpinned the Programme, including at Management Board level, Working Groups and the Provider Forum and (b) the scope to sustain them in the light of the new policy landscape being developed by the then new Coalition Government.

- The scale of further investment by partners moving forward and the nature, scope and role of the Executive Team to deliver a future phase of activity (EMB Consulting and Buckman Associates Ltd, 2011).

Source : Dean (2012a) 
The BladeRunners case study, explored in detail later in this report, is another fine example of a place-based intervention, this time in Canada. It was founded in 1994 when a group of local community advocates began to express concern about the need to include marginalised street-involved youth in the building developments that were sprouting up next to the neighbourhood. Funding, as is typical for placebased interventions, came from provincial rather than national government. It was so successful that according to programme managers, of the 25 young people initially placed on the original GM site, 20 are still working in the construction industry. This initial experiment was regarded as a success, and was later built upon and expanded to other projects and other areas.

\section{Flexible provision}

The need for greater flexibility in provision was a theme in the findings from the OECD and WAPES survey incorporated within this report. LEED has emphasised the importance of greater flexibility in labour market policy. In particular, the LEED study on Integrating Employment, Skills and Economic Development of 11 countries, published by the OECD as Breaking Out of Policy Silos (OECD, 2010c), found that flexibility in the management of government policies is the most important factor affecting policy integration at the local level and that: "in the context of the economic recovery and public budget cuts, policy silos and fragmented short-term policy interventions have also become luxuries that our economies can no longer afford".

The OECD publication, Flexible Policy for More and Better Jobs (OECD, 2009), recommended far greater flexibility at the local level to co-ordinate and adapt both policies and programmes to local strategic priorities emphasising the link between flexibility and employment outcomes.

Disadvantaged groups often face complex barriers to employment and training. This can include negative attitudes to education and learning, a lack of affordable childcare, difficulties in accessing nearby opportunities, difficulties in reconciling welfare and benefits and personal circumstances and needs that preclude best utilising conventional employment and training schemes.

The International Labour Organisation (ILO) report, Preliminary assessment of training and retraining programmes implemented in response to the Great Recession (Hansen and Zulum, 2012), recognised the "expansion of more flexible training delivery methods" in some countries/geographies. They also noted that there was evidence of more flexible training delivery methods in a survey of employer-provided training in the EU. The ILO report recognised the importance of being able to adapt, reorient and expand existing programmes to meet new demands for services and the role that flexible training delivery mechanisms had in this.

To overcome the complex needs of their client group, one of our case studies (Gloucester Works) utilised a network of 40 training providers (including further education colleges) and found that it was often the smaller providers that were best able to provide the flexible training they required.

Disadvantaged individuals tended to suffer from the 'revolving door' between benefits and employment and were often part of the overall labour market churn - passing from one poorly paid job to another between bouts of unemployment. In supporting this group, therefore, the development of a flexible, individualised programme of pre and post-employment support is important. This has indeed formed the basis of the approach to the UK's Work Programme which is taking a 'black box' approach, leaving providers to decide on the package of activities that the client requires.

Employers, too, have differing requirements of training. Again, as illustrated in the Gloucester Works example, early analysis of employer attitudes revealed that they perceived an absence of short, focused, 
bespoke training courses that could assist employers with immediate skills and recruitment issues. Many employers felt they could not afford to wait for extensive training programmes to be completed.

\section{The value of informal and non-formal learning}

Taking account of the full range of an individual's knowledge, skills and competences can be especially relevant when working with those marginalised in the labour market, especially when it comes to young people. This includes recognising that the value of informal and non-formal learning can play an important role here, as opposed to taking into account only learning that takes place in formal education and training systems.

Informal learning results from daily activities related to work, family life or leisure. It is not structured and usually does not lead to certification. In most cases, it is unintentional on the part of the learner (modified from Cedefop, 2011).

Non-formal learning is not provided by an education or training institution and typically does not lead to certification. However, it is intentional on the part of the learner and has structured objectives, times and support (modified from Cedefop, 2011).

Informal Adult and Community Learning (IACL) is an umbrella term describing a broad range of learning that brings together adults to pursue an interest, address a need, acquire a new skill, become healthier or learn how to support their children. This kind of learning, usually unaccredited, is an important part of the wider learning continuum. It can be undertaken for its own sake or as a step towards other, more vocationally-orientated learning/training. It can be delivered by providers in the public, voluntary or private sectors. It can also be organised by people for themselves through the many groups, clubs and societies where people get together to learn.

Many learners are initially engaged in the learning process through informal adult community learning opportunities in the workplace. In the UK, Unionlearn has found that as they develop confidence, learners often progress successfully into learning such as Skills for Life or work-based vocational pathways. During 2010-11, with Unionlearn support, trade unions engaged with more than 34000 learners through the informal adult and community learning route.

\section{Business start-up and entrepreneurship}

Audretsch et al. (2001) recognised the existence of two distinct and separate relationships between unemployment and entrepreneurship - a 'Schumpeter' effect of entrepreneurship reducing unemployment and a 'refugee' or 'shopkeeper' effect of unemployment stimulating entrepreneurship, in a study of 23 OECD countries over the period 1974-1998.

Deprived communities can face many barriers to entrepreneurship. Williams and Williams (2011), in a study of deprived urban neighbourhoods, recognised: lack of self-belief and confidence; lack of affordable workspace; lack of access to finance (and perceived lack of access to finance); poor image; and, fear of crime.

The critical role played by start-ups and young businesses (including non-profit) in driving economic development and job creation is referenced in the OECD LEED Report, Building Quality Jobs in the Recovery (2011b OECD Conference Issues Paper). It recognised that:

in the past, young people's parents made the transition to a world of more stable trades and professions, however this generation and future ones are moving into a world of 'occupational 
quick-sands and volcanoes' in which youth entrepreneurship can be a viable alternative for some young people to dependent labour.

A number of countries encourage some unemployed individuals to start their own business or social enterprise, an example being the new Enterprise Allowance scheme in England. In our Gloucester Works case study, the programme team engaged early with Business Link (whose job it was to work with and support employers) to ensure support to enter self-employment was available to those interested. Work was then undertaken to scope the individual requirements of leading such a development.

\section{Independent advice and honest brokers}

Independent advice and guidance (IAG) is an important activity in connecting unemployed people with the world of work and the range of support services they require to help them prepare for work. Watts (2010), in a paper prepared for the OECD Review of Post-Secondary Vocational Education and Training, Skills beyond School, recognised the need to ensure that career guidance is impartial and free from institutional bias, along with the importance of relevant labour market information and the need for evaluation evidence which is touched on later in this report.

Froy and Giguère (2010) recognised that many community and local organisations now play an invaluable role as brokers or 'linking organisations', connecting clients to a number of follow-on programmes, thereby aiding continuous learning and development. Policies and approaches can benefit also from being 'co-created' with local young people to create greater ownership and ensure that local initiatives are better adapted to their needs.

Bimrose (2009) recognised that, whichever way it is conceptualised, 'career' relates to individual transitions into and around the labour market. 'Career', careers guidance and labour markets are, therefore, very closely aligned. Indeed, Bimrose recognises that the approach to IAG has changed little over time.

The BladeRunners case study from Canada is a fine example of combining tailored IAG to support back-to-work interventions. IAG is provided initially as participants arrive and request to join the programme (often after receiving advice from others about available opportunities). The co-ordinators conduct screening interviews and orientation sessions that allow them to evaluate whether the young people are ready and motivated to enter the programme. Some are then referred to other services in the community if the co-ordinators realise that the timing is not right because other issues have to be dealt with first. One frequent problem is substance abuse and some participants reported having been signposted to a drug or alcohol rehabilitation programme before beginning the BladeRunners training (Molgat, 2012).

The BladeRunners model, and examples of provision like it, would not work without the support that is offered to programme participants. IAG forms part of the general support from the project workers and takes many forms: referrals to various health, education and social services; financial support for obtaining stable housing; support in the form of public transportation vouchers and meals; informal counselling about further training and education; and financial support for additional training programme fees.

It was important to the success of the Gloucester Works case study that the team did not deliver training or services themselves. They were able to be an independent honest broker that could go to the market and source what was required to meet the specific needs of the client. Similarly, it was crucial to house the project with the correct accountable body. This impacted upon the ability of the project to ensure senior level corporate partnership working from other agencies and upon how impartial and independent the project appeared to be. Had Gloucester Works been housed within one of the large public sector providers, it could have mitigated some of the communications and management issues which arose but it could also have struggled to be seen as independent. 
There is a crucial linkage here between the need for independent honest advice and the crucial role that person-centred support can play. The role of the 'buddy' in the Vancouver case study (explored in detail later in this report) and the role of the work-welfare counsellor in the Belgian case studies (Antwerp and Alost) are examples of this. The work-welfare counsellor is an 'anchor', or coach, who follows and supports the jobseeker/client in mapping ambitions, expectations and competences with a view to future employment and/or training. This facilitation seeks to:

- Regard the client as a total and unique person with his/her own aspirations and characteristics;

- Bring together sources of strength (resources, competences, qualities);

- Offer tailor-made possibilities to learn skills and attitudes;

- Stimulate the client to set realistic goals and help him/her in reaching them;

- Provide good, honest, realistic feedback so that the client can recognise unrealistic perceptions and interpretations and correct them.

In the UK, Union Learning Representatives (ULRs), who play a crucial role in one of our later case studies, are also viewed as honest brokers and they have a specific and crucial role within the workplace where they work to drive up the skills levels of colleagues. They are independent of training providers and are able to negotiate training provision with external organisations. Their training centres are accredited for their competency at providing impartial advice (by the Matrix Standard) and training is provided in a large variety of ways, often using IT. The independence of ULRs and their ability to negotiate training provision and support for groups of potential learners underpin the success of their work in supporting Community Learning Champions - activities where ULRs form links with community organisations and help embed appropriate training and back-to-work opportunities.

In the Antwerp and Alost case study from Belgium, the work-welfare counsellor's role was crucial here as they had to have a good overview of the strengths/competencies of the jobseeker (supply side) on the one hand and on the needs and demands of the employer (demand side) on the other hand and (s)he must 'dare to sell' the client to the employer (Van de Voorde et al., 2012).

\section{Holistic or 'joined-up' partnership approaches}

The last twenty years have seen something of a flowering in the number and diversity of organisations operating in the area of employment and back-to-work support. In most OECD countries, these will now include: industry groups and employers, schools, colleges and third level education providers, trade unions, employment agencies, social economy organisations, and local community groups. The relatively low level of collaboration with some organisations, notably economic development specialists, emerged from the OECD and WAPES survey reviewed earlier in this report.

Developing holistic or 'joined up' strategies and governance mechanisms to co-ordinate activity is a particularly important function for those working within local labour markets. A partnership approach can better tackle entrenched barriers, create a more integrated service for young people and providers, and has a relatively strong impact on the degree of local policy integration. However, successful collaboration is not easy, with common obstacles including ambiguity about roles, conflict, contested leadership and narrow institutional mandates (Froy and Giguère, 2010).

Many local community and Non-governmental Organisations (NGOs) providing employment support for young people can be relatively isolated from mainstream institutions. They often operate on the 
periphery with little critical mass, reliant on short-term funding and duplicating services (Froy and Pyne, 2011). It is important that local organisations are well networked to share knowledge and emerging good practice.

Hansen and Zulum (2012), writing for the ILO, recognised the importance of co-operation among partner institutions, stating: "Given the growing inter-relatedness of programme measures already noted, it is increasingly important that the service delivery agencies implementing labour market programmes be able to work together co-operatively". In their study, productive working relationships among institutions were repeatedly cited as a critical success factor in the assessments reviewed. Orderly, efficient channels of communication between the national and sub-national (state, provincial, or regional) levels were also highlighted as important, particularly in a crisis situation.

In the Gloucester Works case study, the Job Hubs were able to offer many services as well as back-towork advice which included housing benefits and disability benefits advice. It created a form of brand for Gloucester Works, with most agencies signposting to Gloucester Works. Gloucester Works did not just work with unemployed clients. The inclusion of an Employer Engagement strand opened the door to allow them to identify new vacancies (most vacancies in the UK are NOT offered through Job Centres). 250 businesses, new to accessing funding for training, opened the door to training employees and to providing apprenticeships. These 250 businesses also reviewed the skills of their own employees.

Green and Hasluck (2009) recognised the importance of holistic approaches, alongside the importance of outreach, individualisation and the position of personal advisers, continuing support, flexibility, motivation and aspirations, partnership working and the role of employers in achieving successful programmes to reduce worklessness.

Multi-sector partnerships are increasingly common and were essential to the success of the BladeRunners model featured in our case study. The original BladeRunners' advocates were successful in obtaining start-up funding for the project from government, with a buy-in from a few key employers in the construction industry who guaranteed employment placements for programme graduates. This original partnership model, based on formal and informal agreements, continues today. Some partnerships need to be formal, especially those that are tied to the funding received from various levels of government when service delivery is expected.

Others are based on a memorandum of understanding (MOU) whereby an organisation such as BC Housing (the government-funded and administered social housing builder and provider in British Columbia) accepts to take in BladeRunners Program participants. However, almost all other BladeRunners partnerships are informal.

Employers in the construction industry seem to prefer this type of informal arrangement, which gives them the flexibility they need when preparing submissions for contracts and dealing with employees. Employers do, however, hire BladeRunners at market rate, and do not pay them less than they would other employees in the same jobs. Partnerships with local community and service organisations and, to a lesser extent, trade unions and post-secondary institutions, have also been essential to the success of BladeRunners, but here again these are informal and rely upon on an 'as-needed' basis according to each individual participant's situation.

\section{Hide the wiring}

Complex partnership delivery can include many organisations, all with a genuine stake in the outcomes. This can cause confusion when trying build up a positive identity for activities and programmes. One rational response is to 'hide the wiring'. There is little need for individuals to be aware of just where 
funding or trainers may be secured from, or to be aware of the often large number of enabling bodies and agencies.

Parramatta City Council (PCC) in Australia has been exploring innovative social procurement. Indeed, over the last fifteen years, there has been an increased focus on the potential value of integrated service delivery and 'joined up' governmental responses to complex societal needs. This emphasis on generating relatively greater public value through a co-ordinated and integrated approach is emphasised in the sustainable procurement framework. The development of PCC's sustainable procurement strategy was initiated when several different functional areas of Council became aware that they were each exploring the strategic possibilities of procurement to deliver on Council-wide triple bottom line objectives. Separately, members of the local economic development team, the Corporate Sustainability Co-ordinator, and the Social Enterprise Programme approached PCC's Procurement Manager to discuss the possibilities of PCC procurement playing a more purposeful role in generating local economic, environmental and social (and social economy) outcomes respectively.

In the Belgian case study, both the work in Antwerp and Alost relied upon a strong and structural partnership, with partners who were firmly locally embedded, knew each other and wanted to take the 'common risk'. Indeed, the project was initiated by a local partnership. The local branch of the public employment service, VDAB, took the lead, in close co-operation with the local network of selforganisations of people living in poverty and supported by welfare organisations. The Leuven University and an Antwerp high school delivered the scientific support, as one of the goals set out at the start was to produce a manual to transfer the methodology and the instruments to other cities. This use of a University/research centre to explore innovation and transferability as the project progressed should be considered as best practice.

In the Gloucester Works example, real efforts were made to develop a successful identity for the work with the intention that employers and individuals would seek the Gloucester Works' service, and would rightly care little for which of the many trainers, agencies and community bodies actually provided the eventual activities. A further useful function in this regard was the centralised data tracking and logging. Individuals were logged and tracked by the Gloucester Works team and their progress through various stages of their journey was monitored. This was underpinned by a data sharing protocol between the Central Team and the relevant provider/support agent.

A client's journey within the Gloucester Works case study could reasonably include: initial contact within a Community organisation; assessment and the provision of an Employment and Skills Action Plan by a private company; one or more training schemes by differing training providers; support with benefits and welfare advice via various agencies; signposting to an employer; and in-work support and training from other organisations, all undertaken under the banner of 'Gloucester Works'.

A lack of linkage between different agencies and providers can lead to a 'revolving door' between benefits and low-paid employment with individuals almost lost within a complex system. This lack of effective linkage can lead to individuals, especially those suffering particular barriers to employment, falling through the cracks as they seek assistance.

Providers and support bodies needed to ensure that the right employment and skills provision was in place for the priority groups and areas in the right location at the right time. An underpinning element of any programme, therefore, should be to develop a joined up strategic planning, commissioning and delivery framework to improve the relevance and focus on employment and skills provision. It will help integrate the wider range of provision (e.g. health, childcare) alongside employability to remove clients' barriers to accessing, sustaining and progressing in employment. 


\section{Person-centred approach}

The diversity in the nature of the 'harder-to-reach' economically inactive population and their circumstances, combined with the fact that they often face multiple barriers to entering employment, requires a client-centred or personalised approach (Syrett, 2008). This contrasts with existing provision, which tends to be standardised and lacks flexibility to respond to individual needs over varying time scales. Successful interventions are characterised by:

- Holistic interventions rather than focusing on only one aspect of employability;

- Individualised approaches providing continuity of support and the right support at the right time;

- High quality personal advisors able to operate flexibly in relation to an individual's needs;

- Assessment and improvement of basic skills embarked upon at the earliest moment; and,

- Continuity of training both in and out of employment; support for job search activity.

The Vancouver BladeRunners Program (see Box below) provides an interesting example of an approach to supporting young people with multiple disadvantages who are already out of education, employment or training, where support comes from Program co-ordinators. Off-the-job support takes many forms: referrals to various health, education and social services; financial support for obtaining stable housing; support in the form of public transportation vouchers and meals; informal counselling about further training and education; and financial support for additional training programme fees. The underlying and fundamental goal of all support is to make sure that participants are able to be placed in jobs and to maintain stable employment and long-term attachment to the labour market. 


\section{Box 3. BladeRunners $24 / 7$ support}

From the beginning, the co-ordinators of the Bladerunners Program realised that, although the training and placement processes were working well, many of the participants were having problems maintaining stability when in work. They also very quickly realised that other issues than job-specific knowledge or training were having an effect on their lives and causing problems with work.

As a result, a 24 hours a day/seven days a week support service was implemented. The '24/7' system allowed participants to contact co-ordinators whenever they needed support, whether to deal with problems on the construction site or to find help for adequate housing, to address substance abuse or addiction issues, to recover from relapses or physical injuries, and to provide general counselling about work habits and routines, and careers. Along with the training and placement components, the 24/7 long-term extensive support system is one of the key pillars of the BladeRunners model.

On the first day of work, a BladeRunners co-ordinator will bring the participant to the construction site and introduce him or her to the foreman, contractor or tradesperson, and to other BladeRunners if any are already working on the site. Over the subsequent days, the co-ordinator will return to the site to ensure that the contractor, the trades people and the BladeRunners participant are satisfied with the placement. If required, co-ordinators will refer participants to other social service providers, assist with housing and transportation needs and counsel young people about further training and permanent job opportunities. Funds are available to help stabilise housing (first month's rent and damage deposit), for transportation (bus tickets) and food (lunches on site, if needed). This support is offered because it is deemed essential to ensure employability.

In the BladeRunners model, clients receive short-term training that is tailored to the participants' needs and abilities, and that offers the basic skills needed to enter the workplace rapidly. Many training programmes for disadvantaged young people are first geared to sending them back to school to complete their secondary education. The BladeRunners model advocates labour market integration as soon as basic skills have been acquired, with the view that it is feasible to acquire other skills on the job and that more specialised training can be undertaken when participants have had a chance to gain experience and observe various trades people at work. According to all those involved, from Program managers to co-ordinators, from employers and to young people, this design allows participants to gain confidence in their employment abilities quickly and to realise that working for a living wage is within their reach.

The support provided by co-ordinators to the participants is tailored to meet the specific needs of each individual young person, is extremely varied in nature, and extensive. The underlying and fundamental goal of all support is to make sure that participants are able to be placed in jobs and to maintain stable employment and long-term attachment to the labour market. Support is offered whenever Program participants need it, whether it is on or off the job. It is available 24 hours a day, seven days a week. BladeRunners participants all have the cell-phone number of 'their' coordinator who can be reached at all times. Although emergency calls are rare, they do occur, and co-ordinators are willing to provide any useful assistance at these times. In the past, access to support from co-ordinators was offered only up to 18 months after placement. However, in practice, Program co-ordinators always maintained an open-door policy and continued to engage with any past BladeRunners participants who expressed a need for support in returning to employment. Today, no time limits are placed on the availability of support (OECD, 2011a).

Within the Bladerunners Program, all participants are paired up with one of the BladeRunners co-ordinators. This is not done through an assignation process, but rather follows the preferences of participants and their choice to engage with one or another of the co-ordinators. The relationships with co-ordinators are valued by BladeRunners participants. The latter often say of the co-ordinators that: "They get it", i.e. they have a deep understanding of the challenges the participants face in their daily lives and are able to communicate with and support them on a wide range of sometimes very sensitive issues. For example, some participants who are parents encounter problems with child protection services in relation to substance misuse; others have anger management problems that are tied to difficult family experiences; yet others face criminal charges for events that occurred before coming into contact with BladeRunners. On any of these issues, co-ordinators will lend an attentive ear and provide support either directly if possible, or through their network of contacts in community organisations.

It is important to realise that most Program co-ordinators have a history in the community and have often encountered in the past some of the same difficulties faced by BladeRunners participants. In this sense 'getting it' also means they have 'experienced it' (one of the co-ordinators was once a BladeRunners participant himself). And many participants and co-ordinators expressed the view that BladeRunners needs to preserve the 'non-judgmental' aspect of the relationships between co-ordinators and participants.

Source : Molgat (2012) 


\section{Client journeys}

For the individuals (clients) seeking support, the client journey is all important. The client journey in the Gloucester Works case study (Dean, 2012a) is an interesting example of how unemployed individuals can flow through various stages of a 'plan' without necessarily recognising its constituent elements, and shows how a relatively structured approach can still be person-centred. To facilitate this, an integrated and cohesive approach was taken to targeting and engaging clients from the priority groups and geographies built upon the existing engagement infrastructure. The client journey is set out below:

Once an individual had been identified as being ready for further assessment and support to guide them towards employment, they were provided with an in-depth employment and skills assessment and associated Action Plan. This Action Plan detailed the necessary steps required to assist the client to gain sustained employment. Assessments were carried out by a local specialist IAG provider, Prospects. The Assessment and Action Planning process included:

- Career planning - providing advice about potential career options and the different routes into employment e.g. vocational, educational etc. The individual was made aware of the job opportunities and vacancies that existed in the local economy and of the associated employer requirements. Job preferences were then examined and a first stage matching of the client to a particular vocation/vacancy type was done.

- Vocational skills - the assessment then looked at the existing vocational skills and work experience that a client had. This was done through various methods including self-identification and mapping of skills against existing training (national vocational qualification) frameworks and other assessment materials. This assessment looked beyond formal work experience and skills to other experiences and skills.

- Core skills - an in-depth assessment of the core skills of the client was undertaken. Including motivation, attitude, confidence levels, communication skills etc.

- Personal support - the assessment looked at any personal barriers to employment and associated personal support issues that needed to be addressed, notably, childcare, financial problems, addictions, illness etc.

- Ongoing communication - between caseworkers to share and update information and good practice. Case conferencing procedures were put in place to assist in the development of pathways for individuals.

The next stages in the journey involved bespoke training provision, vacancy matching and, ultimately after care and retention support. Figure 2 outlines the client journey and offer as delivered by Gloucester Works. 
Figure 2. Client journey and offer as delivered by Gloucester Works

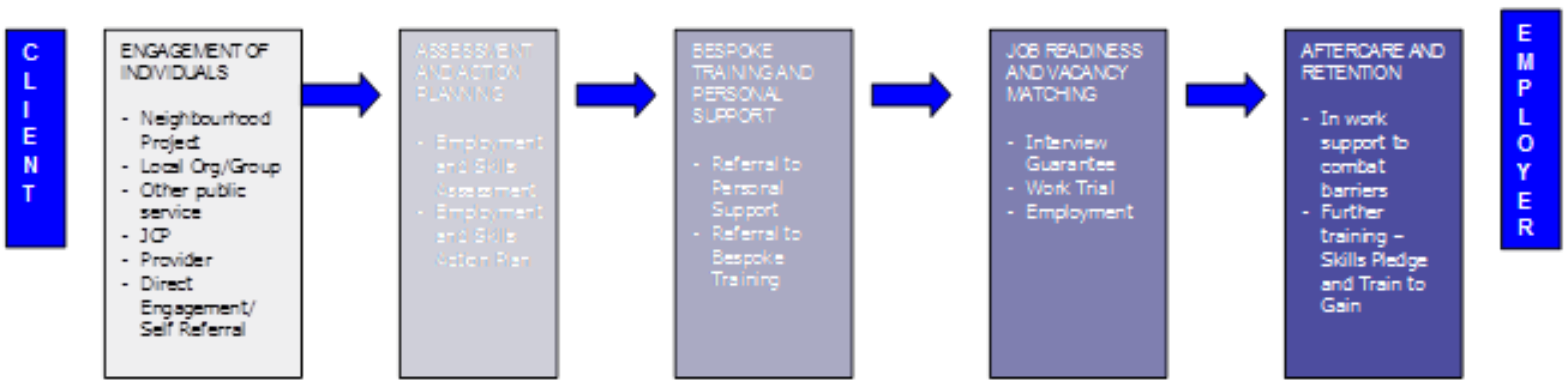

Both the Antwerp and Alost Targeted Trajectories and the Gloucester Works models recognised the crucial role that having a single person as a contact could have in building client confidence and establishing a positive relationship. The Welfare to Work Counsellor's role in the Antwerp and Alost case study is explored below and is a model of good practice.

\section{Box 4. The crucial role of the Work Welfare Counsellor in the Targeted Trajectories activities in Antwerp and Alost, Belgium}

The 'Work and Investment Plan' (WIP), concluded by the Flemish Government and the Flemish social partners on 18 December 2009 in answer to the economic crisis, pays specific attention to vulnerable groups in the labour market, including persons in poverty. That enabled the start of two projects in Antwerp and Alost which focused on experimental trajectories towards work for persons living in poverty. These trajectories were quite innovative: a nonfragmented, cyclical guidance model, which could last for more than 18 months. During the whole trajectory, only one mediator/'buddy' was allocated for every jobseeker and every trajectory was tailor made by the combined efforts of the public employment sector, local organisations of people from impoverished backgrounds, intermediary organisations of the welfare services and the local authorities. Both projects kept in contact but their approach was nevertheless a bit different and, in the Alost case, all the participants were people whose parents also had lived in poverty.

The role of the Counsellor was absolutely crucial to the success of the project. They remained with the jobseeker throughout their journey, providing continuity and a sense of permanence, helping to enhance the confidence of the client. They supported the jobseeker with both work and welfare advice and were encouraged to view them as a unique person with their own aspirations and characteristics. By getting to know the jobseeker, they were better able to identify key strengths and competences and were consequently better able to source appropriate resources and tailormade learning opportunities (skills and attitudes).

Having a strong client relationship also helped with the often-complicated task of encouraging the jobseeker to set realistic goals and providing honest, realistic feedback, enabling the jobseeker to recognise unrealistic work perceptions and expectations, and helping to create new, achievable work life goals.

The Work Welfare $\left(\mathrm{W}^{2}\right)$ Counsellor needs to have established skills in providing IAG. They need to match the strengths and competencies of the jobseeker with the needs, demands and expectations of the employer. They also need to refer the jobseeker to the correct welfare services and, if necessary, care providers. Effectively visualising the jobseekers' 'social map', and establishing a co-operative relationship between the various welfare actors and the partners delivering the training or employment activity. Balancing these competing agencies requires a strong competency in traditional mediation skills.

The Counsellor needs to have the confidence to, in effect, 'sell' the jobseeker to the employer, making the case for the Jobseeker, based upon what they have learned about the him or her.

Source: Van de Voorde et al. (2012) 


\section{Personalisation of support and training}

Griggs et al. (2008), after analysing many evaluations of both personalised and place-based interventions, concluded that:

evaluators judged policies to have the greatest impact if they delivered individually tailored support to the most disadvantaged people with minimal complexity. The evaluators considered policies successful if they reflected local needs and priorities and were shaped by active engagement with stakeholders, including end users.

The use of bespoke training providers, chosen to fit client need, was an example of good practice in a number of our featured case studies - in Belgium (Antwerp and Alost), Canada (BladeRunners) and the UK (Gloucester Works and Unionlearn). In the BEST Pacific Institute case study, the Institute developed a customised e-learning platform which services $85 \%$ of the student population (McCarthy, 2012). It was specifically designed to be highly interactive as a visual and audio engagement process. This customised platform responds to the recognition that Pasifika learners engage best online when the e-learning space is highly interactive, accompanied by support services, has a developed extended aiga (family) of virtual learners, and has visual and audio components that are culturally relevant.

At the same time, the Institute sought to ensure traditional face-to-face delivery reflected enabling, engagement and empowerment processes through collective ways of operating. For example, the preferred pedagogical approach to learning includes group work. The case study recognises that the learning strategy exists as an alignment of familiarity, culturally and spiritually, between that which is represented in the home and the community environments and the Institute's learning environment.

In the Gloucester Works case study, the list of training providers was particularly extensive, combining small specialist providers, voluntary sector providers, large community colleges and large private sector providers. This enabled Gloucester Works to choose the right provision, and the right provider to suit the client, consequently a great many training providers (in excess of 30) were used. The benefits of a tailored approach were extended to the work with employers who perceived a fragmented offer of employer engagement and support activity. The main mechanisms for employer engagement in Gloucester prior to Gloucester Works were not sufficiently 'linked up' nor were they tailored to the needs of employers (EMB Consulting and Buckman Associates Ltd).

In Belgium, the Flemish Government funded a series of projects designed to support prisoners back to work. One of these, the Velcro Project, stressed the need for a positive role between learner and coach (see box 5). 


\section{Box 5. The Velcro Project}

Since the 1980 state reform, the Flemish Government has been responsible for 'the social reintegration of detainees'. In 2000, a 'Strategic Plan for assistance and service for detainees' was finally approved. The Flemish public employment service, VDAB, got the task of facilitating the reintegration of detainees into the labour market, and that meant the start, in 2001, of the programme entitled 'Aan de bak': detention counsellors support detainees with information and labour market orientation; they provide vocational training and help develop communication and solicitation skills.

Through the system of certificates of professional competence, the VDAB values competences that were acquired in prison, and in a number of prisons, web learning was introduced. Detainees who qualify for limited detention and electronic surveillance may follow a vocational training course in a training centre outside prison. Vocational training, individual vocational training on the job, a training workshop on the work floor or employment in the social economy sector are, for most detainees, an ideal stepping stone to a job, as certain technical and non-technical competences usually need (re)freshening.

However, the costs to organise these types of training are relatively high and success is not always guaranteed. Possibilities depend on prison infrastructure - and in some detention centres the infrastructure is quite obsolete. Plus there is the crucial factor of necessary co-operation between the different parties in prison: between the federal level (Ministry of Justice) and all the different Flemish service providers (Departments of Welfare, Education, Work, etc). To make things even more complicated, a jobseeking (former) detainee often faces a multitude of problems situated in several domains (housing, finances, family, welfare, health, etc.). Finally, many employers are rather reluctant to hire former detainees, for a lot of reasons: detention is a black mark on the CV; how will colleagues react; can I trust him/her; what competences do former detainees possess?

Although the VDAB realised quite some successes, a lot of obstacles remain: sensitising and persuading employers to give former detainees a real chance; matching competences of detainees with the demands of specific employers; guidance/counselling for detainee and employer after hiring; valuing all the acquired competences of the detainee; facilitating the transition between detention and a job in the regular economy. To tackle some of these problems, individual detention centres together with local and sub-regional partners and supported by VDAB, developed four interesting projects during the last three years. The projects were subsidised by the Flemish Department of Work, either in the Employment Equity and Diversity programme, or in the Social Economy policy programme.

The 'Velcro' project, in the detention centre of Mechelen in Belgium, utilised a particularly person-centred approach to bridge the gap between detainees 'inside' and employers 'outside'. Detainees could voluntarily join the project, after a screening and an information session, and then have one week to consider if they want to join or not.

At the start of the counselling, a 'contract' was made. This specified both the roles and efforts of the detainee and the coach in the pathway towards what would hopefully be employment and a career. Together they worked on strengthening the offender's attitude and developing communication and employability skills. Simultaneously, the coach started to look for suitable jobs, in collaboration with the detention counsellor of the VDAB. The coach informed the employer about all the practicalities concerned with hiring (former) detainees, but also about the possible pitfalls and how to overcome them.

Once the detainee was hired (be it in limited detention or after release), the coach continued to counsel the former detainee, but also the employer and, if necessary, other colleagues in the organisation. This long 'double engagement' lasted for months if necessary, and appeared to be successful.

Source : Van de Voorde et al. (2012)

\section{Maintaining the link during employment}

Kellard (2002), examining lessons from a number of UK and overseas initiatives, recognised that a range of labour market programmes were being developed, which placed an emphasis on providing postemployment support for (re)entrants to work, typically through a discretionary case management approach. The evaluations of such programmes remained inconclusive, but suggested that adopting a flexible, individual and long-term approach to the provision of in-work support was, indeed, required. 
The new flexibilities within the Work Programme in England allow for significant post-employment engagement for many months after an individual is employed. The driving force behind ensuring this happens is the funding mechanism which only starts to make significant payments to the Work Programme provider after the individual has been employed for a number of months. It is, therefore, in the financial interest of the provider to maintain positive ongoing contact with both client and employer.

Individuals can often be wary of becoming stuck in low-paid occupations with little chance of progression and this can be a disincentive to leaving state benefits, so an element of holistic support where clients can be assisted with the often large amounts of bureaucracy facing them is a benefit.

The problem of 'churn' - where people move frequently between low-paid employment and benefits/welfare - is common to most developed labour markets and can stifle individual progression and development. Our (pre-Work Programme) Gloucester Works case study recognised that a key reason for this revolving door was a lack of emphasis placed upon, and funding of, in-work support for individuals to sustain and progress in employment and to support employers in embedding these individuals into their workforce. It sought to remedy this by maintaining the link with the client after employment with the support provided designed to help the client progress, typically through work-related training.

In the BladeRunners case study, post-employment support has always been available. Until recently, this access to support from co-ordinators was offered only up to 18 months after placement. However, in practice, co-ordinators always maintained an open-door policy and continued to engage with any past BladeRunners participants who expressed a need for support in returning to employment. Today, no time limits are placed on the availability of support.

Our case study examples indicate that successful projects support clients in making the transition from benefits to paid work and that this can be in the form of financial, psychological and physical help. A potentially holistic approach could include incentives to overcome transport barriers and assistance to those with health problems both pre- and post-employment through interventions such as Condition Management and Cognitive Behavioural Therapy. Clients can be made aware of the availability of local childcare and can receive other specialist advice, such as debt management and advice on tax issues. Client tracking had a key role in monitoring whether clients sustained and progressed in employment and in ensuring that they were referred to appropriate support and training. In the Flemish prisons learning model (Velcro Project), it is significant that the coach continues to counsel the former detainee, the employer and, if necessary, other colleagues in the organisation for several months after the detainee was released and commenced employment.

Employers, too, can be wary of recruiting people from disadvantaged groups, something our employer engagement section (later in this report) recognises. This lack of support can make employers unwilling to recruit individuals with continuing support needs.

\section{Community engagement}

According to Head (2007), "[c]ommunity engagement is supposed to help solve community problems. But a broader understanding of community engagement requires some consideration of the motives, intentions and purposes of the three sectors - government, business groups, and the community sector - in becoming involved in more intensive forms of participation and collaboration." In tackling unemployment within disadvantaged groups, there can be some clear advantages in effective community engagement:

- Trust - disadvantaged groups can often relate better to independent organisations rooted within their own communities and a common value set. 
- Access - local community groups can provide facilitated access to individuals from hard-to-reach groups.

- Cost saving - community groups can provide access to groups of individuals where a provider may be forced to approach individuals on a case by case basis.

- Understanding - community groups can provide a useful expert view on the needs of client groups and differing client cultures.

- A more holistic or joined-up approach - back-to-work support can more readily be linked to other available services perhaps already being delivered.

- Local intelligence - an understanding of what opportunities may exist for clients.

- Local delivery of programming - a key element of success in many successful back-to-work interventions.

The BEST Pacific Institute case study (see below) typifies how educational and other support organisations can link with their community. This includes the purposeful development of community networks and the maintaining of staff/student ethnicity ratios to support a cultural strategy. 


\section{Box 6. Best Pacific Educational Institute, New Zealand}

The BEST Pacific Educational Institute (BEST) is a New Zealand post-compulsory Private Training Institute (PTE) that has been government-evaluated and recognised as achieving excellence in 24 out of 26 educational and institutional performance indicators, the highest possible standard. This PTE has been evaluated and reviewed externally by the government and has achieved recognition as "highly confident in educational performance and capability' within the assessment criteria range.

This PTE has been operating since 1988 and now operates across five urban sites. The Institute offers a range of courses ranging from National Diploma in Business, National Diplomas in Computing, and a Certificate in Freight Forwarding through to a Certificate in Tourism and Travel. The Institute also offers programmes for Youth and Training Opportunities.

BEST as a PTE has a specific focus to serve Pacific communities, which is reflected in the demographics of the student body and staff. $75 \%$ of the student body are Pasifika students, with the majority being represented by Samoans. $20 \%$ are Maori. This student body has a high percentage of intergenerational unemployment and/or partial employment histories. The Pacifika community suffers disproportionately high levels of unemployment.

The challenges of the home environment include high unemployment rates, poor health, overcrowding in homes, low educational attainment rates and high crime rates. These home environment factors impact on learning and the capability, as represented in resources that students have in order to capitalise on learning. This is further compounded by the recession and associated government policies. Students also tend to have had negative formal schooling experiences and arrive to learning having to (re)learn how to engage and be motivated.

The guiding principles of enabling students to learn in order to engage as a form of empowerment through which better to respond to life chances is central to the Institute way of operating. Whilst these principles may be adopted in other forums, the intricacies of how this is achieved differ from other educational Institutes in that the guiding principles are informed by Pasifika cultural constructs.

Face-to-face teaching and e-learning have been adapted to best suit the learning needs of Pasifika students. Pasifika students' most preferred mode of learning includes collective forms of operating, Pasifika humour and visually stimulating and kinesthetic types of learning activities. Relevancy within the curriculum is also important and often adjusted to be more meaningful to a student's own community environment.

The adoption of the extended aiga (family), the development of a strong sense of belonging and the inclusivity are the three main cultural constructs that are intertwined and inform how these principles are applied. These three constructs are also informed by broader Pasifika principles of love, service, respect, a covenant between siblings and others and discipline. Importantly, the uniqueness of this Institute has been purposefully developed in response to the recognition that Pasifika students respond well educationally and spiritually in environments that are aligned culturally.

The above strategy has been applied in response to Pasifika students' learning needs within a community of high unemployment, low SES communities, high educational under-achievement rates, poor health and overcrowding in homes. The BEST Institute of Education as an institution has been operating for 25 years and recognises that the adoption of an educational strategy that culturally reflects the values, behaviours and ways of the student population has positive educational outcomes.

BEST creates: "an expectation of success that may not be present for Pasifika students at other institutions" (BEST Strategic Plan, 2012). The qualification completion rate of $65 \%$ and a course completion rate of $69 \%$ in 2010 with a projected 2012 rate of $70 \%$ and $80 \%$ respectively is evidence of educational success. This sits within the context of approximately $78 \%$ having no or low qualifications upon enrolment.

Source : McCarthy (2012)

The importance of intelligence being provided by community groups should not be underestimated. In our Antwerp and Alost case study (discussed earlier), the importance of doing things differently had been highlighted by the network of community-based organisations, following a survey amongst people living in poverty. After analysis of the survey, it became clear that conventional approaches would not deliver the required results. The importance of this community-level engagement was crucial therefore in ensuring a different methodology would need to be used.

Effective engagement with individuals at the neighbourhood level was fundamental to the successful delivery of Gloucester Works as was the development of innovative partnerships. The Job Hubs were an 
example of how this worked. As part of Gloucester Works' commitment to provide help and support with job searches, CVs, applications and advice, they ran frequent Jobs Hubs around the city.

The establishment of the community-based Job Hubs was essential to reaching the intended clients for the project. Locating the holistic offer within the community setting was clearly good practice. A lasting legacy in Gloucester remains the capacity to deliver new programmes through the Job Hubs. Community Engagement is also a key part of the Unionlearn Community Learning Champions case study in Newcastle, England, examined later, and a separate intervention in the City of Wolverhampton, England, below:

\section{Box 7. An example of community engagement by a UK trade union}

The Communication Workers Union (CWU), which represents, amongst others, postal and mail workers, has been working for more than three years with one of the Sikh temples in the City of Wolverhampton to provide a range of adult learning provision to workers, their families and friends and to the broader community.

Significantly the work began, not as a response to a funding call or new project but when a union member was discussing with the lead area CWU ULR his problems with getting time off to take courses in the pre-existing onsite trade union-run learning centre inside the Wolverhampton Mail Centre. The CWU were already active in the local Mail Centre where they had established a learning centre, supported with funding from the UK's Union Learning Fund. The learning centre established by the CWU at the Mail Centre was one of over 150 such centres established so far by them in the UK.

The workforce within the Mail Centre in Wolverhampton is particularly diverse, and consequently the Union had been positive about engaging with differing community groups for some years as part of their strategy to build a diverse working community.

The CWU had already helped around 700 colleagues through courses at the Wolverhampton Mail Centre when the work began to open something similar in the Guru Nanak Sikh Temple in Cannock, where a ULR had been president for 23 years. The temple was already very involved in community activities and was running homework clubs for school children. The City of Wolverhampton College was the CWU branch's education provider in the Mail Centre, and the College saw the potential to have a learning centre at the temple.

With the temple providing the room and buying computers from the college, the union delivering IAG and adult learning support, and the college providing all the courses and materials, the whole thing was under way remarkably quickly. Initially, courses focused upon English, mathematics and IT classes, along with courses in English for Speakers of Other Languages (ESOL). Now, in addition to the first batch of courses, the temple learning centre offers classes in health and safety, cookery, food and hygiene and even wrestling in the onsite gym taught by a former Olympic gold medallist. The union is now looking to run at least one workshop on community engagement in each of its 10 regions over the next 12 months to help spread best practice and enthuse more ULRs about reaching out beyond the workplace.

One further benefit of working with the community is that the increased numbers can often make learning more viable. The lead ULR (Steve Hackford) comments: "If you've got the numbers, you can negotiate better fees and courses are easier to run." He points out that: "Community engagement is a two-way street - the Union can offer Community Learning Champions a lot of support and the wealth of experience we've picked up over the past ten years, while community groups bring skills and knowledge of their own as well, so they might be running sessions for us in certain circumstances." He says: "Working with the community also means we can share resources."

What is surprising about the developments in Wolverhampton is that they have never attracted direct funding. The work was indirectly supported by other funding, such as for ULR training and by state funding for courses via the City of Wolverhampton College. The informal and organic development of the learning centre is evidence of an underlying need both for learning of this kind and of the advantages that can accrue from having delivery centred within the community.

Source : Dean $(2012 b)$ 


\section{Employer engagement}

Previous LEED studies, such as that by Froy and Pyne (2011) have already reported on the significant potential for employers to play a larger role in leading local initiatives as public sector resources diminish and training systems move away from being primarily concerned with the supply side. LEED work has generally found that employment initiatives operating in the community without significant employer involvement are often not successful. Nonetheless, as the Froy and Pyne study also reported, few of the initiatives examined here can be described as 'employer-led'.

Syrett (2008) recognised that successful interventions are characterised by: active engagement of employers ensuring activity is demand led and appropriate skills and competencies are developed; involvement of employers in ongoing training once workless people are in employment to ensure they remain in employment and to create new spaces at the entry level; dialogue with employers and awarenessraising with regard to employment practices and prejudices that may limit the recruitment of particular workless groups; dialogue with employers and awareness-raising to promote the provision of jobs with decent pay and working conditions to provide attractive employment opportunities for the workless.

Establishing relationships with employers is critical to establishing skills systems which seek to fit supply to genuine market demand. The case studies on which this work is based almost all contain fine examples where projects and programmes have engaged successfully with employers. But this is far more difficult than many would imagine, and all too often back-to-work strategies struggle to involve employers, and, as a result, ultimately fail.

A fine example of an approach to local skills strategies with employer involvement is the public private partnership case study from Canada - BladeRunners. Here, employer support has been essential to the success of the Program. Employers play a key role in providing opportunities and training for participants. Program funding comes partly from government and partly from community/industry, and partners also show their support through cost sharing for courses, buying equipment and waiving wage subsidies. Bladerunners Program administrators expressed the view (Molgat, 2012) that the partnerships with local employers have been an important factor in its success.

BladeRunners managers and co-ordinators have developed an impressive network of contacts in the Vancouver building industry and can now count on a number of employers who are willing and interested to take on programme graduates. This network is essential to finding out which projects are about to start up or in phases when BladeRunners participants with different skill sets can be integrated. This network also allows the organisation to become known by different employers who may be approached to hire BladeRunners graduates. According to the BladeRunners managers and co-ordinators (Molgat, 2012), the Program is so well known locally that some of the major building developers are interested to know whether their contractors and subcontractors are also taking in BladeRunners participants. The local aspect of Program delivery also allows BladeRunners co-ordinators to refer participants to services, programmes and housing in their community so that they are able to identify positively with their community while avoiding unnecessary efforts to access services elsewhere.

BladeRunners recognises that maintaining good relations with employers is essential both to strengthening this network and to ensuring employment placement success for employers and participants. It is therefore essential that co-ordinators maintain direct and frequent communication with employers about prospective trainees and follow through on placements with regular site visits. Co-ordinators must accompany participants to the site on their first day of work and drop by the work site every two or three days during the first weeks of employment to check on progress and to make sure that no issues are arising that may hamper punctuality or productivity at work. Bladerunners Program co-ordinators also make clear to employers that they do not expect differential treatment for BladeRunners participants. Furthermore, 
Bladerunners Program co-ordinators and employers both indicated that the support offered to participants by the co-ordinators helps to maintain worker productivity, and is an important component in reducing the risk of placements for employers.

To try and build better relationships with employers, and hence help to place detainees, individual detention centres in Belgium, together with local and sub-regional partners and supported by VDAB (the Employment Service), recently developed four interesting projects (the subjects of our associated OECD case study). The projects were subsidised by the Flemish Department of Work, either in the Employment Equity and Diversity programme, or in the Social Economy policy programme. A brief overview of one project is provided below.

\section{Box 8. Hasselt Detention Centre - employer engagement}

The detention centre of Hasselt set out to tackle the following problems: on the one hand it is difficult for (former) detainees to find a job and yet, on the other, local organisations and businesses experienced difficulties in finding new employees.

To facilitate the match between these two parties, the project ' $\mathrm{Ba}(\mathrm{c}) \mathrm{k} @$ Work' formed a network which focused on 'open communication' between 'the inside' (the detention centre and all of the internal service providers) and 'the outside' (local employers and businesses, the local social partners, outside service providers). At the start, lots of time was invested in better communication and co-operation between the different internal service providers (especially welfare, education and employment) and the direction and personnel of the detention centre.

The final result was a series of common brunch sessions for employers and other useful local stakeholders. A brochure with tips and tricks to facilitate the successful hiring of former detainees completed these meetings. Local employers and social partners delivered a valuable input about the specific questions and needs of local businesses; they found their way in the brochure.

Source : Van de Voorde et al. (2012)

The evaluation of Gloucester Works by EMB Consulting and Buckman Associates Ltd, which helped inform a case study featured in some depth earlier in this report, recognised that the most successful inwork training was that developed in consultation with employers, though this was not always possible. The offer for employers was to help them understand their recruitment and skills needs over the immediate, short, medium and long terms, ensuring that longer-terms plans were matched against macro-economic projections. Through its linkages with employers, Gloucester Works was able to identify vacancies and understand recruitment practices and job requirements and to scope the job and skills content of vacancies. It was able to develop themed training packages suited to different sectors and to develop bespoke recruitment and training package to meet employer requirements. This activity helped encourage employers to invest in the ongoing development of their workforce, supporting the low skilled to progress.

By working with partners in retail, hospitality and leisure, care, construction, warehousing and storage, Gloucester Works was already offering bespoke employability training programmes that delivered the essential skills necessary to work in these sectors. The courses were designed to provide those who may have been out of work or who worked in a different sector with the vital skills they need to apply for and secure a job successfully in these growth sectors in Gloucester.

\section{The potential role of trade unions in supporting vulnerable people back to work}

The WAPES and OECD Survey reviewed earlier in this document suggests that there may be an opportunity for greater collaboration with certain external groups - and one of these is certainly Trades Unions. The recent OECD report, Better Skills, Better Jobs, Better Lives: A Strategic Approach to Skills Policies (2012b), recognised the Unionlearn model as an example of good practice, stating: 
The Trade Union Congress (TUC) established Unionlearn, a network of 'learning representatives' who provide a high-profile strategic framework and support for union work on skills development and workplace learning. Unionlearn representatives provide information and advice and encourage employers to sign up to a 'skills pledge' that commits them to training their staff to a specific level of qualification or diploma.

The report goes on to recognise that trade unions help to deal with imbalances in training provision, and that they have an important role to play, not just in developing people's skills, but also in making sure they are properly utilised in the economy.

Trade unions can work together with employers on skills policies, particularly on curricula development and the provision of workplace-based training. While employers tend to prioritise short-term and narrow-specific skills, trade unions may pay greater attention to the future of the workforce and therefore be more concerned with broader, transferable skills and long-term developments. They also have incentives to protect the interests of existing workers, ensure that those in work use their skills adequately and have access to good quality training and see that investments in training are reflected in better-quality jobs and higher salaries" (OECD, 2012b).

Hansen and Zulum (2012), in discussing the role of the social partners during times of crisis, recognised that there is a need for rapid decision-making, facilitated by good social dialogue. In addition, while governments were preoccupied with short-term considerations, in several countries, the social partners (both trade unions and employers' organisations) played an important role in providing a longerterm perspective regarding the value of investments in human capital for long-term economic performance.

Employers, quite sensibly, will emphasise the need for business-relevant training and skills and the importance of flexible, just-in-time delivery. However, the needs of employees and potential employees can be rather different. The role of Unionlearn in the UK is an interesting example of how individuals can be supported to gain the skills and qualifications they need to ensure stable employment and career progression as a result of facilitation by other agencies and organisations outside of the mainstream. In the Trade Union Congress report, Swords of Justice and Civic Pillars (TUC/Goldsmiths, 2010), it was recognised that calls have long been made for the use of community-based strategies to organise vulnerable workers in Britain. According to the data available (TUC, 2010), union learning is successful in engaging learners from groups traditionally under-represented in adult learning. Union learning is also successfully targeting people who have not recently been involved in education or training and who are not confident about taking part in courses. While one in ten adult learners as a whole say they are not confident learners, four in ten union learners describe themselves in those terms and over half have not taken part in education or training in the previous three years.

Union-led learning can be highly inclusive. In the UK, Unionlearn opens up $89 \%$ of projects to all employees, not simply union members, and more than two in five projects target a specific ethnic, minority or migrant worker group as part of their activities to raise demand for learning. Union learning is not only attracting people who would not otherwise participate in learning; it is also carrying relatively low deadweight (i.e. people who would have taken another route if union learning were not available).

The Swords of Justice and Civic Pillars report found that community-based strategies can yield numerous advantages for unions. They can strengthen community-based strategies to promote active citizenship and community cohesion. This is a win-win situation because shared strategies can benefit trade unions in various ways. Greater community engagement can:

- Help unions to engage difficult to organise segments of the workforce, particularly through the learning agenda; 
- Enhance the capacity of unions to achieve their core objectives, most notably around service delivery;

- Facilitate the recruitment and development of union activists and reps;

- Project positive images of trade unionism.

\section{Box 9. Unionlearn in the community: tackling disadvantage}

Unionlearn is the learning and skills organisation of the Trades Union Congress (TUC) in the UK. Unionlearn works to assist unions in the delivery of learning opportunities for their members as well as managing GBP 15 million (British pounds) Union Learning Fund (ULF). Over the past 12 years, more than 28000 ULRs have been trained and 230000 people are being given training and learning opportunities through their union every year. Unionlearn is also responsible for providing education and training opportunities for workplace reps and professionals via TUC Education. Each year, more than 50000 trade union members enrol in trade union education courses organised by the TUC.

Union learning is growing fast; almost every union is now involved in union learning, supported by Unionlearn, helping hundreds of thousands of learners at all levels, from basic numeracy and literacy to degree level qualifications. In a recent survey of 400 employers, with a total of six million employees, $87 \%$ said that they wanted to continue to support union learning, with two-thirds saying that it benefited the organisation and $81 \%$ saying it benefited the individual.

\section{Union Learning Representatives}

Crucial to Unionlearn's activities in the workplace and within communities is the role of the Union Learning Representative (ULR). ULRs have been key in building participation in lifelong learning. As well as helping individual members, Unionlearn evaluations (CERIC, 2010) have demonstrated that ULRs have had a positive effect upon workplaces and organisations themselves.

A UK Government Survey by Ofsted praised the role of ULRs, saying that learners receive: "outstanding peer support from ULRs" (TUC, 2009). Up to 4000 ULRs are trained annually with the support of Unionlearn, and more than 2000 follow-on training modules to help them support colleagues in the workplace were delivered by TUC Education, including Skills for Life, Supporting Learners (IAG) and Equality and Diversity. ULRs support high numbers of Skills for Life learners, including those on English for Speakers of Other languages (ESOL) courses. An everincreasing proportion of union learners on the union route are being supported on vocational programmes at Levels 2 and 3. There are also more union learners accessing continuing professional development and higher education opportunities.

\section{Community Learning (and other) Champions}

Education or training for those who are not confident about taking part in courses. While one in ten adult learners as a whole say they are not confident learners, four in ten union learners describe themselves in those terms and over half have not taken part in education or training in the previous three years.

Within UK trade unions, there are now many types of champion who can and do support learning within the community, including Disability Champions, Health Champions and learning mentors. Community Learning Champions (CLSs) have specific roles in driving up learning within disadvantaged communities. They are often from a similar background to the people they are working with and have good local knowledge. They act as both advocates and role models for learning. CLCs are linked to organisations that provide community-based learning opportunities for adults and have signed up to be part of the CLCs National Support Programme.

A recent study (Martin Yarnitt Associates, 2011) concluded that CLCs typically perform a range of functions including:

- Signposting;

- Outreach and initial engagement;

- Support and mentoring; and,

- Representation of other learners. 


\section{Box 9. Unionlearn in the community: tackling disadvantage (cont'd)}

CLCs are trained to recognise that disadvantaged potential learners may have many reasons why they cannot access learning. This can include the hours that they work, the level of skills they have, their ethnicity or social background and previous negative experiences of learning. To engage with potential learners, it is important that CLCs understand the barriers that may stop them learning.

CLCs are trained to 'map' the local community to identify the range of places and services that people use, and where they work. This is useful for 'targeting' an audience, where CLCs focus on people with something in common, e.g. people who work the same shift pattern or have a similar background or attend a community centre. The good practice example from Newcastle included considerable mapping, with the lead ULR taking three months to plan the work and make the necessary contacts.

\section{Work with the community in Newcastle, England}

Newcastle UNISON (a Trades Union) is leading a unique partnership project with Newcastle City Council to develop CLCs to spread the word about lifelong learning in black and minority ethnic (BME) and other communities in the city. The UNISON branch is the only union organisation to secure funding from the Community Learning Champions (CLC) programme financed by the National Institute of Adult and Continuing Education (NIACE), something it achieved in the second round of CLC funding, in 2010.

The project built on existing work with vulnerable workers in the City. It developed and supported CLCs from a number of BME and vulnerable communities in Newcastle upon Tyne, in a number of innovative ways. It also followed the good practices from early work by targeting and working with community organisations. A number of ULRs from BME communities had been recruited through earlier projects, and were already acting as informal learning advocates in their respective communities. They were a crucial ingredient in the development of Newcastle CLCs.

Core to the project offer to individuals was the provision of tailored IAG on learning and employment, and signposting, procuring and supporting them into bespoke opportunities. ULRs from Newcastle City Council would then mentor and support CLCs throughout the process, from meeting with community groups, identifying champions, providing support through training, mentoring them in their activities as CLCs, and working with the learning providers (in this case, typically the Workers' Educational Association (WEA)).

An advisory group oversees the project, with representatives from Citywide Learning, the WEA, Jobcentre Plus, Newcastle Futures (which provides advice and support to local unemployed people) and Newcastle City Libraries. The partnership included Newcastle City Council and local learning providers who all helped to develop, promote and support the CLCs. Partners recognised the work as an opportunity to link in with local issues relevant to the BME communities involved in the project and having positive knock-on effects for issues such as such as language, cultural, economic, social cohesion and equality of access.

The Newcastle CLC Project initially approached council workers from the Sudanese, Iranian, Brazilian, Pakistani and Congolese communities to identify potential learning champions and then broadened its approach, spending three months reaching out to organisations that worked with community groups on learning and training, learning providers and individuals. Subsequently the project has run a number of training courses and trained nearly $40 \mathrm{CLCs}$, of whom only a few had previous experience of adult education. While the courses delivered in Newcastle adhered to the guidelines set out by NIACE, the project tailored the course to the needs of the individual participants. The idea was to give participants the tools, the knowledge and the confidence to encourage members of their communities to get involved in learning as a means of progression.

During the formation of Unionlearn, learning was regarded as 'a natural issue for partnership' between unions and employers and a key agenda of concern for a modern union movement. In Unionlearn's recent work with CLCs, led by the Newcastle branch of UNISON, the Union is leading a unique partnership project with Newcastle City Council to develop CLCs to spread the word about lifelong learning in BME and other communities in the city.

The project's partnership approach has been crucial. Working with community groups allows the Union to encourage people beyond the workplace to broaden their horizons. "I think engaging with the community on learning stretches people's awareness levels of what the possibilities are for them but also shows them there's more out there than they've got now, they can do more than they're already doing," Rizwan Sheikh (the Project Manager) argues. "The beauty of adult learning is that it's affirming and confidence-building and gives you the encouragement to do more and learn more - participants on our training courses are saying 'I now want to do this' or 'I now want to do that' and most of them of people who haven't engaged in any learning for a number of years - and that's the difference that we can make."

Source : Dean $(2012 b)$ 


\section{Sustaining innovation}

Inevitably in many projects and grant-funded interventions, it can be difficult to sustain innovation once the project funding runs out. However, there are ways of achieving greater success through having good practices adopted and disseminated effectively. Successful projects seek to mainstream lessons into both practitioner and policy audiences. Crucial to gaining sustainable projects are:

- The involvement of practitioner and peer groups - linking those in comparable positions both within and external to the project/intervention helps spread good practices emerging form the activities and prevents 'wheel-reinvention'.

- Ensuring accurate formative and summative evaluations are published, ideally including: a description of the approach; analysis of numbers; qualitative interviews and cost comparisons of the intervention activities with other programmes.

- Involvement of policymakers at appropriate times in the project lifecycle - new interventions to support the long-term unemployed within the labour market are often driven by national, regional or local policies. Once projects and interventions are running, it becomes necessary to ensure policymakers remain sufficiently informed of developments without becoming overwhelmed with unnecessary detail. Unionlearn has managed to maintain funding through major shifts in UK Government policy by clearly communicating benefits (such as cost and target group) and working to ensure partners (including employers) and funding bodies recognise the benefits and are happy to promote the programme in partnership.

- Embedding lessons into everyday delivery - it is central, therefore, to involve organisations, often as partners, who are able to make good use of the lessons learned.

- Diverse funding opportunities - reliance upon a single funding stream can be problematic. Maintaining a reasonably diverse source of income can help sustain activity - 'as one door close another one opens'. Similarly, most sustainable programmes often display remarkable levels of entrepreneurship from project workers.

- Celebrate and publicise success - it is important to involve local newspapers and local radio as these are a crucial route to the target group. Long running, successful community projects are often able to attract new participants via word-of-mouth.

- Gaining an identity for the project - gaining widespread recognition for the activity/project can benefit from the use of a single identity or brand.

In the Antwerp and Alost case study, one of the interesting elements was the production of a manual to transfer the methodology and the instruments used to other cities in Belgium. Leuven University and an Antwerp High School delivered the necessary support to enable this to happen.

\section{The role of the social economy}

Fonteneau et al. (2011) defined the social and solidarity economy as: "a concept that refers to enterprises and organisations, in particular co-operatives, mutual benefit societies, associations, foundations and social enterprises, which specifically produce goods, services and knowledge while pursuing economic and social aims and fostering solidarity." This confirms earlier definitions such as that of the European Commission (2010a), cited in Buckingham and Teasdale (2012), where the social 
economy was defined as including co-operatives, mutual societies, non-profit associations, foundations and social enterprises.

Galera and Borzaga (2009) highlighted the significant degree of variation between countries in their recognition of the social economy, suggesting that two main approaches to social enterprise can be discerned from the international literature. The first is associated with the 'rediscovery' of non-profits' role in service delivery and work integration as well as heightened concerns for community on the part of cooperatives, and the second stream, which is more rooted in the American context, emphasises revenue generation.

\section{Labour market integration}

Buckingham and Teasdale (2012) recognised that recent policy attention has increasingly focused on the role of social enterprise organisations (SEOs) in work integration for vulnerable groups, including, crucially, the long-term unemployed. Monzon and Chavez (2012) calculated that SEOs together accounted for $6.5 \%$ of aggregate employment in the EU. This re-birth of interest in the social economy appears to be as a result of the problems many counties were having in tackling issues such as long-term unemployment and the social exclusion of vulnerable and disadvantaged groups which neither the private nor the public sector seemed to be tackling effectively. This niche role was recognised in the OECD publication, The Social Economy: Building Inclusive Economies (Noya and Clarence, 2007), which went on to suggest that: "what is critical about the idea of the social economy is that it seeks to capture both the social element as well as the economic element, inherent in those organisations which inhabit the space between the market and the state."

Aiken (2007) recognised that SEOs were "uniquely placed as mission-driven organisations with a commitment to a specific disadvantaged group" (p. 5) which should enable them to reach disadvantaged groups within communities. (Fonteneau et al., 2011), echoes this, stating that: "social enterprises have emerged as innovative institutional solutions for supported employment favouring those workers who are discriminated against by conventional enterprises" (p. 90). In particular, they recognised that SEOs are often seen to have a role in creating employment opportunities for vulnerable or excluded groups. The ESEDRA case study below explores a good example of a SEO succeeding in labour market integration.

All of the case studies explored within this section have, to a greater or lesser degree, focused on labour market integration of disadvantaged and vulnerable groups.

\section{Box 10. ESEDRA Co-operative}

In Italy, the social co-operative model emerged in the 1970s and grew steadily throughout the 1980s against a backdrop of high employment. In 1991, Italian legislation recognised and regulated social co-operatives, as workersowned co-operatives that carry out their activities: "for the general benefit of the community and for the social integration of citizens". ESEDRA is a B-type social co-operative - the core mission of B-type social co-operatives is the integration through work of disadvantaged people. Social co-operatives have four categories of members:

- Workers who are paid by the co-operative;

- Service users and their families;

- Volunteers (up to $50 \%$ of members); and

- Funding members who put capital into the co-operative but are not directly involved in the co-operative's activities. 


\section{Box 10. ESEDRA Co-operative (cont'd)}

Since its beginning, the co-operative focused on a specific sector of activity such as the production of electrical control panels, plants for energy production and planning and maintenance of green spaces, and offered its clients a complete service from planning and maintenance to post-sale assistance. In 2001, the co-operative started to shift from traditional electronics to photovoltaic power systems, developing the new sector of renewable energies. B-type social co-operatives manage to move thousands of disadvantaged people from conventional welfare structures to reintegrate them fully in the labour market, by transforming them into producers and generators of value, both for themselves and for others. The evolution of ESEDRA can be identified by four steps:

Solidarity - the social co-operative ESEDRA was born in 1994 from another social co-operative called Cetera, and it derives its name from a room of the 'Domus Romana' where wayfarers were welcomed. Initially, the co-operative did business only in the electro-technical sector, but starting from its second year of life, it extended its presence to the environmental sector.

Solidity - in 2000, ESEDRA acquired the building which is now its office, starting in this way the capitalisation process of the company.

Innovation - in 2001, the co-operative started a process of adjustment from the traditional electro techniques to the photovoltaic installations, developing in this way the new sector of renewable energy.

Development - in 2010, ESEDRA did a spin-off that led to the creation of two new social co-operatives, ESEDRA Energy and ESEDRA Environment, which were previously sectors of the co-operative concerned. This led to the creation of the Gruppo Cooperativo Paritetico ESEDRA.

ESEDRA's social mission states that (translated): "The social co-operative ESEDRA, through labour market integration, will foster basic skills useful and necessary to operate in the field of employment". Its main activity with young people is not the construction of a professional profile, but instead the growth and reinforcement of a set of skills (linked to the interpersonal relationships, the communication, the guidance to problem-solving tasks and the ability to use tools and working methods, and the working autonomy) that are the foundations for active engagement in the labour market. Its entrepreneurial mission aims at building a model of social enterprise able to:

- $\quad$ Be very attentive and to enhance the value of the people involved, by helping their improvement and their personal and social emancipation.

- $\quad$ Gain an active presence in its own territory, developing both partnership agreements with enterprises having a similar system, and working in network with the local social system, so that it could meet the citizens' social requirements linked to the labour market integration, but it could also bring about an actual community development.

- $\quad$ Focus on the smaller-scale: this provides the opportunity to deal with solutions to emerging social needs in a flexible way and to establish a close relationship in its own social context.

- Develop among members a democratic participation in the co-operative's life.

- Enhance managing transparency, make the economic value distribution clear and adopt accurate forms of social accountability.

- Engage in a process of constant improvement, so that the operational units could work according to the highest levels of quality.

As of 31 December 2011, ESEDRA Co-operative Group employed 83 people with different kinds of contracts and employment statuses. They all have a work contract according to the National Framework Contract of Social Cooperatives (CCNL). Disadvantaged workers are typically in one or more categories: people with a disability, people with drug or alcohol addictions, offenders or ex-offenders or long-term unemployed. Work integration is the main mission of ESEDRA. Its development has been driven by the desire to give work opportunities to disadvantaged people. The economic growth and the increase of the turnover it has seen are instrumental in providing more work opportunities to disadvantaged people. ESEDRA has shown that it is possible to combine economic and entrepreneurial growth whilst simultaneously supporting vulnerable people from the local area in gaining the skills they need to sustain employment.

Source : Daniele (2012) 
Some more critical commentators argue that the claims whereby SEOS are making major progress in moving disadvantaged unemployed people back to work are exaggerated and have suggested that there has been a tendency to aggregate positive characteristics from a small number of case studies and assume these must apply to all SEOs (Teasdale, 2012). Furthermore, Buckingham and Teasdale (2012), from an analysis of the available literature, postulate that little is known about the aggregate contribution of SEOs to creating employment for marginal groups, although it is often claimed that this is a primary role of social enterprises in Europe and that there appears to be a wide discrepancy between the claims in policy literatures that social enterprises empower vulnerable workers, support decent working conditions, and foster democratic participation and some empirical studies which find social economy work to be low paid and insecure.

Nonetheless, as Syrett (2008) identifies, SEOs often play a fundamental role in providing support systems for residents in deprived neighbourhoods. Crucially, these bodies often have the necessary access as trusted locally-based organisations to populations that often distrust mainstream state agencies. Syrett goes on to suggest that successful interventions are often characterised by active engagement of voluntary and community agencies working with other local partners to access 'difficult to reach' groups and enhance trust in state services; capacity building of voluntary and community services bodies so that they are 'fit for purpose' and able to compete for, and deliver, contracts effectively.

\section{Social flexibility}

Social flexibility is a comprehensive set of flexibility measures (Vancoillie, 2010). Social flexibility requires the employer to adjust the job to the employee, and not the other way around. Social labour flexibility stands for creating tailor-made jobs, easily accessible for certain target groups, by making the work flexible, in order to meet the highly individual demand of clients. It is a bridge between tailor-made jobs and flexible services consisting of many interrelated measures. It ranges from coaching within a supportive environment to more unconventional wage and labour conditions. 


\section{Box 11. Job creation through social entrepreneurship and the social economy at VZW IN-Z}

This case study looks at the job creation ambitions and strategies of a particular social enterprise, IN-Z, which employs 1,200 employees in easily accessible, long-term jobs. IN-Z contributes to the well-being at home of elderly and other persons, meeting their individual demands in a very flexible way.

The original idea of the founders of IN-Z was that the creation of a series of new personal and household services for the elderly would also create new job opportunities for unemployed women who found no access to jobs in e.g. the already existing, regular social services. They established an evidence base for the success of their model (delivered entirely through volunteering) and started to attract financial support from differing tiers of policymakers. Ultimately, despite governmental policy shifts and the need to be entrepreneurial in spirit, IN-Z attracted mainstream funding and support.

\section{Positive about diversity}

IN-Z from the beginning chose to employ a diverse group of 'help(st)ers'. The reason was twofold. Diversity was valued for its own sake, and every person was to be respected for his or her own individuality. On the other hand, clients differ too and have individual needs and expectations; therefore a diversity of help(st)ers is a valuable asset, allowing for a better service. IN-Z offers easily accessible jobs, coaching, extra participation, though at a wage lower than wages prevailing in the regular sector, and some people that do not belong to some target groups may have personal reasons to enter such a job for a shorter or longer period of time.

Most help(st)ers are women, which was an initial target because the target area (Limburg, NL) was short of jobs for women at the time IN-Z started up. Other target groups, such as low qualified people, the long-term jobseekers and over-fifties, are also included. The same, however, goes for persons with some mental or physical constraints, immigrants speaking no Dutch or having difficulties with the language, persons from disadvantaged neighbourhoods or living in poverty, and single parents with children.

\section{Individual coaching}

Sufficient and extensive guidance, support and coaching by staff with the correct competences is crucial, both to job quality and to quality of work. As mentioned before, all help(st)ers are coached by their individual co-ordinator. Each co-ordinator has 15 to 30 help(st)ers to take care of (depending on the kinds of service assigned to them). Coordinators are doing a triple job: coaching, managing and supervising at the same time. The coaching, thus, takes place on a daily basis between the employer and employee. Supervision - hence performance quality - sets the limits within which to work. Coaching, aimed at empowerment, goes together with managing, aimed at assigning clients and tasks to the employee. The entwining of both of these processes, as so often is the case in the social economy, is crucial in carving out tailor-made jobs.

\section{Group dynamics as means to participation, empowerment and training}

Participation, in the generic meaning of the word, is stepping out of isolation into a group. At best, it also means to socialise, which in itself is an empowering activity. In IN-Z, opportunities exist for help(st)ers to benefit from gatherings that aim to remedy isolation and share experiences and learning.

\section{Matching}

Matching is a key process, a qualitative way of coupling the inside world of labour organisation to the outside world of social service demand. Matching is the very opposite of a blind dispatching of employees to clients. The latter requires polyvalent employees, ready to handle any situation without much further support. It supposes, furthermore, that employees have all the customary means for transport, whereas some employees, of course, may not have a car or even a driving license (the latter is the case for an estimated 7\% of IN-Z's help(st)ers). Therefore, the matching of workers to customers suggests a two-way flexibility, both of the service provider vis-à-vis the users and of the employer in respect of the employees. One is intrinsically connected with the other. This process of 'matching' gets a lot of attention at IN-Z to ensure the right employee ends up at the right time in the right family.

\section{Dynamic 'flexibility chart' and work schedule}

Every help(st)ers has a flexibility chart. The chart is a table of hours and days in a 24/7 format. With the help of three colours - red, orange and green - the employees' availability for service hours (and also guidance or training hours etc.) is then noted. Red blocks on the chart stand for all the hours that the help(st)er is not available (for whatever reason). Green blocks stand for availability and orange ones for 'available if need be' (e.g. for a replacement and conditionally). Likewise, service schedules exist showed the demand of clients. Matching then starts off by comparing all flexibility charts with all service schedules. Virtual matches become actual ones - i.e. the definite weekly working scheme - if the co-ordinator decides that the personality and competences of the employee match the situation at hand. Employees are therefore asked to take up flexible work schemes, but on their own terms. 
Box 11. Job creation through social entrepreneurship and the social economy at VZW IN-Z (cont'd)

\section{Collective labour agreement on flexible working hours}

By a collective labour agreement at company level, all working hours are contained in a system of 'annualisation' of working hours - averaging weekly working time on an annual basis.

\section{Flexible job times}

Help(st)ers usually start with a part-time contract and job time is defined in a participative way. Any percentage of job time between 33 and $100 \%$ can be chosen. Reasons for changing job times include the age of the children, divorce, marriage, and changes in physical circumstances.

\section{Open-ended contracts}

For some employees when commencing employment with $\mathrm{IN}-\mathrm{Z}$, it is the first time they have had an open-ended contract. Temporary jobs or ended contracts are not used in IN-Z (and on the whole they are absent within the Belgian social economy). A long term perspective on a job is an important element for job quality, especially for disadvantaged groups. Also, it is clear that within the system of social flexibility, the use of temporary jobs would not improve the flexibility of the service. There is no need for it, because there are other and more participative ways of dealing with peak moments.

\section{Dealing with changing flexible working requests}

An important element in social flexibility is that the employer is an agile administrator when faced with such flexible working requests. In IN-Z, therefore, a flexible working request can be arranged in a day, or even retroactively if necessary.

\section{A better work/life balance}

Social flexibility allows for a better work/life balance. Both family-friendly and age conscious work policies have been central tenets in the creation of tailor-made jobs from the very beginning of IN-Z.

\section{An agenda for the future}

A usual distinction in current labour flexibility strategies is the one between contractual and functional flexibility (Delarue et al., 2006; Gryp, 2011). Contractual flexibility is the 'standard' kind of labour flexibility. It uses mechanisms such as short-term contracts or temporary employment, extra time, part-time work and temporary unemployment. Functional flexibility, inclined to open-ended contracts, is often recognised in task rotation, teamwork and selforganisation, and in work-flow innovations that build up employee involvement. Social flexibility obviously does not fully fit the distinction; it uses some of its 'numerical' techniques, such as part-time work and overtime, but these techniques are adopted in a qualitative, participative way.

The relationship of social and functional flexibility is a more nuanced one. Employee involvement is required in both types, though in discussing social flexibility the frequent use of words like 'participation' and 'empowerment' signal an involvement of a more individual or personal kind.

Source : Vancoillie (2012)

\section{Appropriate financial mechanisms}

Funding mechanisms can play a crucial part in whether an SEO can effectively engage in back-towork activity. Respondents to Buckingham and Teasdale (2012) emphasised that government financial support should go beyond short-term contract funding, which made it hard to plan for the future. Instead, respondents seemed to prefer grants or subsidies which were seen as emphasising trust-based relations. In some instances, respondents argued that competitive tendering of public contracts endangered the trust between SEOs (see Buckingham, 2009) and by implication, the distinctive approach to collaboration fostered by SEOs.

Most SEOs are comparable in scale to SMEs or Micro Enterprises rather than large organisations and they have the same funding issues. There is a real need for funding agencies and bodies to be transparent in what they are paying and to pay SEOs on time. Benefits could also accrue from greater co-operation and 
sharing of costs and resources. Policymakers need to recognise most SEOs are working with low-paid individuals in work often having little potential for significant growth or profit.

Financial mechanisms which maintain support for those moving off benefits into employment would indirectly subsidise the wages of these workers, and favour those organisations employing them.

Sunley and Pinch (2012), in a study in the UK, concluded that: "it is unrealistic to expect most SEOs in deprived urban areas to move substantially away from charitable and public sector funding as these sources are too closely tied to their skills, capabilities and priorities" and suggested instead that: "an obvious way to improve their sustainability is to address some of the volatility surrounding public contracts".

\section{Political engagement}

The OECD LEED survey explored in Buckingham and Teasdale (2012) noted a stated need for policymakers to engage with SEOs better and to seek more realistic policies. Amongst some respondents, there was a perception that genuine political interest and engagement with SEOs was lacking. Some suggested policymakers could provide free centralised support and training to SEOs - perhaps through shared spaces for fledgling social enterprises to share administrative (and training) resources and to learn from each other's best practices.

\section{Client traction}

A number of authors (Billis and Glennerster, 1998; Borzaga et al., 2010) have noted that due to the positioning, history and values of many SEOs, allied to their not-for-profit and independence from the public sector, they are already in a greater position of trust with vulnerable and disadvantaged client groups.

\section{Sustainable development}

SEOs play an increasing role in sustainable local development (Birkhölzer, 2009) and there are a number of drivers for this, including:

- For the common good;

- An integrated holistic approach;

- Serving unmet needs;

- Re-establishing local economic cycles;

- Building and improving social capital;

- Community-centred development.

Ardelaine is a successful SEO from the Rhône-Alpes region of France with a proven track record in sustainable development. It is explored in some detail in below. 


\section{Box 12. Ardelaine, a co-operative dedicated to local sustainable development}

Ardelaine is a co-operative whose primary mission is sustainable local development by promoting respect for the environment throughout the supply chain. The heart of its development strategy is, therefore, to create and sustain local jobs.

In 1975, a group of five people bought an old woolen mill in St Pierreville, the heart of the Ardeche in RhôneAlpes, in an enclave facing rural depopulation. Their desire was to rehabilitate the old premises to upgrade a local natural abandoned resource from a local development perspective for restructuring an industry, the wool industry: from sheep-shearing to finished products (mattresses, quilts, textiles) through marketing, tourism, culture and food. After seven years of preparation, Ardelaine was born in 1982 with a capital of 3200 francs (EUR 488). Since 1982, Ardelaine has created approximately one new job each year. In late 2011, there were 37 full-time equivalent jobs for 42 employees including 30 women and 12 men. Currently, 40 people are on permanent contracts and two are on temporary contracts. Generally, employees are hired on eight to 12-month fixed-term contracts so they can experience the job and culture of the company. After this, their contract is transformed into a permanent contract if their work meets the needs of the company and if the operation and business needs are aligned with aspirations. Ardelaine has a turnover of approximately EUR 1790000.

Ardelaine's willingness to restructure a production chain led it to develop diversified activities. The co-operative has restructured the entire wool supply chain: sheep-shearing at about 250 breeders in Ardèche and Haute Loire, wool washing, carding (wool-combing and dusting), production (mattress, box spring, quilt or clothing), maintenance (mechanical and building), administration and management and marketing of products (on-site, mail order selling, online via Internet, trade shows, fairs and some health food stores). It achieves its turnover from a balanced distribution between the different marketing methods (of around EUR 500000 each).

Ardelaine has implemented a strategy to enhance and increase tourism and some 20000 people come and visit annually. In May 2007, Ardelaine was labelled a 'Living Heritage Company' by the Ministry of Small and Medium Enterprises Trade, Crafts, and Professions. This recognition is important because it carries the credibility of the company from the national to the local level.

Ardelaine's major success factor is in its development strategy, which it has oriented towards a culture of social entrepreneurship, with the objective being to generate enhanced cash flow and a practical investment policy. While Ardelaine's work remains in the wool sector, it is defined primarily as a local development company.

A key factor cited by Fare (2012) in Ardelaine's successful job creation lies in limiting wage differentials - they currently do not exceed 1.2 between the different employees. Executives have chosen not to increase their own salaries but instead to encourage investment and to create jobs. Ardelaine, a rural enterprise, multidisciplinary and medium-sized, is therefore able to compete on cost.

The main perceived obstacle to the creation of further activities is a lack of local partners and a lack of strategic partnerships and lasting relationships with local authorities. These would be necessary to form an enhanced local development policy and to ensure synergy between the different actors in the territory.

Source : Fare (2012)

\section{The importance of new business models}

Grassl (2011) recognised that the critical distinction of social entrepreneurship lies in something real not so much its structure but in the values of the organisation itself. Any promising business model for social enterprise must, in the light of the previous analysis, fulfil these necessary (if not yet sufficient) conditions:

1. It must be driven by a social mission (i.e., abstain from distributing profit to shareholders).

2. It must generate for positive externalities (spillovers) for society.

3. It must recognise the centrality of the entrepreneurial function.

4. It must achieve competitiveness in markets through effective planning and management. 
Designing the appropriate business model for an organisation's environment is a complex task made more complicated for SEOs in that they are driven by a desire to give something back as well as to be able to trade successfully. The case study below from Spain explores how five struggling co-operatives succeeded through merger and a set of common beliefs.

\section{Box 13. Claros: The Dream of a Worker Co-operative Fusion}

Claros emerged in 2001 from the fusion of five worker co-operatives engaged in home care services for elderly people. Located in different Spanish cities - they all shared the same common scenario: to survive in an uncertain industry. Claros initially had a staff of 31 women, providing their services within a precarious business sector characterised by few professional qualifications, and at the edge of the boundaries of social labour regulation. When these co-operatives resolved to merge, they were gradually increasing their organisational indebtedness and decided to launch a new organisational structure, whilst remaining a co-operative.

Claros merged into a single co-operative entity as a method of designing a more efficient organisational response to a difficult economic climate. The unification involved giving up the identity of each of the primary co-operatives and creating a new reality, different from the entities that initially comprised it.

Ten years later, Claros S.C.A. occupies eighth place in the national ranking of social economy enterprises. Claros began with four care home contracts with city councils, and by 2011 - its tenth anniversary - it had 41 contracts, with public authorities, in various cities of Andalusia and Valencia and a turnover of EUR 4.5 million.

The strategic purpose of Claros has been to establish itself as a social enterprise, and a key driver has always been the desire to support excluded and disadvantaged women back into the labour market. In organisational terms, it has sought quality rather than quantity and its objectives remain:

- to achieve business resilience with co-operative coherence; and,

- to realise a 'new corporate and organisational model' and to grow networks, alliances, management capability, and wisdom.

Claros employs nearly 3000 people and has a commitment to financial autonomy. The co-operative launched an issue of equity securities as a means of raising money for new care homes. Claros also take a positive attitude to training, and has in particular sought to professionalise the role of Care Home Assistant.

Claros' continued activities seek to:

- complement the public system of social services;

- maintain loyal and transparent relationships of co-operation with individuals and entities 'clients';

- engage in a 'vocational commitment' based on professionalism and quality of implementation;

- conceive work as a contribution to the development, autonomy and welfare of those in need of Claros' professional and business competition; and,

- maintain commitment to the necessities of individuals and disadvantaged collectives.

Source : Ariza and Morales (2012)

\section{Concluding thoughts on SEOs and labour market integration}

Buckingham and Teasdale (2012) made the following recommendations for strengthening the hand of SEOs, both as employers of vulnerable groups and as organisations helping to reintegrate vulnerable groups to the workplace:

- Making SEOs favoured providers of public services;

- Awarding public sector contracts of a longer duration to SEOs and ensure that these give full cost recovery for the services provided; 
- Ensuring that subsidies recognise the social contribution of SEOs;

- Government provision of and/or funding of training for SEO employees;

- Reducing the legislative burden for SEOs (although this may have the adverse consequence of enabling other organisations to present as SEOs to benefit from the aforementioned fiscal advantages);

- Greater rhetorical support for the social economy by policymakers; and

- Embedding social enterprise courses in national curricula.

The role of SEOs appears to be of increasing significance. Buckingham and Teasdale (2012) found that, during 2011, employment levels increased in over $40 \%$ of the SEOs and fell in just $11 \%$ during a period when aggregate unemployment in many of the territories was increasing. Looking only at those SEOs providing employment to vulnerable groups, the aggregate figures seem even more impressive. During the course of 2011, looking specifically at jobs for vulnerable individuals, SEOs generated an increase of almost $10 \%$. Additionally, those SEOs aiming to place vulnerable individuals into the mainstream labour market found employment for almost a third of their clients.

There are, inevitably, threats to the ongoing successes of SEOs in supporting disadvantaged people back to work. Aiken and Bode (2009) suggested that emerging managerialist partnership structures (in the UK and Germany) were tending to convert third sector organisations into 'just-in-time' deliverers in both welfare regimes whilst simultaneously eroding the distinctive potential SEOs have to provide more than just labour market integration.

There is no doubt that new SEOs, such as social co-operatives and other voluntary organisations, as well as employing many millions of people, also have a capacity for establishing both support for those out of work, but perhaps more crucially, route ways back into paid employment. Furthermore, the blending within SEOs of their intentions to produce societal benefits with active work programmes to directly support vulnerable groups ensures that the social economy continues to be crucial to the success of many back-to-work initiatives.

At the same time, it is vital to recognise that SEOs are unlikely to compensate for or replace statefunded services for vulnerable people. 


\section{SUPPORT FOR INTERVENTIONS ${ }^{1}$}

\section{The role of innovative financing}

Following the economic crisis of 2008, most OECD countries have set about reducing public expenditure. It seems inevitable that this will leave smaller budgets for interventions within the labour market and will also lead to a growth in experimentation with new means of financing back-to-work welfare. It is therefore essential that, if the plight of disadvantaged groups is not to be worsened, there must be new funding mechanisms. Governments need to recognise that investment in successful labour market transitions and successes will lead to even greater rewards in the future and will also save money in the longer term. As a recent OECD report (OECD, forthcoming) found:

In the context of reducing public sector funds at both the local and national levels in many OECD and non-OECD countries, there is a need for local interventions to move away from a traditional reliance on direct public sector financial support. Public sector resources will continue to be available in some way but project implementers are increasingly expected to work with the private sector and the local community to secure alternative assistance, become self-financing or find ways of mainstreaming interventions after a fixed period of time. While this can place a greater burden on the agencies as they are force to dedicate more time to fundraising and marketing activities, it can have the positive spin-off effect of creating stronger links with local employers, increasing their profile and engendering a more pro-active, independent, and innovative approach.

The need for new financial models to underpin back-to-work support for disadvantaged (and other) groups has been driven by a number of factors, but most particularly the need, post the 2008 crisi, to do 'more with less'. Put simply, there have been growing numbers of people needing assistance and fewer resources to help them. But there are other drivers too, including the recent growth in social investment funds in the USA (Ramsden, forthcoming).

Unemployment amongst disadvantaged groups was high in many countries even before the 2008 recession. Many PES and other support systems seem to maintain problems rather than solving them and, too often, especially training ones are simply postponing problems or 'kicking the can down the road'.

National systems often differ greatly in style and devolution of power/funds, and too often they can appear fragmented with examples of good practice in pockets struggling to gain acceptance into the mainstream. Often, too, the organisations that actually 'make the difference' to people's often complex and chaotic lives are not rewarded. Is it really the employability skills course that gets a former addict a job? Or was it the support from a small charity they received to overcome their drug dependency? Or was it the family member that took them back in after contact with the youth service? This report, like the LEED Programme itself, focuses on local approaches, and it is at the local level that we often find so many of the much-needed innovations. It is clear that there has been a shift in funding paradigms. Traditional funding models are normally either:

1 The author would like to acknowledge the forthcoming report, Innovative Financing and Delivery Mechanisms for Getting the Unemployed into Work, prepared by Peter Ramsden for OECD LEED in the development of this section. 
- A sector funding model, with funds being raised through taxes and through transfer payments down the governance hierarchy. Here, budgets are set annually and pay directly for activities, actions or inputs.

- Project funding via a grant funding model. Here, grants are awarded and pay for project activities, actions or inputs.

More characteristically modern funding examples incorporate aspects such as:

- Payment by outputs or results;

- Incentive and reward systems';

- Contracting out (either to private or social enterprises);

- Using loans to replace grants;

- Social investment; and

- Social impact bonds.

Traditional funding mechanisms have other problems, long recognised, on top of their cost. When funding is dependent upon grants, for instance, there is a premium for effective bid writing and some (often larger) organisations become good at 'hoovering-up' what grants come available. Many funding programmes continue as they are 'the established way of working' and the cost of grant funding in bureaucracy and relative cost per 'output' is often high. Finally, the cost of ending a programme of grants is higher than factored as valuable lessons, skills and team members are often lost.

England is currently engaged in what could accurately be described as a national-scale social experiment - the Work Programme. Part privatisation of back-to-work support and part attempt at encouraging greater flexibility of provision, the Work Programme combines freedoms for private, public and third sector deliverers with a new outcome-related funding regime. Organisations taking part are required to be successful before costs can be covered and, potentially, profits generated. Nonetheless, a large number of major (almost exclusively) private sector agencies have already fully engaged with the Work Programme.

The social economy and third sector have already developed a crucial role in most OECD countries, supporting disadvantaged groups with a whole plethora of services. Increasingly, this includes the provision of work-focused and back-to-work support alongside their more traditional activities of enhancing social inclusion and addressing disadvantage.

Social enterprises focus on work integration activities, such as skills training, the provision of employment opportunities directly and/or through wider support activities in helping people access the open labour market (Aiken and Spear, 2005). Despite the ability to trade, the main objective of social enterprises is not profit maximisation but the satisfaction of socially relevant needs under the constraints of economic sustainability. Social enterprises are often based and embedded in local communities, contributing to the development of formal and informal networks, allowing them to engage with hard-toreach people (Mendell and Nogales, 2007).

Goldsmith et al. (2010) recognised four stages in the evolution of welfare, three historic and one emergent. 
- Stage 1 - where caring for people was largely left to families and charities, often with large elements of philanthropy.

- Stage 2 - marked by the emergence of ideas such as the welfare state in Britain and the Great Society in America, the Government took on the job of ending poverty. Private efforts became less significant.

- Stage 3 - the state tried to foster partnerships with the private sector through competitive outsourcing, but although this sometimes made a big difference, too often the partnerships were too prescriptive and driven by cost-cutting.

- Stage 4-government will tap the ability of the private sector, for-profit and non-profit, to deliver what Goldsmith describes as "disruptive, transformative innovation".

One of the emergent mechanisms for funding elements of welfare provision is microfinance. Originally focusing on self-employment loans, Microfinance has seen variable growth but there are already some success stories, notably ADIE in France and MIKRO in Poland. New initiatives have seen diversification into areas such as insurance, savings products and personal lending (e.g. Fair Finance, UK) and more targeted approaches, as typified by Permicro Torino in Italy and Neem Katrineholm in Sweden.

\section{Box 14. Examples of microfinance initiatives}

\section{Adie, France}

Adie is one of the oldest microfinance institutions in Europe, founded by Maria Nowak in 1989. It grants loans for start-ups and existing enterprises as well as personal microcredit for employment and micro insurance. The loan amount is up to EUR 6000 which can be coupled with start-up grants funded by the government or by the local authorities and non-interest bearing subordinated loans. Individual financing generally does not exceed EUR 10000 . In 2010, Adie granted over 12000 loans and since 1989, the association has granted 93000 loans. Adie Connect online services (www.adieconnect.org) provide the option to apply for a microcredit online and also provides access to online business development services and enhanced exposure to online communities.

\section{Permicro, Italy}

Permicro has a professional business model which provides loans to clients, rather than 'hand-outs to beneficiaries'. They contribute intensive support to the recipients of the loan and are now working in a number of cities to build up economies of scale. They provided 1000 loans in 2010 despite only starting as an organisation in 2007. They employ a Social Guarantees lending model and utilise networks from existing associations, community centres, churches, and co-operatives to provide social capital. If the customer returns the loan, the network is rewarded with better subsequent loan terms, whereas, if members do not fulfil their repayment commitment, credit for others in the group will be more expensive to arrange.

\section{Neem Katrineholm}

An example of a very small project, Neem Katrineholm's clients are mostly migrant women and personify a group which would ordinarily never be considered for conventional loans. The project is useful in helping its clients to build up a credit history and already it has led to the establishment of 43 companies and the creation of 51 jobs.

Source : Ramsden (forthcoming)

\section{Decentralisation}

Denmark has the highest spend in the OECD (1.4\% of GDP) on active labour market outcomes. It also has a high level of local discretion and marked incentives for its municipalities to succeed. Denmark's four Employment Regions set the targets, fix minimum standards, support good practice sharing and maintain an IT platform. Gradual decentralisation of responsibilities has resulted in a high level of local 
discretion on spending and flexibilities. Municipalities finance a third of active measures in enterprises, the other two-thirds being from national funds. Municipalities can keep the financial gains made by getting the unemployed into work.

\section{Social Impact Bonds}

"Social impact bonds (SIBs) are designed to help reform public service delivery. SIBs improve the social outcomes of publicly-funded services by making funding conditional on improvements. Investors pay for the project at the start, and then receive a payment based on the results achieved by the project. Rather than focusing on inputs (e.g. number of doctors) or outputs (e.g. number of operations), SIBs are based on achieving social 'outcomes' (e.g. improved health). The outcomes are predefined and measurable" (UK Government Cabinet Office, 2012).

\section{Box 15. Example of a Social Impact Bond, Peterborough, UK}

The first SIB has worked with 3000 short-term prisoners from Peterborough Prison over the last six years. Their aim is to reduce the rate of reoffending by more than $7.5 \%$ (within 12 months of leaving prison). Individual or organisational 'bondholders' can get up to a $13 \%$ rate of return - and each $1 \%$ above the $7.5 \%$ target increases returns. However, it is on the understanding that there will be no returns for four years.

The first bond issue raised the equivalent of EUR 6 million and bonds were largely bought by charity investors and a smaller number of private foundations.

Source : Ramsden (forthcoming)

\section{Wacky finance: social media, peer-to-peer and crowd funding}

The emergence of the internet and social networks has created new exciting opportunities for funding projects and programmes. Sites like Justgiving.com and their equivalents are transforming charitable giving by making it easy to collect money from sponsors, but the real change in financing new projects is taking place around peer-to-peer and crowd funding investments.

In peer-to-peer investing, one can surf the internet and find a person that you want to invest in. An example is Kiva.org which is a form of microcredit site in which the investor lends to a specific target borrower. The website Kickstarter (www.kickstarter.com) takes this a stage further as it is possible to invest with others in a new creative 'crowd funded' project. One available in 2012 was the Olympic City which enabled someone to sponsor a photography project to produce images of the legacy of previous Olympic stadium sites. If one invested in this project at the lowest entry level of USD 85 one would receive the photo book that they would produce. Higher levels of support bring greater benefits and all provide the satisfaction of producing a photo archive to show to future Olympic bid cities showing that achieving legacy is a challenge.

Self-employment and part-time temporary work are both growing in importance as large firms downsize, people live longer, healthier, more active lives, and the weakening of pension systems obliges people to work for longer. Consequently, the online world of self-employment is growing in importance. FREELANCER.Com and ELANCE.com allow buyers to advertise a project that they need completing. Freelancers from all over the world bid to carry out the work. The type of work advertised is mostly computer-based and ranges from software and website development to bookkeeping.

There have been experiments with part-time and temporary employment sites in various countries. Slivers of Time, in the UK, advertises part-time employment in which the employee is employed not by the firm offering the work but by an intermediary body. The UK organisation, Women Like Us 
(www.womenlikeus.org.uk), has created a market for women with child care responsibilities to seek part time employment in their local area. These new forms of employment broker and intermediary are likely to become increasingly important with a growing number having a social enterprise ethos.

\section{Social procurement}

A significant resource for generating social value from existing resource is that of social procurement. In an era of growing interdependence between government and non-government sectors in the production and delivery of public services, a variety of new types of market relationships are emerging (Bovaird, 2006). The economic crisis affecting many countries has led to reduced public funding, and this, combined with changing attitudes to the delivery of services, has motivated new thinking by policymakers about how to make the most strategic use of public spending. As major purchasers, the public sector has the potential to achieve some of its social policy objectives by linking its procurement to greater strategic aims.

There is no commonly-accepted definition of social procurement, but typically, the term refers to the purchasing of a range of assets and services with the aim of creating social value (Barraket and Weissman, 2009). Social procurement is often, although not exclusively, enacted through the purchasing of services from social economy organisations and, in particular, from social enterprises. Social procurement can therefore be used to generate a range of social and environmental outcomes. Importantly, it has recently been utilised to stimulate work opportunities for people experiencing multiple barriers to employment in a number of locations (e.g. Erridge, 2007).

The widespread contracting-out by the public services to third sector organisations in recent years (Carmel and Harlock, 2008; Kelly, 2007; Muñoz and Tinsley, 2008) has led to increased interest in using public procurement as a mechanism for achieving social outcomes. While interest in social procurement has been renewed in recent years, it is not a new activity, but a continuation and expansion of a long history of the use of government purchasing to achieve social justice outcomes which began in the $19^{\text {th }}$ century in Europe, and in the $20^{\text {th }}$ century in the USA (McCrudden, 2004).

Sometimes social outcomes are purchased directly from suppliers (such as with social service procurement); however, often these social outcomes are embedded as part of non-social service procurement - such as via major infrastructure projects (McCrudden, 2004; Watermayer, 2000). In this sense, social procurement can be viewed as part of an overarching policy objective which seeks to achieve 'value for money'.

Effectively, social procurement seeks to maximise expenditure outcomes, using purchasing power to generate social value, while simultaneously achieving other objectives.

Contemporary policy frameworks for the implementation of social enterprises exist in many parts of the world. In the UK, the Scottish Procurement Directorate (2007) advises that procurement processes should: "ensure that the social dimension is fully taken into account when requirements are being drawn up, at advertising, at selection stage ... to ensure that the target audience is aware of requirements and how to respond to them; and after contract award" (Scottish Procurement Directorate, 2007). The UK's Office of the Third Sector has produced user friendly materials to help decision-makers consider social outcomes in procurement, and commissioned research to investigate any hindrances which might inhibit the inclusion of social clauses in procurement contracts (Office of the Third Sector, 2008).

There are a number of different ways of planning and implementing social procurement. Table 2 summarises four that have been identified as mechanisms for planning and implementing social procurement by the Victorian State Government in Australia, based on a study by Barraket et al. (2012). 
Table 2. Approaches to Social Procurement

\begin{tabular}{ll}
\hline Mechanism for enacting social procurement & \multicolumn{1}{c}{ Explanation } \\
\hline Direct Subcontracting & $\begin{array}{l}\text { Direct subcontracting involves encouraging suppliers who win } \\
\text { contracts to subcontract part of the work to entities that can } \\
\text { deliver social outcomes. "Direct subcontracting may be } \\
\text { included as a requirement of the tender; a preferred }\end{array}$ \\
$\begin{array}{ll}\text { deliverable, which is considered in the evaluation of the } \\
\text { tender; or may be negotiated as part of the contract" } \\
\text { (Department of Planning and Community Development, }\end{array}$
\end{tabular}
2010).

Employment Requirements

Social Clauses in contracts
Employment requirements involve stipulating in the contract that local or disadvantaged residents are employed by a contractor or in partnership with other organisations (such as group training schemes).

A third method involves the inclusion of specific social clauses within a contract. These clauses require that, in addition to the delivery of goods and services, specific social objectives are also achieved by the contractor. Sometimes the manner in which these can be achieved is left up to the contractor (descriptive clauses) and at other times the outcomes and the way they are to be achieved are set by government (prescriptive clauses).

Purchasing agreements and partnerships

Purchasing agreements and partnerships involve the creation of a Memorandum of Understanding or various partnerships with suppliers who can deliver goods and services as well as achieving positive social impacts (such as social enterprises). Sometimes this involves reserving a percentage of a larger contract for social enterprises. Such arrangements need special approval from the Victorian State Government Minister if they exceed a certain threshold value.

Source: Barraket et al. (2012)

Of course, the purchasing agreements and partnerships approach may not be possible in certain contexts. For example, in the EU, reserving certain contracts for a specific class of organisation, with the exception of sheltered workshops, may breach competition policy (European Commission, 2010b). In such cases encouraging larger contractors to sub-contract to smaller organisations may provide a way to comply with competition requirements while promoting social value creation through procurement.

The first three approaches add stipulations to competitive tendering and contract documents which specify outcomes (such as employment or other social outcomes). Alternatively, they stipulate that the winner of the contract needs to sub-contract part of the work to an organisation which can achieve social outcomes. The last option, by contrast, may mean a relaxation in competitive tendering arrangements, which is not possible in some policy contexts. 


\section{Box 16. A social procurement strategy implemented by Parramatta City Council, Australia}

Parramatta City Council (PCC) is the local government with oversight of Parramatta located in western Sydney, Australia, and is characterised by a high degree of cultural diversity, a young demographic and population growth. The City of Parramatta is characterised by pockets of both socio-economic advantage and disadvantage.

Social procurement objectives have been integrated into the sustainable procurement framework at PCC. This framework, in turn, forms part of PCC's overarching approach to best practice in public procurement. The framework has been formalised in policy and is implemented through internal and external stakeholder education, by developing new tools to assist Council staff fulfil policy objectives, and ongoing collaboration both within the Council and between the Council and other agencies. Formative outcomes of activity to date (Barraket et al., 2012) suggest that the framework can contribute to local economic diversification, employment creation for people experiencing barriers to work in the mainstream labour market, and environmental savings.

PCC is committed to the development of its local economy, including its social economy, and has had a programme dedicated to social enterprise development since January 2007. PCC defines social enterprise as businesses that trade for social, environmental and/or cultural purposes and reinvest their surplus or profit in developing the public benefits of the enterprise. Stimulating markets for social enterprise, as part of a diverse local economy, formed part of the impetus for PCC's sustainable procurement strategy. Within the context of its overarching procurement framework, PCC has committed to contributing to these outcomes through its purchasing decisions.

\section{Strategic leadership in Parramatta City Council, Australia}

PCC employs 735 full time equivalent staff across a broad range of functional areas. Local government's responsibilities in Australia typically include maintenance of local roads, waste management, building regulations and land subdivisions, public health and provision of recreation facilities. Councils also typically contribute to local social, cultural and economic development through the provision of a variety of services.

The development of PCC's sustainable procurement strategy was initiated when several different functional areas of Council became aware that they were each exploring the strategic possibilities of procurement to deliver on Council-wide triple bottom line objectives. Separately, members of the local economic development team, the Corporate Sustainability Co-ordinator, and the Social Enterprise Programme approached PCC's Procurement Manager to discuss the possibilities of PCC procurement playing a more purposeful role in generating local economic, environmental and social (and social economy) outcomes respectively.

In May 2011, PCC ratified a revised policy for procurement. This forms part of a wider framework for sustainable procurement being implemented by PCC, which emerged through discussions between staff in several Council units that formalised into one conversation in the second half of 2009. While undertaking to ensure best practice in legislative compliance, the procurement policy also recognises that PCC: "care(s) about social, economic and environmental sustainability for our city and ... on delivering positive outcomes for our communities" (Parramatta City Council, 2011). Within the context of its overarching procurement framework, PCC has committed to contributing to these outcomes through its purchasing decisions. The stated objectives of PCC's procurement policy include making sure that the Council's procurement practices: "Improve the local amenity of communities and are socially responsible encourage sustainability and economic development in Western Sydney [and] foster a viable Australian market for sustainable products and services."

PCC's sustainable procurement strategy recognises procurement as a strategic, as well as an operational, function of local government (sustainability in this case refers to social, local economic and environmental sustainability for the City of Parramatta and its residents). The policy that underpins this strategy locates sustainable procurement within the context of best practice local government procurement. In this sense, sustainable procurement objectives are integrated with PCC's overarching procurement model, rather than forming part of a stand-alone policy. The figure below provides an overview of this policy approach.

The PCC sustainable procurement strategy aims to take a holistic and integrated approach to generating social, economic and environmental outcomes for the residents of Parramatta and Western Sydney through its purchasing policies, within the remit of Council functions. This raises challenges in terms of the limits to local government powers and obligations within Australia's federated system of government. For example, in Australia, responsibilities for employment services rest with the federal and, to some degree, state governments. Australian local governments are neither mandated nor incentivised to be active in responding to unemployment. While much has been made, in other jurisdictions, of the possibilities of social procurement to generate employment, this focus does not provide an incentive to engage in social procurement in the Australian local government and, consequently, the PCC context. 


\section{Box 16. A social procurement strategy implemented by Parramatta City Council, Australia (cont'd)}

\section{Figure 3. Overview of PCC Procurement Policy}

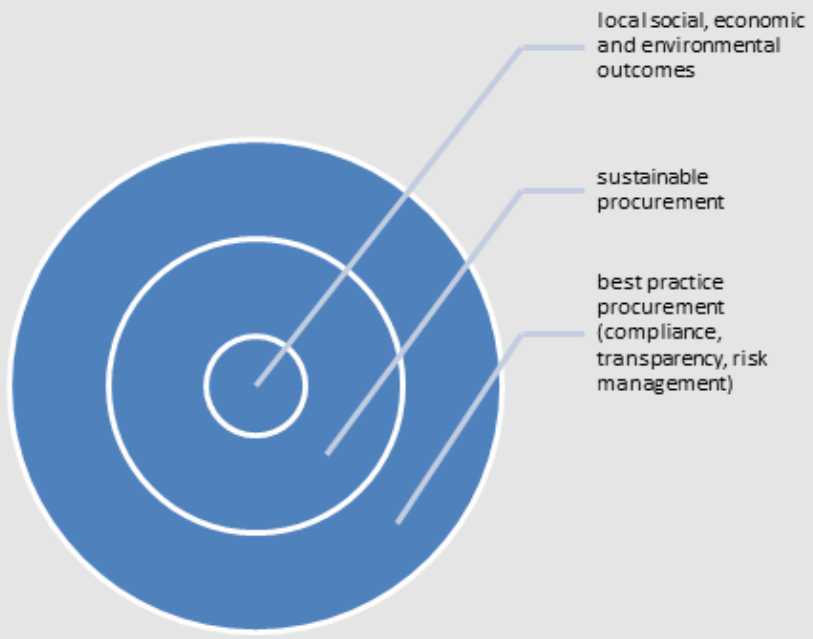

Establishing Council support for the strategy required the development of a persuasive case based on local government's specific responsibilities and strategic objectives: "Ultimately, everything [with regard to achieving Council's sustainability objectives] comes back to procurement” (Corporate Sustainability Co-ordinator).

Aligning the strategy with local government's responsibilities for local economic and social development provided the basis for such a case. Specifically, this included communicating to internal stakeholders the potential benefits of a strategic approach to sustainable procurement to:

- $\quad$ Stimulate and support the local economy;

- Reflect better the diversity of local residents and businesses represented in Parramatta and western Sydney;

- Realise environmental benefits through the use of local supply chains;

- Consolidate Council's support of social enterprise development by applying its relatively large purchasing power rather than concentrating only on relatively small grant support programmes;

- Encourage local business development and social innovation by using purchasing decisions to encourage innovative responses to sustainability issues;

- Generate new opportunities for residents to participate economically, socially and civically; and,

- $\quad$ Contribute to local neighbourhood renewal through new business and supply chain development.

As in most local governments and government agencies at all levels in Australia, procurement has been traditionally viewed as an operational, rather than a strategic, activity within PCC. This positioning of procurement has informed the work requirements of staff with responsibilities for procurement and, consequently, the workforce profile of those involved in procurement. PCC procurement staff have thus traditionally engaged in operational rather than strategic aspects of the procurement process. This has influenced not only the nature of their work activities, but also the nature and breadth of their relationships with other staff and functional areas of Council. The wider review taking place was part of a move to position the procurement function to take a more strategic role. This fitted well with the sustainable procurement project, as it is essentially a strategic approach to the procurement practice of the organisation. 


\section{Box 16. A social procurement strategy implemented by Parramatta City Council, Australia (cont'd)}

The sustainable procurement strategy requires a new way of thinking about procurement - both its functions and effects - as a strategic activity. This shift challenges some conventions of traditional procurement and demands new skills, relationships and attitudes amongst those implementing the strategy. The process of developing the sustainable procurement strategy has illuminated the presence of a range of champions for the strategy at all levels of the organisation and, in some cases, in unlikely places. Yet, the systematic implementation of the strategy requires continued attention to developing the workforce competencies, intra-organisational relationships and staff attitudes needed to ensure the best possibility for success.

The overarching objective of the sustainable procurement strategy is to stimulate local economic development including business development and employment creation - by diversifying the local supply base. As a major purchaser of goods and services within the local economy, PCC believes it has a significant role to play in encouraging local economic diversity.

While PCC utilises a broad definition of social enterprise, it has identified three main functions of social enterprise amongst those with which it works: creating employment or pathways to employment for people disadvantaged in the mainstream labour market; responding to unmet needs by providing services or goods in response to local demand; and generating income to reinvest in broader social or charitable purposes. While PCC does not target specific groups within its social enterprise programme, it has, to date, had a high proportion of contact with social enterprises initiated by and for Parramatta's migrant and refugee communities. The following figure illustrates Parramatta's Sustainable Social Procurement Framework.

\section{Figure 4. Parramatta's Sustainable Social Procurement Framework}

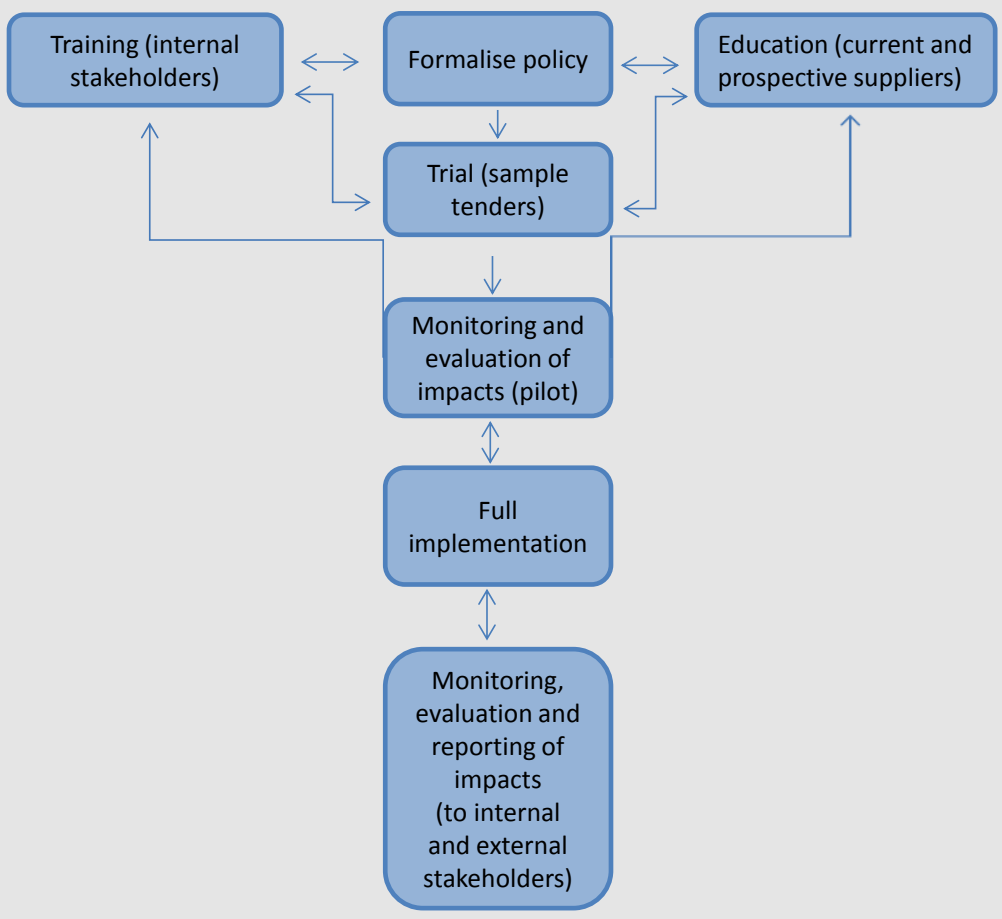

Source : Barraket et al. (2012)

Social enterprises face a number of challenges in developing business sustainability. These include: access to a suitably skilled workforce given the hybrid mission-based business nature of social enterprise; challenges accessing finance and business development support due to the relative newness of some social enterprise models; and productivity deficits that constrain market competitiveness amongst those social enterprises seeking to provide training and employment for people highly disadvantaged in the labour market (Burkett and Langdon, 2005). With regard to accessing procurement opportunities, social 
enterprises generally face challenges similar to small business. These include: lack of experience with the procurement process leading to lack of participation and, thus, lack of track record; and small organisational size that does not match large-scale procurement requirements.

Barraket et al. (2012) comment that effective implementation of the sustainable procurement framework is, however, a significant undertaking that requires considerable changes to organisational culture and systems. This is not a quick fix solution, likely to have rapid outcomes, but a longer-term strategy focused on contributing to transformational impacts over time. A number of lessons for those seeking to implement social procurement can be identified:

- Effective approaches to sustainable procurement require rethinking procurement as a strategic rather than an operational function of governments.

- A strategic approach to sustainable procurement involves integrating sustainability considerations.

- Shifting the function of procurement requires changes to workforce competencies, organisational relationships, information capturing and management systems.

- Institutional entrepreneurs are critical to making change happen.

- Transparent approaches to sustainable procurement require systematic use of indicators of social, environmental and economic value that are useable and understandable to both suppliers and procurement staff.

- The impacts of this innovation cannot be known in the short term; medium and long-term outcomes require baseline knowledge and systematic ongoing evaluation.

\section{Provision of up-to-date intelligence}

Watts (2010), writing for the OECD, recognised the importance of relevant labour market information. Syrett (2008) recommended establishing a strong evidence base and local intelligence which enables an understanding of the workings of the local labour market, the barriers faced by different groups, and the differing aspirations and motivations of those not economically active, before establishing a plan of what needs to done locally with the role of different agencies in achieving this.

The case studies and learning models accompanying this work emphasise the role that evidence-based policymaking has in assisting the design of effective, targeted interventions. Most OECD countries now have effective mechanisms for collecting robust data on employment and the labour market (such as the Labour Force Survey in the EU), but there is a major difference between data and intelligence. There is also often a paucity of reliable local data, particularly when pertaining to potentially numerically small groups within the labour market. It is here that the value of qualitative research can be seen, and it is the combination of quantitative data and qualitative evidence on disadvantaged groups that provides the intelligence needed to inform effective interventions.

Much current data seeks to understand the nature of local skills supply and demand mismatch. Whilst this is essential for employment strategies, without the qualitative elements, it can often lack the nuanced approach needed to understand disadvantage properly.

In our Antwerp and Alost case study, the Flemish Government had been made aware of the need to do things differently following a survey amongst people living in poverty. After analysis of the survey, it 
became clear that conventional approaches - typically a linear trajectory with limited time span, changing counsellors from different organisations, and fixed criteria - as was normally taken by organisations such as VDAB, would not deliver the required results. Instead, a different methodology would need to be used which incorporated built-in evaluation and testing.

The need for the implementation of Gloucester Works was identified in a City Employment and Skills Plan for Gloucester. The purpose of the Gloucester City Employment and Skills Plan (GCESP) was to develop a model of employment and skills provision that: fitted the needs of employers; ensured that individuals possessed the skills necessary to compete in the economy; supported economic growth forecasts and aspirations; and assisted in meeting the employment needs arising from the major (re)developments. This would become Gloucester Works. In preparing the GCESP and the groundwork for Gloucester Works, the consultancy company, Shared Intelligence, undertook in-depth discussions with stakeholders and carried out a high-level exercise to map and assess the effectiveness of current provision in terms of client and employer engagement and employment and skills services. This identified a number of gaps, duplication and fragmentation in provision.

In our Canadian case study, the Bladerunners Program does not collect data on labour market demand or trends in the local construction industry. Instead, it has an ear to the ground through its network and is able, quickly, to identify short and mid-term construction activity that would be conducive to placements. In addition, the relatively short training period allows the programme to make slight adjustments in response to changes in demand for trainees - either through reductions in the size of an incoming cohort or changes in the training schedule.

\section{Evaluation}

Evaluation and monitoring is particularly critical in times of financial constraints where competition for funding is greater and success needs to be proven. Putting in place personal incentives for programme implementers (e.g. including this in performance objectives) can have a positive impact. It must be stated, however, that 'proving' success is not always easy, especially when interventions are qualitative and focus on the longer term building of participation and soft components such as levels of motivation and aspirations (Froy and Pyne, 2011).

Ideally, evaluation should be built in from the outset and should address areas such as:

- Impact achieved on the ground, particularly in helping the target groups and those furthest from the labour market.

- Cost-benefit analysis.

- Comparisons with alternative projects and programmes seeking similar ends.

- Progress made in supporting and retaining people in sustainable employment.

- The success with which employers and investors were supported, able to grow their workforce, grow their business and recruit staff to vacancies being created.

- The strength, quality and robustness of the partnerships that underpinned the Programme and the scope to sustain them in the light of a changing policy landscape.

- The scale of further investment needed by partners moving forward (EMB Consulting and Buckman Associates Ltd., 2011). 
The Parramatta City Council case study into social procurement recognised that the impacts of the innovations involved could not be known in the short term, and recommended baseline identification followed by subsequent medium and long-term (ongoing) evaluations.

In the Antwerp and Alost case study, after initial analysis of the situation, it became clear that a new methodology needed to be developed, and it is to their credit that they built in evaluation and testing which has helped to continually improve performance and support dissemination of the new delivery model. 


\section{RECOMMENDATIONS FOR LOCAL APPROACHES TO TACKLING LONG-TERM UNEMPLOYMENT IN VULNERABLE GROUPS}

This section draws together the pivotal recommendations contained within the report. These are aimed primarily at policymakers and strategic directors seeking to design and improve their provision of specialist support to unemployed adults from disadvantaged communities and groups.

The recommendations have largely emerged from the detailed examination of a series of case studies commissioned by the OECD LEED Programme, which themselves were generated in response to a growing body of evidence highlighting the persistence and exacerbation of pockets of long-term unemployment within disadvantaged groups and the damage that this does to the life chances of those unfortunate enough to find themselves out of work for a prolonged period.

To produce this report, the author has also drawn on information from a large online survey, held in collaboration with the WAPES, exploring how different public employment services are responding to the challenge posed by long-term and structural unemployment.

\section{Recommendations}

\section{Understand the area and the context}

The OECD (2008) has recognised the importance of building the capacity for capturing and analysing local labour market intelligence, as a necessary step to designing the most appropriate intervention and monitoring its impact. Prior to commencing area-based interventions, it is critical to understand both the local labour market (where and in what jobs/sectors the clients will gain employment), and the skills and employment profiles of the people living there (including any target groups).There could well already be existing similar (or complementary) provision which can be built on rather than starting from 'zero'. In particular, community-level organisations can help deliver or facilitate access to target groups from a position of trust.

Understanding the context for the project or programme will also allow linkages with other relevant activities. Ideally, back-to-work interventions should be linked to regeneration/new development. This assures the presence of 'real jobs' and offers the potential both to meet genuine employer need for new staff and for local government and agencies to include requirements/lobby for new developments to incorporate jobs for the long-term unemployed and vulnerable groups.

All local interventions will have their own unusual/unique characteristics such as geography, predominant sectors, emerging opportunities, partners, vulnerable groups or financing and this should to be recognised from the outset. One project cannot typically be replicated in another area.

Projects working with particular target groups will benefit from an early and nuanced understanding of the groups cultural principles. Adoption of an educational strategy that culturally reflects the values, behaviours and ways of the student population should have positive outcomes. The BEST Pacific Institute of Education case study exemplifies the benefits of understanding your client group and tailoring delivery of support to them. 


\section{Strategic leadership}

Accompanying the effective local leadership in delivering the project, there needs to be strategic leadership, recognising just where the project sits within the broader framework of provision and seeing where linkages, opportunities and threats may occur from new and competing developments and programmes. In a nutshell, the project should not exist in a bubble but be located within a strategy, its objectives and boundaries clearly understood.

\section{Target limited resources to those most in need}

With limited funding for projects, it makes sense to focus on particularly vulnerable groups and those some distance from the labour market. It can be tempting to work with those easiest to place, particularly in funding models which prioritise results. This should be recognised when planning interventions and their funding models, and resisted. But there is always a small dilemma here as universal systems can be far cheaper and easier to administer. Project managers should be given the flexibility to target or broaden provision as the project evolves.

\section{Seek sustainability and added value}

Projects should seek to integrate their offer within the broader policy landscape. The Belgian detainee projects explored in the accompanying OECD case study were all closely linked to Flemish labour market policy. This may not guarantee long term financing, but the likelihood was improved and the project could also link to a broader network, with the possibilities for further dissemination improved.

The aligning of different strands of activity such as regeneration, mainstream funding, charitable donation and project funding can be complicated, but it can also produce added-value through real benefits in scale. Drawing down mainstream funding should accentuate sustainability. The ESEDRA Co-operative and Claros case studies are examples of how voluntary and community level organisations can successfully access mainstream funding.

\section{Person-centred}

Long-term unemployed adults often have significant, and different, barriers to successful engagement within the labour market. Identifying individual needs and developing a personalised intervention will enhance both the likelihood of success and the experience of the individual receiving support. In some cases, with projects seeking to engage over the longer term with particularly excluded individuals, the jobseekers are not treated as clients or customers but as partners within the project.

The bespoke end-to-end service (from first meeting through to training and work placement) in the Gloucester Works example was highly valued, maintaining a single personal contact and ensuring training and offers of employment were appropriate to the individual. Detailed initial assessments of client's skills and aptitudes combined with client interviews should help to ensure subsequent provision is appropriate.

When working with those some distance from the labour market, the importance of personal support from coaches and mentors cannot be over-emphasised. Our cited BladeRunners case study recognised the importance of the enthusiastic co-ordinators, who grew in their jobs during the process and really built up a relation of trust and confidence with the jobseekers. Similarly, the personalised mentoring roles in the Antwerp and Alost examples were critical to the project's success. 


\section{Make training and support work-focused and engage employers}

Combine paid employment and work experience with training, enabling participants to build their skills and develop an attachment to the labour force. LEED work has generally found that employment initiatives operating in the community without significant employer involvement are often not successful (Froy and Pyne, 2011).

The temptation may be to focus almost exclusively on the jobseekers, but as they are expected to spend many years in employment, it is also critical to spend time with the employers, clarifying expectation and helping them to understand the kinds of issues and support the client may need. Owners, HR managers, colleagues and supervisors can all benefit from support when employing potentially vulnerable adults, who may have limited experience of the needs and requirements placed upon them in the workplace. The network of employers built up by the Bladerunners and Velcro case studies, and the support given to employers, are examples of what can be achieved.

\section{Joined-up offer}

Employers can be faced by a confusing array of employer programmes and possible projects and programmes. Attempting to draw these together under a common identity can help give confidence to employer involvement. A large and diverse number of organisations were drawn together in the Gloucester Works project enabling the project to deliver support from initial assessment, through training and into work placement, all under the one banner.

Clients can often be presented with a complex selection of differing services offering advice, placement, training and welfare. Linking provision under a single banner may not be welcomed by all organisations (who can quite sensibly be protective of their 'image') but it undoubtedly simplifies the offer for clients.

\section{Partnerships}

Partner organisations need to have a shared genuine mutual interest in the outcomes of communitybased strategies and sufficient commitments of time, finance and human resources. Effective partnerships on the ground need to include high levels of trust and a willingness to be flexible in delivery.

A number of the case studies demonstrate the need for effective partnerships. The Gloucester Works case study involved a particularly bespoke partnership designed specifically with the intention of delivering a major co-ordinated programme and involving all of the large essential strategic partners and a network of smaller delivery partners.

\section{Involve workplace representatives and trades unions}

Workplace representatives have an important role to play in supporting people in employment and can have conversations with employees and community workers that employers may struggle to have. With workplace mentoring and buddying, such effective tools for helping people overcome problems in an unfamiliar work environment, ensuring that these roles are understood and ideally facilitated by workplace representatives, make practical sense.

The Unionlearn case study demonstrates the impact that trade unions can have, both within the workplace when given the role of driving up skills levels and within the community when they are enabled to use their organisational and supporting strengths to empower others through networks and community groups. 


\section{Embrace changing public sector roles and finance mechanisms}

In many countries, the public sector has a long and distinguished history of financing and managing projects and programmes with excluded groups and individuals. In a world of shrinking financial capacity for delivering such programmes, the public sector needs to embrace a new role as an enabler of social innovation. This could involve a shift to a more conscious and systematic approach to public sector working and a shift from running tasks and projects to orchestrating the processes of co-creation within communities and in partnership with community-level partners: seeking not to do things 'for' people, but instead, to do them 'with' people.

Peter Ramsden's forthcoming OECD LEED report highlights these changes and the role that innovative finance might need to play. Whether linking internal positive training and recruitment practices to the procurement process, or taking advantage of the emergence of new financing techniques such as crowd-funding and microfinance, innovative financing will play an ever more important role in funding community level programmes.

\section{Evaluation and dissemination}

Ensuring lessons are captured through evaluation and/or active dissemination and mainstreaming is crucial to ensuring new projects no longer need to 're-invent the wheel' and should be a step towards sustainability. Effective evaluation need not be costly. It should be built into new programmes from their commencement and should seek to inform both the development of the programme, and others about its successful and transferable lessons.

The case studies gathered by the OECD LEED Programme for this study are good examples of how to share lessons, particularly with practitioner audiences. Many projects (such as in the Antwerp case study) recognise the importance of disseminating the project instruments and results. They summarise this as "act local, think (more) global".

\section{Conclusion}

This report has sought to nuance the important role that a number of innovative and successful areabased approaches have played in tackling the long-term unemployment of vulnerable groups. It has examined what works and why and has sought to draw some strategic recommendations for those looking to improve or modify existing provision.

The current, extremely challenging economic conditions impacting on many OECD countries are requiring national governments and sub-national authorities to do more with less. It is imperative, therefore, that both policymakers and practitioners learn from existing good practice and that the lessons learned through effective implementation on the ground are understood and shared.

Long-term unemployment continues to have devastating effects on individuals and communities but our report confirms that many lessons have been learned about how to implement effective back-to-work interventions for the long-term unemployed: how to work with disadvantaged groups; the importance of community-level activity; the importance of partnerships and cross-partner co-ordination; the role of innovative finance; and the need for person-centred delivery, to name but a few.

The OECD continues to argue, rightly, that proper co-ordination of regional and local labour markets is needed to find solutions to some of their most important deficiencies. Long-term unemployment may be around for some time to come, but this report demonstrates that we can, already, design effective programmes to mitigate its impact on those groups that are already vulnerable. 


\section{REFERENCES}

Aiken, M. (2007), "What is the Role of Social Enterprise in Finding, Creating and Maintaining Employment for Disadvantaged Groups?", Social Enterprise Think Piece for the Office of the Third Sector, Cabinet Office, London.

Aiken, M. and I. Bode (2009), "Killing the Golden Goose? Third Sector Organizations and Back to Work Programmes in Germany and the UK", Social Policy \& Administration, Vol. 43, Issue 3, pp. 209225.

Aiken, M. and R. Spear (2005), "Gateways into Employment: Third Sector Organisations Working with Groups Disadvantages in the Labour Market", Conference Paper, Consumers' Cooperative Institute, Tokyo.

Ariza, A. and A. C. Morales (2012), "Claros: The Dream of a Worker Cooperative Fusion", OECD LEED Internal Case Study.

Audretsch, D. B., M. A. Carree and A. R. Thurik (2001), "Does Entrepreneurship Reduce Unemployment?”, Tinbergen Institute Discussion Paper Series, Amsterdam.

Barraket, J., C. Furneaux and J. McNeill (2012), "Generating Social Value through Public Procurement: the Case of Parramatta City Council”, OECD LEED internal case study.

Barraket, J. and J. Weissman (2009), "Social Procurement and Its Implications for Social Enterprise: A Literature Review”, Working Paper, No. CPNS 48, The Australian Centre for Philanthropy and Nonprofit Studies, Brisbane.

Bason, C. (2010), Leading Public Sector Innovation: Co-creating for a Better Society, The Policy Press, Bristol.

Bell, D. N. F. and D. G. Blanchflower (2010), "UK Unemployment in the Great Recession", National Institute Economic Review, Vol. 214, pp. 3-25.

Billis, D. and H. Glennerster (1998), "Human Services and the Voluntary Sector: Towards a Theory of Comparative Advantage", Journal of Social Policy, Vol. 27, No. 1, pp. 79-98.

Bimrose, J. (2009), "Careers Guidance, Identity and Development”, Institute for Employment Research, Univeristy of Warwick, www.beyondcurrenthorizons.org.uk/careers-guidance-identity-anddevelopment/.

Birkhölzer, K. (2009), "The Role of Social Enterprise in Local Economic Development”, paper for the second EMES International Conference on Social Enterprise, Trento 1-4 July.

Borzaga, C., S. Depedri and E. Tortia (2010), "The Growth of Organizational Variety in Market Economies: the Case of Social Enterprises”, EURICSE Working Paper, No. 03/10, Trento. 
Bovaird, T. (2006), "Developing New Forms of Partnership with the 'Market' in the Procurement of Public Services", Public Administration, Vol. 84, Issue 1, pp. 81-102.

Buckingham, H. and S. Teasdale (2012), "Job Creation through the Social Economy and Social Entrepreneurship”, OECD LEED Working Paper,

www.oecd.org/cfe/leed/130228_Job\%20Creation\%20throught\%20the\%20Social\%20Economy\%20a nd\%20Social\%20Entrepreneurship_RC_FINALBIS.pdf

Burkett, I. and D. Langdon (2005), Social Enterprise \& Social Tendering: A guide for Government Departments, Large Social Welfare Organisations and Corporations, New Mutualism Group, Palmwoods, Queensland.

Carmel, E. and J. Harlock (2008), "Instituting the 'Third Sector' as a Governable Terrain: Partnership, Procurement and Performance in the UK”, Policy \& Politics, Vol. 36, No. 2, pp. 155-171.

Cedefop (2011), Glossary - Quality in Education and Training, Publications Office of the European Union, Luxemburg.

CERIC (2010), Assessing the Impact of Union Learning and the Union Learning Fund: Union and Employer Perspectives, CERIC Policy Report, No. 4, University of Leeds, UK.

Daniele, D. (2012), “ESEDRA Cooperative”, Internal Case Study OECD LEED Programme, Trento.

Dean, A. (2012a), "Gloucester Works: An Area Based Approach Targeting Disadvantaged and Minority Populations", Internal OECD LEED Case Study, Trento.

Dean, A. (2012b), "Unionlearn in the Community: Tackling Disadvantage", Internal OECD LEED Case Study, Trento.

Delarue, A., S. Gryp and G. van Hootegem (2006), "The Quest for a Balanced Manpower Capacity: Different Flexibility Strategies Examined”, IET Enterprise and Work Innovation Studies, Vol. 2, pp. 69-86.

Department of Planning and Community Development (2010), Social Procurement: A Guide for Victorian Local Government, Department of Planning and Community Development, State Government of Victoria, Melbourne.

EMB Consulting and Buckman Associates Ltd. (2011), Evaluation of the Gloucester City Employment and Skills Plan, EMB Consulting and Buckman Associates Ltd., Bristol.

European Commission (2010a), "Small and Medium-sized Enterprises (SMEs) - Social Economy", European Commission Enterprise and Industry website,

http://ec.europa.eu/enterprise/policies/sme/promoting-entrepreneurship/social-economy/, accessed 14 May 2013.

European Commission (2010b), Buying Social: A guide to taking account of social considerations in public procurement, Office for Official Publications of the European Union, Luxembourg.

Erridge, A. (2007), "Public Procurement, Public Value and the Northern Ireland Unemployment Pilot Project", Public Administration, Vol. 85, No. 4, pp. 1023-1043. 
Fare, M. (2012), “Ardelaine - a Co-operative Dedicated to Local Sustainable Development”, Internal OECD LEED Case Study, Trento.

Fonteneau. B., et al. (2011), Social and Solidarity Economy: Our Common Road towards Decent Work, International Training Centre of the ILO, Turin.

Froy, F. and S. Giguère (2010), "Putting in Place Jobs that Last: A Guide to Rebuilding Quality Employment at Local Level", OECD Local Economic and Employment Development (LEED) Working Papers, No. 2010/13, OECD Publishing. doi: $10.1787 / 5 \mathrm{~km} 7 \mathrm{jf} 7 \mathrm{qtk} 9 \mathrm{p}$-en

Froy, F. and L. Pyne (2011), "Ensuring Labour Market Success for Ethnic Minority and Immigrant Youth", OECD LEED Working Papers, No. 2011/09, OECD Publishing. doi: $10.1787 / 5 \mathrm{~kg} 8 \mathrm{~g} 210547 \mathrm{~b}$-en

Galera, G. and C. Borzaga (2009), "Social Enterprise: an International Overview of its Conceptual Evolution and Legal Implementation", Social Enterprise Journal, Vol. 5, No. 3, pp. 210-228.

Goldsmith, S., T. Burke and G. Georges (2010), The Power of Social Innovation: How Civic Entrepreneurs Ignite Community Networks for Good, John Wiley and Sons, San Francisco.

Grassl, W. (2011), "Business Models of Social Enterprise: A Design Approach to Hybridity", paper to the ACRN Conference on Social Entrepreneurship Perspectives, Linz, Austria, 26-27 August 2011.

Green, A. E. and C. Hasluck (2009), “Action to Reduce Worklessness: What Works?” Local Economy, Vol. 24, No. 1, pp. 28-37.

Griggs, J., A. Whitworth, R. Walker, D. McLennan and M. Noble (2008), Person or Place-based Policies to Tackle Disadvantage? Not Knowing What Works, Joseph Rowntree Foundation, York.

Gryp, S. (2011), Flexibility in Business: Balancing Contractual and Functional Flexibility, Den Haag, Leuven.

Hansen, E. and A. Zulum (2012), "Preliminary Assessment of Training and Retraining Programmes Implemented in Response to the Great Recession”, ILO Employment Working Paper, No. 122, Geneva.

Head, B. W. (2007), “Community Engagement: Participation on Whose Terms?”, Australian Journal of Political Science, Vol. 42, No. 3, pp. 441-454.

Kellard, K. (2002), "Job Retention and Advancement in the UK: a Developing Agenda", Policy Press, Vol. 10 Issue 2, pp. 93-98.

Kelly, J. (2007), "Reforming Public Services in the UK: Bringing in the Third Sector", Public Administration, Vol. 85, No. 4, pp. 1003-1022.

Machin, S and Manning, A. (1998), "The Causes and Consequences of Long-Term Unemployment in Europe", Elsevier Handbook of Labor Economics, Vol. 3, pp. 3085-3139.

Martin Yarnitt Associates (2011), Community Learning Champions - Report on the National Community Learning Champions Support Programme 2009-2011, Unionlearn/Martin Yarnett Associates/Niace/WEA, 
www.communitylearningchampions.org.uk/sites/default/files/downloads/CLC-Final-report-FINAL2.pdf.

McCarthy, M, (2012), “BEST Pacific Institute of Education - Pacific Model”, OECD LEED Internal Case Study.

McCrudden, C. (2004), "Using Public Procurement to Achieve Social Outcomes", Natural Resources Forum, Vol. 28, No.4, pp. 257-267.

Mendell, M. and R. Nogales (2007), "Social Enterprises in OECD Member Countries: what are the Financial Streams?", in A. Noya (ed.), The Changing Boundaries of Social Enterprises, OECD publishing, Paris.

Molgat, M. (2012), "The BladeRunners Program - Supporting the Transition to Employment of Disadvantaged youth in Vancouver, Canada", Internal OECD LEED Case Study.

Monzon, J. L. and Chavez, R. (2012), “The Social Economy in the European Union”, CIRIEC working paper, Liege.

Muñoz, S. and S. Tinsley (2008), "Selling to the Public Sector: Prospects and Problems for Social Enterprise in the UK", Journal of Corporate Citizenship, Issue 32, pp. 43-62.

Noya, A. and E. Clarence (2007), The Social Economy: Building Inclusive Communities, OECD Publishing, Paris.

OECD (2008), Venice Action Statement on Enhancing Flexibility in Labour Market Policy, OECD Publishing, Paris.

OECD (2009), Flexible Policy for More and Better Jobs, OECD Publishing, Paris.

OECD (2010a), OECD Employment Outlook 2010: Moving beyond the Jobs Crisis, OECD Publishing, Paris.

OECD (2010b), Learning for Jobs, OECD Reviews of Vocational Education and Training, OECD Publishing, Paris.

OECD (2010c), Breaking Out of Policy Silos, OECD Publishing, Paris.

OECD (2011), "Building Quality Jobs in the Recovery", Conference ISSUES Paper, International Conference, Dublin, Ireland, 13 - 14 October.

OECD (2012a), OECD Employment Outlook 2012, OECD Publishing, Paris.

OECD (2012b), Better Skills, Better Jobs, Better Lives: A Strategic Approach to Skills Policies, OECD Publishing, Paris.

OECD (forthcoming), Local Strategies for Youth Employment, OECD LEED Working Paper.

Office of the Third Sector (2008), Social Clauses Project: Report of the Social Clauses Project, UK Cabinet Office, London. 
Parramatta City Council (2011), Parramatta City Council Procurement Policy, Policy No. 287, Parramatta City Council, Parramatta, www.parracity.nsw.gov.au/_data/assets/pdf_file/0012/92100/POLICY287ProcurementPolicy.pdf.

Ramsden, P. (forthcoming), Innovative Financing and Delivery Mechanisms for Getting the Unemployed into Work, OECD LEED Working Paper.

Schuller, T. (2009), "Crime and Lifelong Learning”, IFLL Thematic Paper, No. 5, National Institute of Adult Continuing Education, Leicester.

Scottish Procurement Directorate (2007), Social Issues in Public Procurement: A Guidance Note by the Scottish Procurement Directorate, Scottish Procurement Directorate, www.scotland.gsi.gov.uk/Topics/Government/Procurement/PublicProcurement/policynotes/sppn062 007guidance.

SLIM (2009), ESF - Position and Progress, Learning Theme Report, Marchmont Observatory, University of Exeter, Exeter.

SLIM (2010), Employment \& Skills: The Role of Regeneration in Supporting Communities, Learning Theme Report, Marchmont Observatory, University of Exeter, Exeter.

Sunley, P. and S. Pinch (2012), "Financing Social Enterprise: Social Bricolage or Evolutionary Entrepreneurialism", Social Enterprise Journal, Vol. 8, No. 2, pp. 108-122.

Syrett, S. (2008), “Worklessness: The Role of Local Action and Local Economic Development”, paper produced for the NCRA Panel, Centre for Enterprise and Economic Development Research, Middlesex University.

Teasdale, S. (2012), "What's in a Name? Making Sense of Social Enterprise Discourses", Public Policy and Administration, Vol. 27, No. 2, pp. 99-119.

TUC (2009), “TUC UnionLearn (U-Net)”, Inspection Report, Ofsted, Manchester, http://archive.excellencegateway.org.uk/pdf/link\%201\%20unionlearn\%201\%20ofsted\%20report.pdf

TUC/Goldsmiths (2010), Swords of Justice and Civic Pillars: the Case for Greater Engagement between British Trade Unions and Community Organizations, TUC Report, London, www.tuc.org.uk/union/tuc-19609-f0.pdf.

TUC (2010), Union Learning, Adding Value: an Evaluation of Unionlearn and the Union Learning Fund, TUC Report, London, www.unionlearn.org.uk/sites/default/files/Union\%2Blearning\%2Badding\%2Bvalue.pdf.

UK Government Cabinet Office (2012), "Social Impact Bonds - Introduction to Social Impact Bonds, Information on Commissioning a Social Impact Bond, Sources of Funding and Available Support", UK Government Cabinet Office website, www.gov.uk/social-impact-bonds, accessed 14 May 2013.

Vancoillie, J. (2010), "Sociale Flexibiliteit", in Castermans, G., C. Gijselinckx and N. Vallet (eds.), Handboek Management in de Sociale Economie, Politeia, Brussels.

Vancoillie, J. (2012), "Job Creation through Social Entrepreneurship and the Social Economy”, Internal OECD LEED Programme Case Study, Trento. 
Van de Voorde, M., A. Verboven and M. Tahri (2012), “Targeted Trajectories Towards Durable Work for Persons from Impoverished Backgrounds”, Internal OECD LEED Case Study, Trento.

Watermayer, R. (2000), "The Use of Targeted Procurement as an Instrument of Poverty Alleviation and Job Creation in Infrastructure Projects", Public Procurement Law Review, Vol. 5, pp. 226-250.

Watts, A. G. (2010), "Career Guidance and Post-Secondary Vocational Education and Training", paper prepared for the OECD Review of Post-Secondary Vocational Education and Training, Skills beyond School, OECD, Paris.

Williams, N. and C. C. Williams (2011), "Tackling Barriers to Entrepreneurship in a Deprived Urban Neighbourhood”, Local Economy, Vol. 26, No.1, pp. 26-30. 
ANNEX 1: TABLES FROM THE INTERNATIONAL SURVEY OF PES

Table 3. Country Responses

\begin{tabular}{|c|c|}
\hline Country & Number of responses \\
\hline Canada & 112 \\
\hline United States & 18 \\
\hline Hungary & 12 \\
\hline Australia & 8 \\
\hline Croatia & 2 \\
\hline Denmark & 2 \\
\hline Belgium & 1 \\
\hline Bulgaria & 1 \\
\hline Central African Republic & 1 \\
\hline Chad & 1 \\
\hline China & 1 \\
\hline Germany & 1 \\
\hline Japan & 1 \\
\hline Kenya & 1 \\
\hline Latvia & 1 \\
\hline Montenegro & 1 \\
\hline Netherlands & 1 \\
\hline Portugal & 1 \\
\hline Serbia & 1 \\
\hline Slovenia & 1 \\
\hline Sweden & 1 \\
\hline Turkey & 1 \\
\hline United Kingdom & 1 \\
\hline Total & 171 \\
\hline
\end{tabular}


Table 4. Approach to Tackling Long-term Unemployment - TARGETING

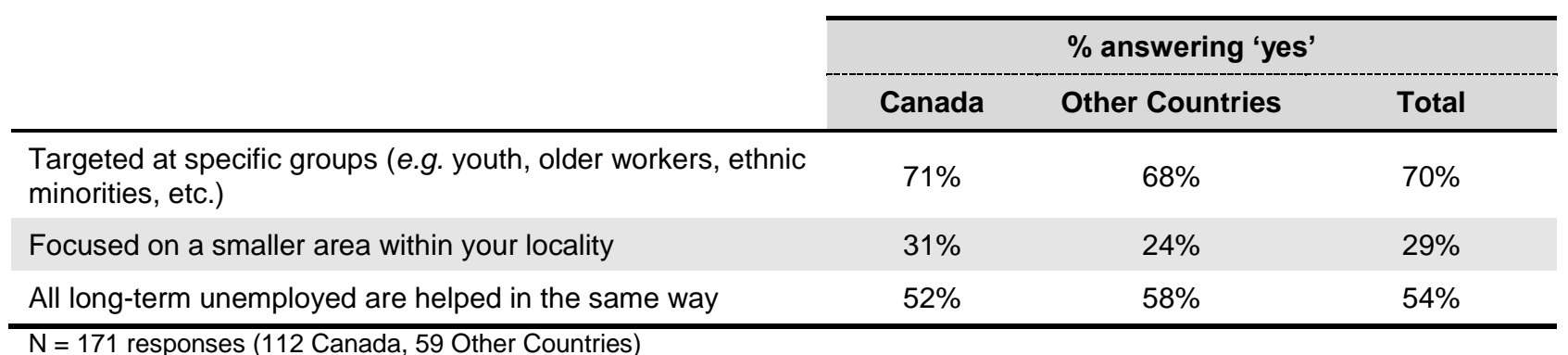

$\mathrm{N}=171$ responses (112 Canada, 59 Other Countries)

Table 5. Approach to Tackling Long-term Unemployment - GROUPS TARGETED

\begin{tabular}{lccc} 
& \multicolumn{3}{c}{ \% answering 'yes' } \\
\cline { 2 - 4 } & \multicolumn{3}{c}{ Total } \\
\hline Ethnic minority groups & Canada & Other Countries & $39 \%$ \\
Low-skilled & $36 \%$ & $46 \%$ & $51 \%$ \\
\hline Older workers (over 50 years) & $46 \%$ & $63 \%$ & $53 \%$ \\
Young people (up to 24) & $53 \%$ & $53 \%$ & $50 \%$ \\
\hline Disabled & $45 \%$ & $61 \%$ & $46 \%$ \\
\hline Ex-prisoners & $42 \%$ & $53 \%$ & $27 \%$ \\
Single parents & $21 \%$ & $41 \%$ & $28 \%$ \\
Women & $27 \%$ & $31 \%$ & $30 \%$ \\
\hline Other & $28 \%$ & $34 \%$ & $15 \%$ \\
\hline Ne171 responses & $15 \%$ & $14 \%$ & \\
\hline
\end{tabular}

$\mathrm{N}=171$ responses (112 Canada, 59 Other Countries) 
Table 6. Flexibility and Resources

\begin{tabular}{|c|c|c|c|c|}
\hline Canada & Insufficient & $\begin{array}{c}\text { Barely } \\
\text { Sufficient }\end{array}$ & Sufficient & $\begin{array}{c}\text { No } \\
\text { response }\end{array}$ \\
\hline Flexibility in designing programmes & $12 \%$ & $28 \%$ & $58 \%$ & $3 \%$ \\
\hline Flexibility in budget management & $19 \%$ & $34 \%$ & $46 \%$ & $1 \%$ \\
\hline Flexibility in deciding programme eligibility & $13 \%$ & $33 \%$ & $50 \%$ & $4 \%$ \\
\hline Flexibility in contracting/outsourcing arrangements & $26 \%$ & $28 \%$ & $43 \%$ & $4 \%$ \\
\hline Staffing & $23 \%$ & $30 \%$ & $46 \%$ & $1 \%$ \\
\hline Staff training & $20 \%$ & $36 \%$ & $44 \%$ & $1 \%$ \\
\hline General financial resources & $24 \%$ & $38 \%$ & $37 \%$ & $2 \%$ \\
\hline Financial resources for evaluation & $37 \%$ & $26 \%$ & $33 \%$ & $4 \%$ \\
\hline Evidence base for 'what works' & $17 \%$ & $36 \%$ & $45 \%$ & $3 \%$ \\
\hline Other Countries & Insufficient & $\begin{array}{c}\text { Barely } \\
\text { Sufficient }\end{array}$ & Sufficient & $\begin{array}{l}\text { No } \\
\text { response }\end{array}$ \\
\hline Flexibility in designing programmes & $12 \%$ & $37 \%$ & $46 \%$ & $5 \%$ \\
\hline Flexibility in budget management & $20 \%$ & $39 \%$ & $32 \%$ & $8 \%$ \\
\hline Flexibility in deciding programme eligibility & $19 \%$ & $36 \%$ & $42 \%$ & $3 \%$ \\
\hline Flexibility in contracting/outsourcing arrangements & $15 \%$ & $39 \%$ & $41 \%$ & $5 \%$ \\
\hline Staffing & $8 \%$ & $53 \%$ & $34 \%$ & $5 \%$ \\
\hline Staff training & $3 \%$ & $42 \%$ & $49 \%$ & $5 \%$ \\
\hline General financial resources & $25 \%$ & $42 \%$ & $27 \%$ & $5 \%$ \\
\hline Financial resources for evaluation & $36 \%$ & $39 \%$ & $15 \%$ & $10 \%$ \\
\hline Evidence base for 'what works' & $17 \%$ & $47 \%$ & $24 \%$ & $12 \%$ \\
\hline Total & Insufficient & $\begin{array}{c}\text { Barely } \\
\text { Sufficient }\end{array}$ & Sufficient & $\begin{array}{c}\text { No } \\
\text { response }\end{array}$ \\
\hline Flexibility in designing programmes & $12 \%$ & $31 \%$ & $54 \%$ & $4 \%$ \\
\hline Flexibility in budget management & $19 \%$ & $36 \%$ & $42 \%$ & $4 \%$ \\
\hline Flexibility in deciding programme eligibility & $15 \%$ & $34 \%$ & $47 \%$ & $4 \%$ \\
\hline Flexibility in contracting/outsourcing arrangements & $22 \%$ & $32 \%$ & $42 \%$ & $4 \%$ \\
\hline Staffing & $18 \%$ & $38 \%$ & $42 \%$ & $2 \%$ \\
\hline Staff training & $14 \%$ & $38 \%$ & $46 \%$ & $2 \%$ \\
\hline General financial resources & $25 \%$ & $39 \%$ & $33 \%$ & $3 \%$ \\
\hline Financial resources for evaluation & $36 \%$ & $30 \%$ & $27 \%$ & $6 \%$ \\
\hline Evidence base for 'what works' & $17 \%$ & $40 \%$ & $37 \%$ & $6 \%$ \\
\hline
\end{tabular}

$\mathrm{N}=171$ responses (112 Canada, 59 Other Countries) 
Table 7. Community Engagement/Collaboration - Total

\begin{tabular}{|c|c|c|c|c|c|}
\hline \multirow[b]{2}{*}{ Agencies / Partners } & \multirow[b]{2}{*}{$\begin{array}{l}\text { we collaborate } \\
\text { (\% of all respondents) }\end{array}$} & \multicolumn{4}{|c|}{ we are in contact at least: } \\
\hline & & $\begin{array}{l}\text { every } \\
\text { month }\end{array}$ & $\begin{array}{l}\text { every } 3 \\
\text { months }\end{array}$ & $\begin{array}{l}\text { every } 6 \\
\text { months }\end{array}$ & $\begin{array}{l}\text { less than } \\
\text { every } 6 \\
\text { months }\end{array}$ \\
\hline Employers & $88 \%$ & $89 \%$ & $8 \%$ & $1 \%$ & $2 \%$ \\
\hline $\begin{array}{l}\text { Economic development } \\
\text { organisations and regional } \\
\text { development specialists }\end{array}$ & $72 \%$ & $45 \%$ & $28 \%$ & $14 \%$ & $13 \%$ \\
\hline $\begin{array}{l}\text { Health care organisations (public } \\
\text { sector) }\end{array}$ & $58 \%$ & $41 \%$ & $30 \%$ & $13 \%$ & $16 \%$ \\
\hline $\begin{array}{l}\text { Representatives of at-risk } \\
\text { groups (e.g. people with } \\
\text { disabilities, ethnic minorities, } \\
\text { etc.) }\end{array}$ & $84 \%$ & $71 \%$ & $14 \%$ & $7 \%$ & $8 \%$ \\
\hline $\begin{array}{l}\text { Other social economy/third } \\
\text { sector/non-governmental } \\
\text { organisations }\end{array}$ & $81 \%$ & $68 \%$ & $19 \%$ & $8 \%$ & $5 \%$ \\
\hline $\begin{array}{l}\text { Representatives of local/regional } \\
\text { government departments }\end{array}$ & $84 \%$ & $75 \%$ & $17 \%$ & $4 \%$ & $4 \%$ \\
\hline $\begin{array}{l}\text { Social welfare organisations } \\
\text { (public sector) }\end{array}$ & $87 \%$ & $77 \%$ & $15 \%$ & $6 \%$ & $2 \%$ \\
\hline Trade unions & $51 \%$ & $26 \%$ & $31 \%$ & $11 \%$ & $32 \%$ \\
\hline $\begin{array}{l}\text { Colleges, universities and other } \\
\text { training institutions }\end{array}$ & $84 \%$ & $74 \%$ & $15 \%$ & $3 \%$ & $8 \%$ \\
\hline
\end{tabular}


Table 8. Community Engagement/Collaboration - Canada

\begin{tabular}{|c|c|c|c|c|c|}
\hline \multirow[b]{2}{*}{ Agencies / Partners } & \multirow[b]{2}{*}{$\begin{array}{l}\text { we collaborate } \\
\text { (\% of all respondents) }\end{array}$} & \multicolumn{4}{|c|}{ we are in contact at least: } \\
\hline & & $\begin{array}{l}\text { every } \\
\text { month }\end{array}$ & $\begin{array}{l}\text { every } 3 \\
\text { months }\end{array}$ & $\begin{array}{l}\text { every } 6 \\
\text { months }\end{array}$ & $\begin{array}{l}\text { less than } \\
\text { every } 6 \\
\text { months }\end{array}$ \\
\hline Employers & $87 \%$ & $90 \%$ & $7 \%$ & $2 \%$ & $1 \%$ \\
\hline $\begin{array}{l}\text { Economic development } \\
\text { organisations and regional } \\
\text { development specialists }\end{array}$ & $70 \%$ & $44 \%$ & $31 \%$ & $12 \%$ & $13 \%$ \\
\hline $\begin{array}{l}\text { Health care organisations (public } \\
\text { sector) }\end{array}$ & $52 \%$ & $31 \%$ & $37 \%$ & $15 \%$ & $17 \%$ \\
\hline $\begin{array}{l}\text { Representatives of at-risk } \\
\text { groups (e.g. people with } \\
\text { disabilities, ethnic minorities, } \\
\text { etc.) }\end{array}$ & $86 \%$ & $72 \%$ & $14 \%$ & $8 \%$ & $7 \%$ \\
\hline $\begin{array}{l}\text { Other social economy/third } \\
\text { sector/non-governmental } \\
\text { organisations }\end{array}$ & $82 \%$ & $69 \%$ & $24 \%$ & $5 \%$ & $2 \%$ \\
\hline $\begin{array}{l}\text { Representatives of local/regional } \\
\text { government departments }\end{array}$ & $81 \%$ & $75 \%$ & $16 \%$ & $6 \%$ & $4 \%$ \\
\hline $\begin{array}{l}\text { Social welfare organisations } \\
\text { (public sector) }\end{array}$ & $89 \%$ & $78 \%$ & $15 \%$ & $4 \%$ & $3 \%$ \\
\hline Trade unions & $47 \%$ & $22 \%$ & $30 \%$ & $16 \%$ & $32 \%$ \\
\hline $\begin{array}{l}\text { Colleges, universities and other } \\
\text { training institutions }\end{array}$ & $84 \%$ & $74 \%$ & $19 \%$ & $1 \%$ & $6 \%$ \\
\hline
\end{tabular}


Table 9. Community Engagement/Collaboration - Other Countries

\begin{tabular}{|c|c|c|c|c|c|}
\hline \multirow[b]{2}{*}{ Agencies / Partners } & \multirow[b]{2}{*}{$\begin{array}{l}\text { we collaborate } \\
\text { (\% of all respondents) }\end{array}$} & \multicolumn{4}{|c|}{ we are in contact at least: } \\
\hline & & $\begin{array}{l}\text { every } \\
\text { month }\end{array}$ & $\begin{array}{l}\text { every } 3 \\
\text { months }\end{array}$ & $\begin{array}{l}\text { every } 6 \\
\text { months }\end{array}$ & $\begin{array}{l}\text { less than } \\
\text { every } 6 \\
\text { months }\end{array}$ \\
\hline Employers & $92 \%$ & $86 \%$ & $10 \%$ & $0 \%$ & $4 \%$ \\
\hline $\begin{array}{l}\text { Economic development } \\
\text { organisations and regional } \\
\text { development specialists }\end{array}$ & $76 \%$ & $45 \%$ & $23 \%$ & $18 \%$ & $14 \%$ \\
\hline $\begin{array}{l}\text { Health care organisations (public } \\
\text { sector) }\end{array}$ & $69 \%$ & $54 \%$ & $19 \%$ & $11 \%$ & $16 \%$ \\
\hline $\begin{array}{l}\text { Representatives of at-risk } \\
\text { groups (e.g. people with } \\
\text { disabilities, ethnic minorities, } \\
\text { etc.) }\end{array}$ & $81 \%$ & $68 \%$ & $16 \%$ & $5 \%$ & $11 \%$ \\
\hline $\begin{array}{l}\text { Other social economy/third } \\
\text { sector/non-governmental } \\
\text { organisations }\end{array}$ & $80 \%$ & $66 \%$ & $9 \%$ & $16 \%$ & $9 \%$ \\
\hline $\begin{array}{l}\text { Representatives of local/regional } \\
\text { government departments }\end{array}$ & $90 \%$ & $76 \%$ & $20 \%$ & $0 \%$ & $4 \%$ \\
\hline $\begin{array}{l}\text { Social welfare organisations } \\
\text { (public sector) }\end{array}$ & $83 \%$ & $74 \%$ & $17 \%$ & $10 \%$ & $0 \%$ \\
\hline Trade unions & $59 \%$ & $32 \%$ & $32 \%$ & $3 \%$ & $32 \%$ \\
\hline $\begin{array}{l}\text { Colleges, universities and other } \\
\text { training institutions }\end{array}$ & $83 \%$ & $76 \%$ & $7 \%$ & $7 \%$ & $11 \%$ \\
\hline
\end{tabular}





\section{Tackling Long-Term Unemployment Amongst Vulnerable Groups}

This working paper reports on the work undertaken as part of the Tackling Long-term Unemployment Amongst Vulnerable Groups project. It includes the findings of a survey undertaken jointly by the OECD LEED Programme and the World Association of Public Employment Services in 2012, and also case studies and learning models from around the world on innovative practices to support the long-term unemployed into work. The report emphasises the important role a diverse range of actors can play in helping the long-term unemployed address the complex issues which may hinder their move into the labour market. 